\title{
THE POTENTIAL BENEFITS OF REAL-TIME MONITORING OF COMBINED SEWER OVERFLOWS IN THE CITY OF TORONTO
}

by

\author{
Ronak Kordnejad \\ Bachelor of Commerce (BTM) \\ Ted Rogers School of Management \\ Ryerson University \\ Toronto, Canada
}

2011

A thesis presented to Ryerson University

in partial fulfillment of the requirement for the degree of Master of Applied Science in the program of Environmental Applied Science and Management

Toronto, Ontario, Canada, 2018

(C) Ronak Kordnejad, 2018 


\section{AUTHOR'S DECLARATION FOR ELECTRONIC SUBMISSION OF A THESIS}

I hereby declare that I am the sole author of this thesis. This is a true copy of the thesis, including any required final revisions, as accepted by my examiners.

I authorize Ryerson University to lend this thesis to other institutions or individuals for the purpose of scholarly research.

I further authorize Ryerson University to reproduce this thesis by photocopying or by other means, in total or in part, at the request of other institutions or individuals for the purpose of scholarly research.

I understand that my thesis may be made electronically available to the public. 
The potential benefits of real-time monitoring of combined sewer overflows in the City of Toronto

Ronak Kordnejad

Master of Applied Science, 2018

Environmental Applied Science and Management

Ryerson University

\begin{abstract}
This thesis focuses on the current state of combined sewer overflows (CSO) in the City of Toronto and the potential benefits of utilizing real-time monitoring system to explore options for optimizing current models and reducing future overflows. CSOs containing sanitary and stormwater sewage over spill during wet weather conditions, contaminating bodies of water. Antiquated sewer systems built to support population at the time, no longer have the required capacity to support exponential growth causing environmental damage.

Key research findings include exploring the current CSO state in the City of Toronto, remediation plans executed by the City in hopes to reduce CSO and finally concluding the City's progress to date. Extensive research on CSOs in North American cities has shown initiative towards reducing CSOs while using real-time monitoring systems which can be utilized in the City of Toronto. Future research is required to find effective and efficient ways of implementing such systems.
\end{abstract}




\section{Acknowledgement}

I would like to thank my supervisor Dr. Farid Shirazi for his support and encouragement during the past several years. It was your direction and guidance that led me to take on post-graduate studies.

Knowledge is power! 


\section{Dedication}

\section{$\tau_{0}$}

My late grandfather

An educated, ambitious, goal-oriented \& inspirational man who trained my mind to think. 


\section{Table of Contents}

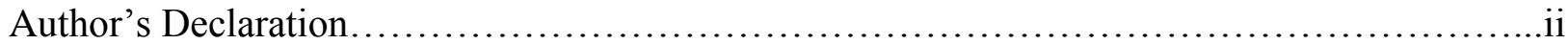

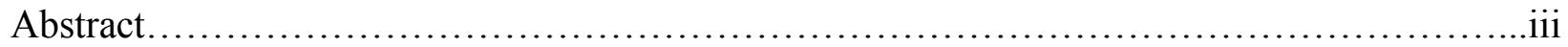

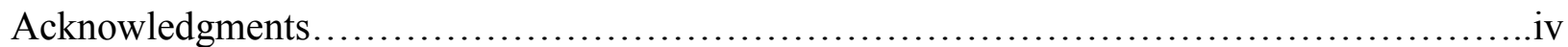

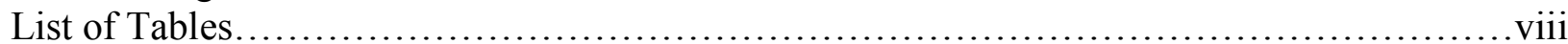

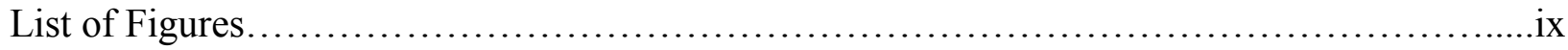

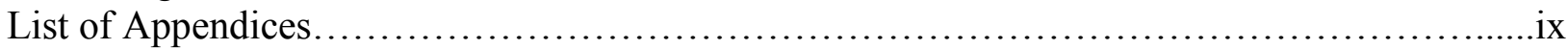

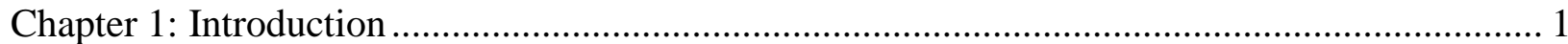

1.1 Introduction to Importance of Water and the External Influences...................................... 2

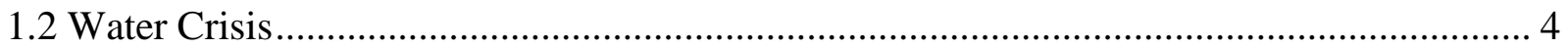

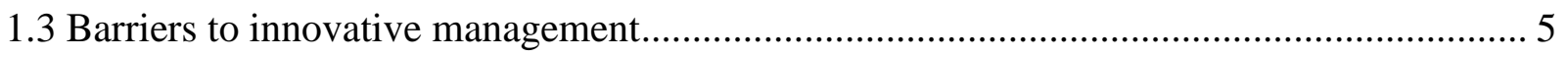

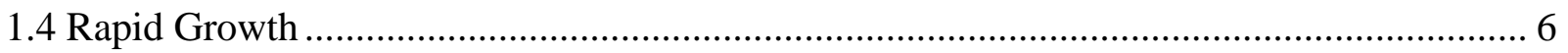

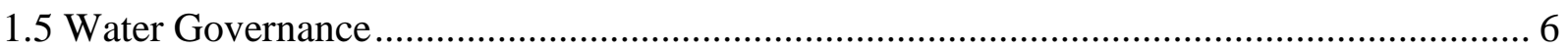

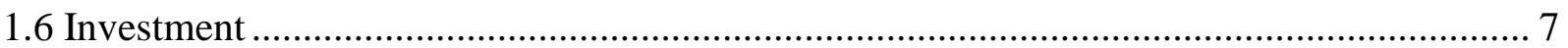

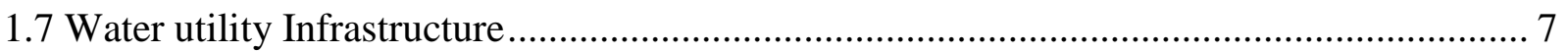

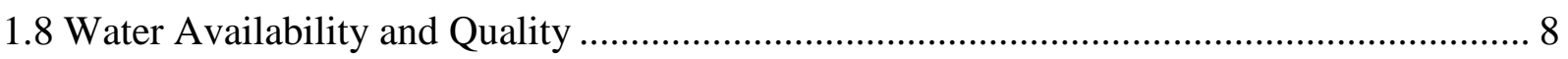

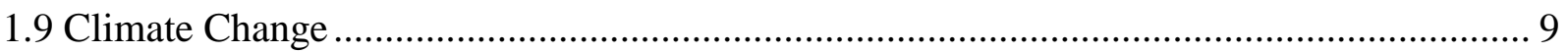

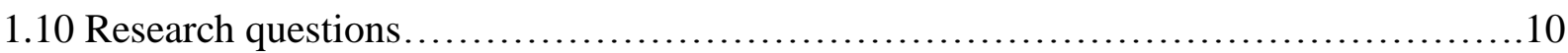

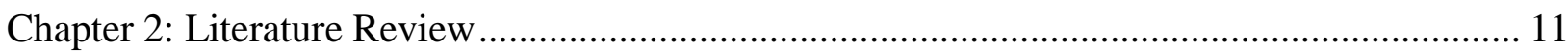

2.1 City of Toronto's Combined Sewer Monitoring Plan ..................................................... 12

2.2 City of Toronto's Combined Sewer Plan Development ………………........................... 14

2.3 City of Toronto's Current Best Practices in Managing Combined Sewer Overflows ........ 15

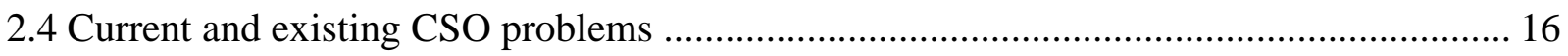

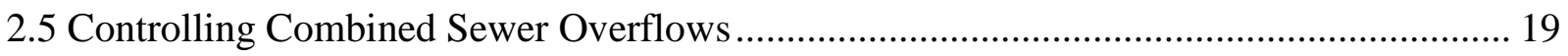

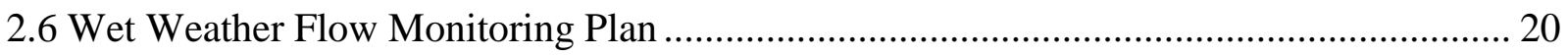

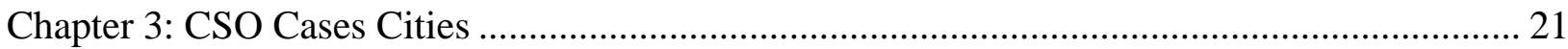

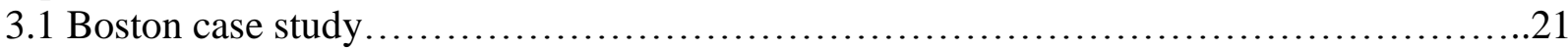

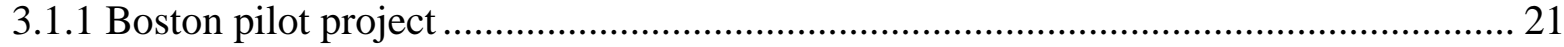

3.1.2 Boston's Combined Sewer Overflow Background ................................................... 22

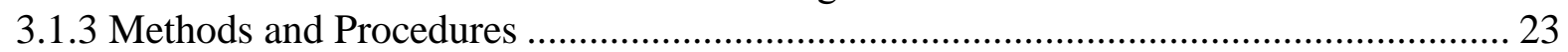

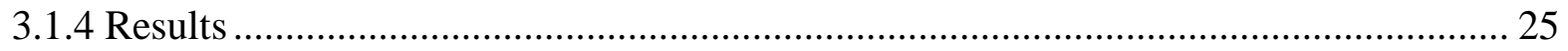

3.1.5 The Current Best Practices in Managing CSOs in Real-Time ..................................... 27

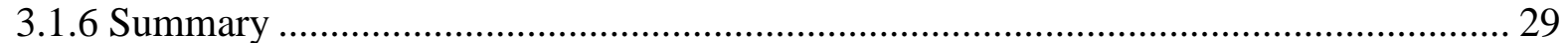

3.2 City of Poughkeepsie New York case study ............................................ 30

3.2.1 City of Poughkeepsie New York, Combined sewer..................................................... 30

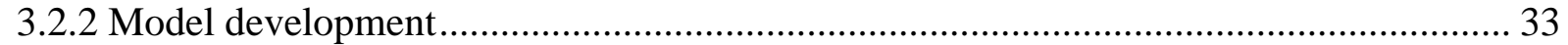

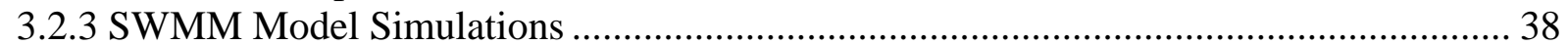

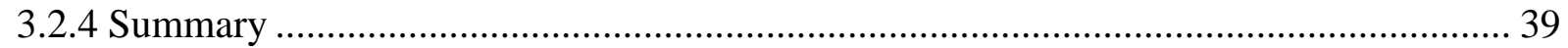

3.3 Riverside and Evanston, IL case study ............................................ 40

3.3.1 Monitoring and analysis of combined sewer overflows, Riverside and Evanston, IL.....40 
3.3.2 Combined Sewer Overflow Monitoring Overview ............................................... 41

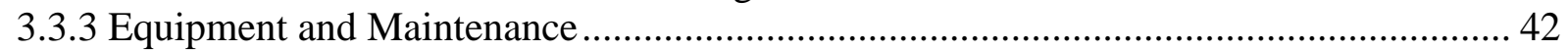

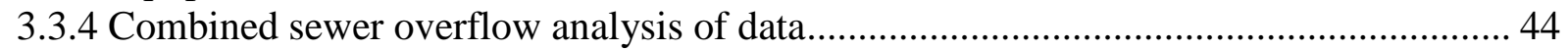

3.3.4.1 Combined sewer overflow at Riverside........................................................... 44

3.3.4.2 Combined sewer overflow at Evanston, Illinois............................................... 49

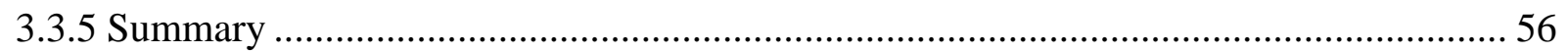

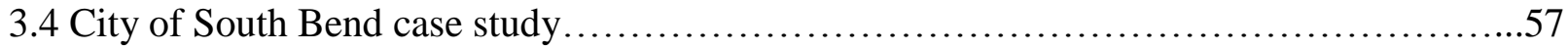

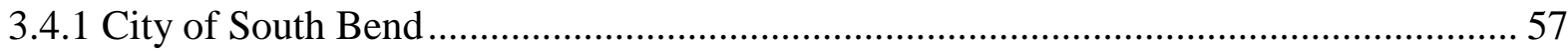

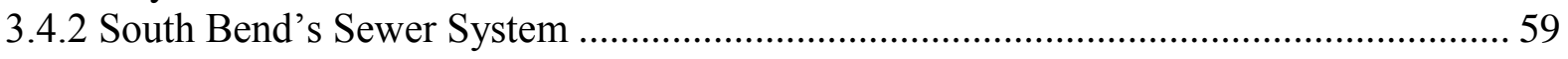

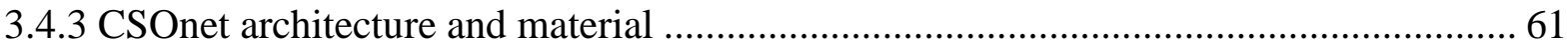

3.4.4 Future of CSOnet: Distributed Storm Water Management System ........................... 62

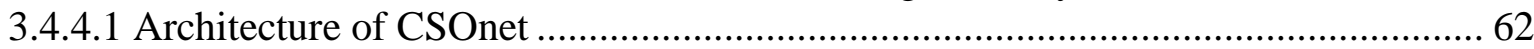

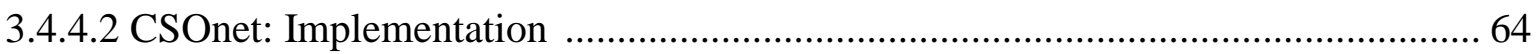

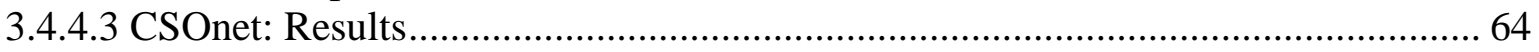

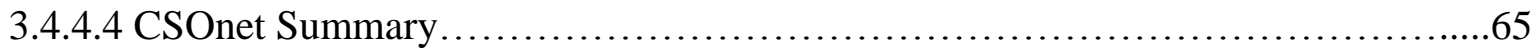

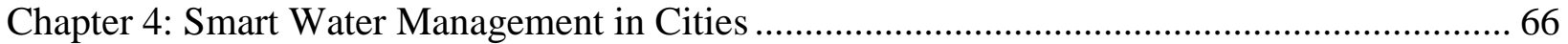

4.1 Potential Benefits of Smart Water Management Technologies ...................................... 68

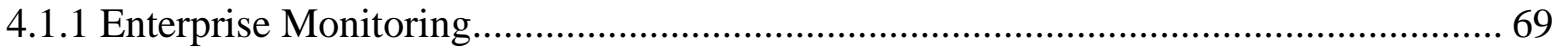

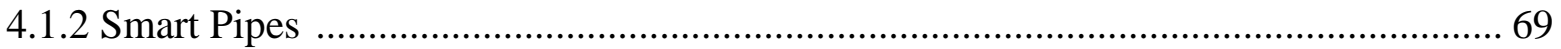

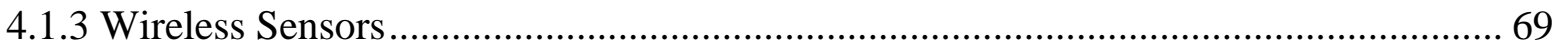

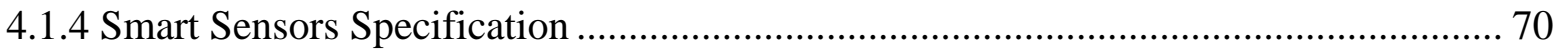

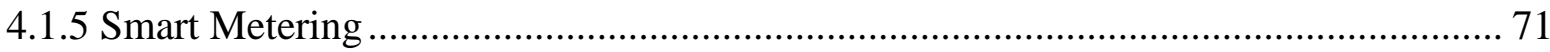

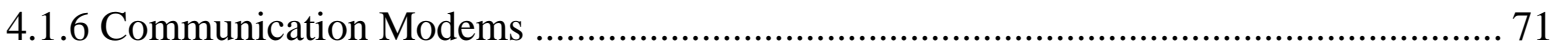

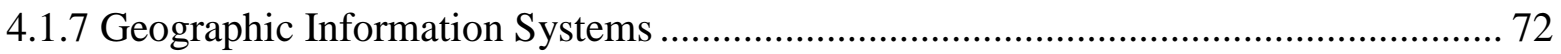

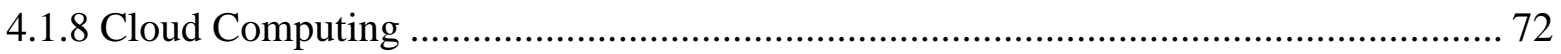

4.1.9 Supervisory control and data acquisition- SCADA ............................................ 72

4.2 Optimization Tools and Decision Support Methods ..................................................... 73

4.3 Web Based Information Tools ............................................................................. 73

Chapter 5: Smart and Sustainable Water Management in Toronto ........................................... 75

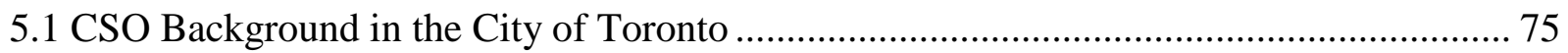

5.2 Combined Sewer Overflows Environmental Impact on the Great Lakes..................75

5.2.1 Smart Water Management Integration: Potential Benefits ..................................... 78

5.3 Wireless Mobile Sensors in Underground Pipes ....................................................... 80

5.4 Smart Water Management Opportunities............................................................... 82

5.5 Monitoring System implemented in the City of Toronto ............................................ 85

5.6 Current state of Smart Pipes in the City of Toronto....................................................... 86

5.7 Use of Cloud in Smart Monitoring Systems ............................................................ 86

5.8 Use of historical data for the future........................................................................ 88 


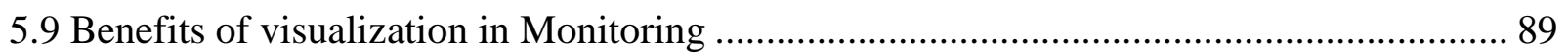

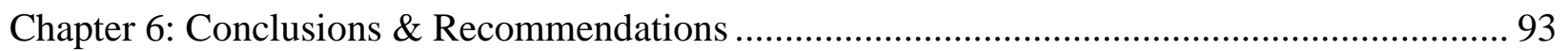

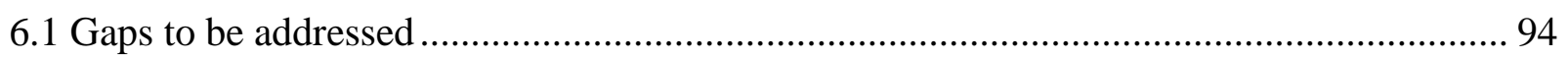

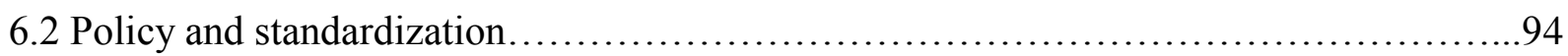

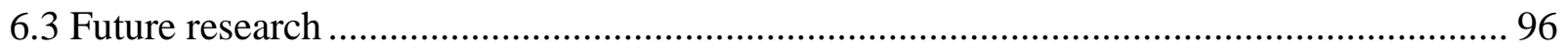

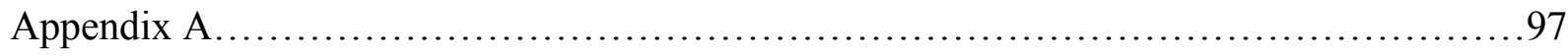

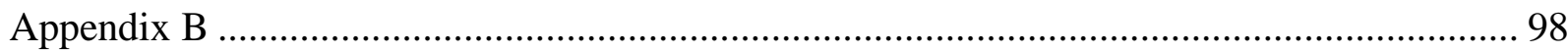

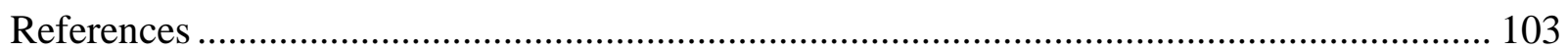




\section{List of Tables}

Table 1.0: Urban Population.........................................................

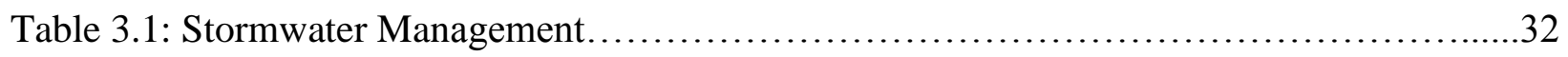

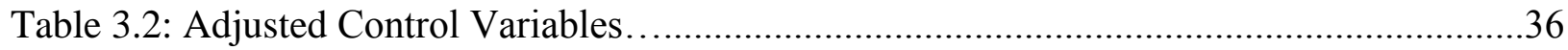

Table 3.3: Mill Street 24 hour stork CSO Curve............................................

Table 3.4: CSO comparison to total yearly amount of precipitation.........................64 


\section{List of Figures}

Figure 1.1: Influencing factors on urban water management challenges.....................5

Figure 1.2: Climate Change Effects............................................ 9

Figure 3.1: Boston Water and Sewer CSO pilot location map...........................22

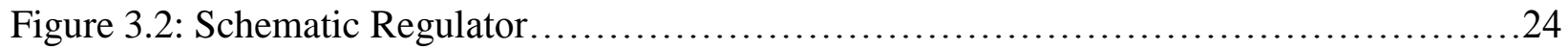

Figure 3.3: Scattergraph: Rotation Guide........................................27

Figure 3.4: City of Poughkeepsie - Stormwater Management Model...........................31

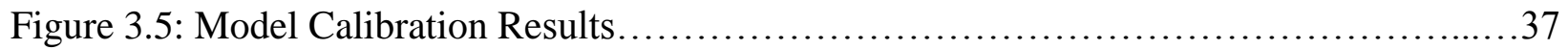

Figure 3.6: Stage and velocity at the "siphon pipe", Evanston............................53

Figure 3.7: CSOnet Architecture Prototype................................................59

Figure 3.8: The CSO Diversion System .......................................61

Figure 4.1: Current smart water Management technologies and tools......................68

Figure 5.1: Representation of smart water management technologies and tools................85

Figure 5.2: A high level schematic of Sensor Networks for Smart City.....................91

\section{List of Figures in Appendix A}

Figure A1: Projected Water Stressor ............................................... 97

\section{List of Figures in Appendix B}

Figure B1: Scattergraph: Flow over a weir with no restriction..........................98

Figure B2: Scattergraph: Mar 302014 Storm Event.....................................98

Figure B3: Scattergraph: Dec 92014 Storm Event...................................99

Figure B4: Scattergraph: Oct 232014 Storm Event.................................99

Figure B5: American Sigma 920.................................................. 100

Figure B6: Riverside: Discharge at the 'Gage Street pipe' and the 'long pipe'................100

Figure B7: Stage at the "outfall pipe" and the Des Plaines River, Riverside..................101

Figure B8: Stage and velocity at the "outfall pipe", Riverside..........................101

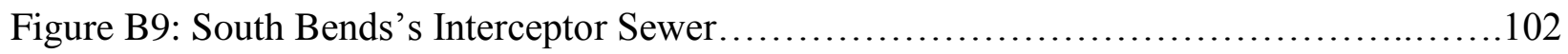

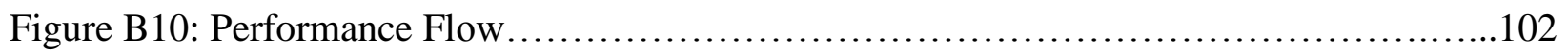

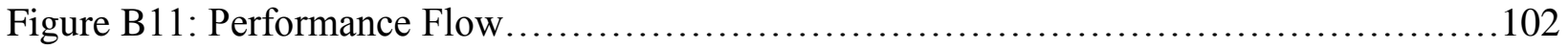




\section{Chapter 1: Introduction}

In 2011 it was estimated that the world's population will increase from 3.6 billion to approximately 9.8 billion by 2050 (Zhang et al, 2014). Table 1.0 depicts the demographic distribution of urban populations across the world. As indicated, more than $50.8 \%$ of the world's total population in 2011 was estimated to live in urban areas, compared to 45\% in 1990 and 34\% in 1960 . It is expected that $69 \%$ of the world's total population of 9.8 billion will live in urban areas by 2050, an increase by two-folds compared to a century ago. Cities contribute to human development as well as constrain it. They are centres of affluence as well as concentrations of poverty. They bring out the best in human enterprise as well as the worst in human greed. They contain some of the best social services available in the country. But also, host many social ills such as overcrowding, unsanitary living conditions, drug addiction, alienation, social unrest and environmental pollution (UNDP, 1990).

Table 1.0: Urban populations

\begin{tabular}{|l|c|c|c|}
\hline \% Urban Population & $\mathbf{1 9 6 0}$ & $\mathbf{1 9 9 0}$ & $\mathbf{2 0 1 1}$ \\
\hline All developing countries & 22 & 37 & 39 \\
\hline Least developed countries & 8 & 20 & 29.7 \\
\hline Sub-Saharan Africa & 15 & 31 & 37.7 \\
\hline Industrial countries & 61 & 73 & 78.3 \\
\hline World & 34 & 45 & 50.8 \\
\hline
\end{tabular}

Source: United Nations Development Programme, 2011

Water cycle plays a vital role in the urban growth, all aspects, including the source of water, production, various distribution methods, as well as consumption and the treatment of wastewater before entering lakes and rivers. These influences go hand in hand to support the global population, generate natural energy and give life to the living. Water convergence has directly influenced the growth of urbanized areas.

Mentioned influences go hand in hand to support the global population, generate natural energy and give life to the living. Water convergence has directly influenced the growth of urbanized areas. The increased population will introduce many challenges for managing urban water systems including sewer overflow. 
Combined sewer overflow or raw sewage discharge is a mix of contaminated human excrement and water containing 200 chemicals and other pollutants (Wristen, 1999).The sewer system carries industrial and household pollutants and sometimes urban runoffs, with a possibility of adding harmful pollutants. If improperly treated, the overflow is a cause of disease once it contaminates the environment. The toxic substance move directly upwards in the food chain and spreads while contaminating the natural resources.

\subsection{Introduction to Importance of Water and the External Influences}

The availability of water has direct linkage to different operations in the city. The housing industry and construction of new developments demands additional sources of water and distribution. Economic development heavily relies on fresh water for productivity, washing, growth and cooling. Another important pillar falls under the overall health of the population, fresh and reliable water supply is essential for the city's well- being. Other water dependencies are tourism, parks and recreational activities.

Another important factor in supplying water is managing the underground water networks carrying waste. Improperly managing and or incidents with transport pipes can cause pollution to ground and surface water.

The increasing rate of growth in the population produces high amounts of waste, as well as carbon footprint. The cycle of water production including all its pillar are inter-related to the challenges faced each year by urban planners. Environmental challenges faced by urban organizers include fresh water supplies to residents, municipalities and all functions of the society. This fast paced increase in population places stress on water supplies.

According to Water Security for Better Lives, water security is summarized in maintaining four threshold levels: risk of shortage, risk of inadequate quality, risk of floods, and risk of running out of fresh water (Gemma, Sang, Mc Intosh \& Ospina, 2014). With proper division of issues, water-related problems are resolved by assessing the issue and providing a solution in an integrated way or in silos.

Water services are in charge of managing the water supply, distribution and wastewater treatment. Water utility services are positioned to extend services in these areas: 
- Water diversion including treatment and distribution of water to cities

- water supply service to different sectors including residential and commercial

- proper drainage service is required for the overall public health of the population and overflow prevention

- waste water treatment is required for safeguarding the environment

The urban system relies on the correct amount of water quantity and quality to sustain its cycle, any disruptions will affect the system negatively. With the increase in population having direct effect on water production and consumption water resource management becomes an important matter. Change in water consumption and the fast paced land development creates challenges in water resource sustainability. External forces including climate changes and aging infrastructure pipe networks also tips the balance with sustaining water management (Gemma et al., 2014).

Based on OECD's (Organization for Economic Co-Operation and Development) definition, smart water systems are summarized in the ability to capture real- time data and increase response times by transmitting data between remote locations for end user interpretation (Gemma et al., 2014). These smart systems are a series of innovative technologies with informative and communicative aspects supporting water managerial decisions.

Cutting edge information communication technologies known as ICT products and solutions provide a sustainable water management guide for consumption and production. Water management can be easily done when technological products are integrated to help organize data collected from water resources.

The cost of technological products used towards water innovative approaches promises safe and optimal provisioning of resources for the city's population. Innovative technologies can be structured to monitor and diagnose issues, ensure low maintenance costs to manage water networks. 
Utilizing technology in cities with smart water management helps overcome environmental challenges and reduce the impacts of climate changes.

The content of this section will explore the issues involved in smart water management problems and potential benefits faced by cities. Furthermore it highlights smart water management as an important focus area to utilize technological tools to response to challenges.

To effectively design smart water management in cities it is important to consider all perspectives while implementing systems. Smart water technology and tools integrated within water systems can create new plans, update existing infrastructure pipes and meet water demands per capita.

\subsection{Water Crisis}

Most cities have multiple complex costly infrastructure systems. Resource distribution challenges are expected to increase due to decrease in natural resources, high investment increase, management costs and aged infrastructures. It is essential to utilize innovative systems to respond to these challenges.

Provisioning of clean water is key for cities, old pipe infrastructure, rapid population growth, weak water governance and inadequate investments are some of the key factors to reinforce water management systems (Gemma et al., 2014). Other factors such as climate change and various stressors forcing challenges and constraining adequate water resources.

Figure 1.1 showcases the impact of climate change and other stressors exacerbate challenges faced by water management systems. These challenges force water management systems to effectively prepare and adjust to these conditions. Here are some of the key factors influencing water management systems summarized in the figure 1.1: 


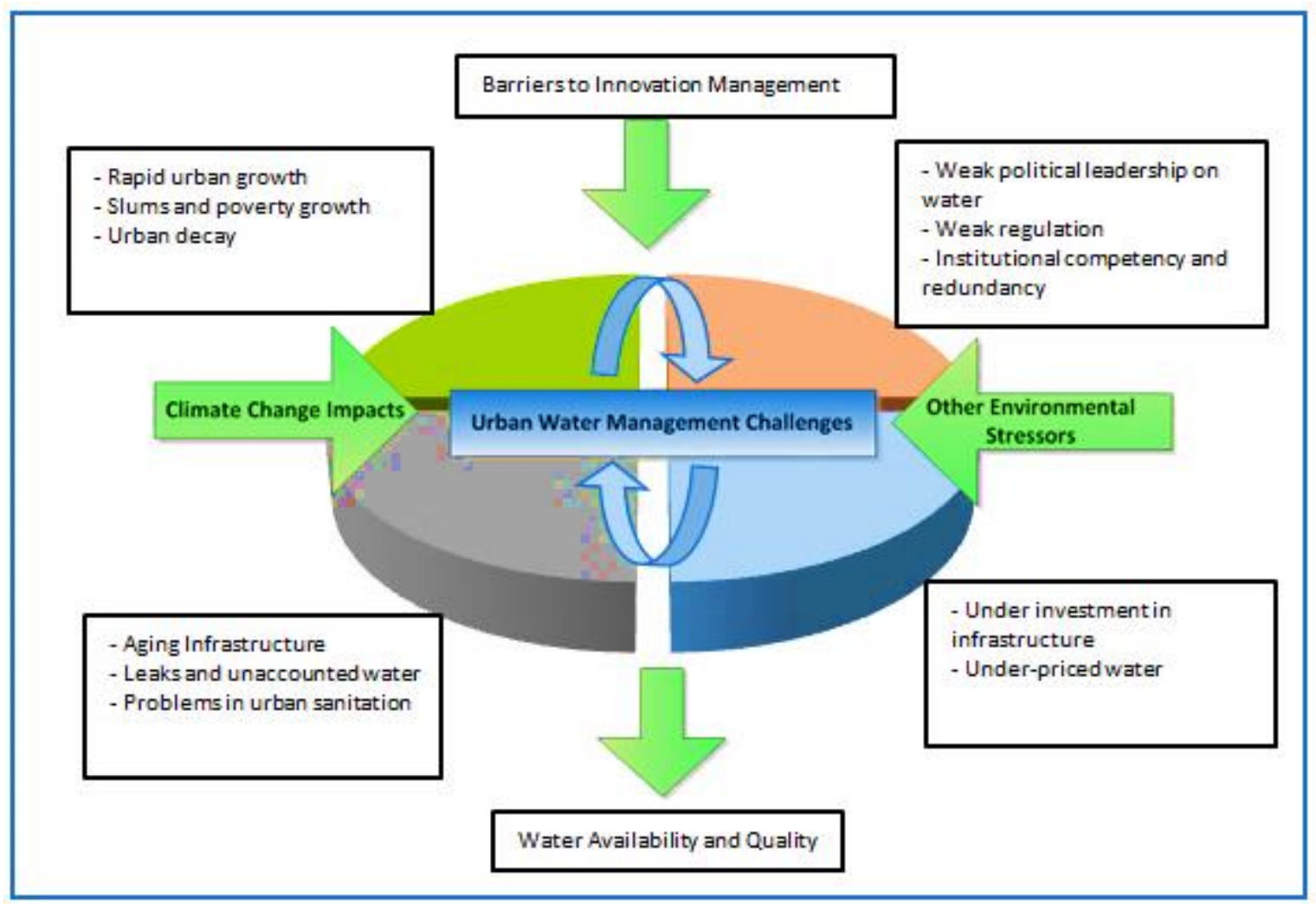

Figure 1.1: Influencing factors on urban water management challenges Source: Adapted and modified from McIntosh, 2014

Figure 1.1 showcases the impact climate change and other stressors exacerbate challenges faced by water management systems. These challenges force water management systems to effectively prepare and adjust to these conditions. Here are some of the key factors influencing water management systems:

\subsection{Barriers to innovative management}

In order to effectively manage the current issues of sustainable water management, technological leadership is required. Creativity and innovation are drivers for organizational success (Agbor, 2008) in particular, conditions of rapid environmental changes as well as the issues of urban development. Therefore, city planners and organizations need creative leaders in order to plan and implement innovative methods in order to overcome the barriers of sustainable urban water system management. Innovation to change in water management sector helps reformat methods used in the past to control combined sewers by changing the process of monitoring. 
This study attempts to address barriers in managing combined sewer overflows while exploring the potential benefits of real-time monitoring of combined sewer overflows in the City of Toronto. Shattow (1996), use of information technology, to support innovations is an important ingredient in success factor. Organizations integrated with innovative cultures prove to show improvements (Khalil, 1996). Applying best practices of innovative management will improve data collection, baselining and predicting future (Martins \&Terblanche, 2003) CSO plans.

\subsection{Rapid Growth}

Increase in population growth has direct linkage to increased business sectors and new markets. Megacities known as cities with more than 10 or 20 million in population are tremendously growing.

Increase in population and growing cities demands an increase on local water resources. Vanishing rivers, decrease in water resources, unsustainable water usage has serious consequences on natural resources. River depletion amongst other water resource issues has severe effects in cities, and accessible water supply.

Challenges faced by cities to provide adequate water supply has established informal supplies of water and other systems. Most of these systems are unregulated and may impose a health risk on the population they serve. Many cities are facing water importations a direct correlation to carbon prints.

\subsection{Water Governance}

Clear policies are required to respond to exacerbated water resources and challenges supporting water management practice. Unfortunately, unreasonable water regulations and practice along with political governmental layers have led to a redundant and conflicting water management. Uncoordinated and unsustainable approaches in managing water has resulted in wastage of water resources. Governmental subsidies and increased rates have caused unnecessary consumption around the globe.

Additional challenges faced by water management is based on the ruling government at the time. Decision making strategies and outcomes are highly dependent on the political situation and the elected government. Overlapping political sectors, outdated policy makers, and traditional practices formulating blindsided decisions lead to poor implementations. Without 
proper data management and enhanced technology to decipher raw data into usable information, water management can become unfeasible. Without proper adaptive technological solutions and a team of experts, city's water resources are at risk. Poor leadership surrounding water structure has limited the capability to make effective decisions around existing water resource management (OECD, 2011).

Some of these challenges are seen in existing water structure policies and gaps have been identified in the decentralized governance responses. The OECD report, 'Water Governance in OECD Countries': A Multi-level approach suggests, implementation of performance metrics, water information business systems along with storing databases, collaboration across municipalities and participation of citizens are tools used for better coordination of water policies across multiple levels of the industry (OECD, 2011).

\subsection{Investment}

Without proper investment for effective system-wide implementations, increase of population, aging infrastructure, overutilization and under capacity of pipes pose a demanding need on infrastructure. Therefore, investments will be required to subsidize for the high cost and implementation of such services. The high cost and vast responsibilities shared between different layers of the governmental sectors, businesses and the public population have been the source of income to generate finance for maintaining the water infrastructure (Gemma et al., 2014).

Financing services surrounding water and sanitation has been a huge responsibility for participating parties. The vast majority of the water distribution system is mostly dedicated to restoring, maintaining and repairing aging infrastructure. For sustainable water infrastructure practices, sufficient investments levels are required to formulate long and short decisions and address challenges.

\subsection{Water utility Infrastructure}

Growing population in cities is exceeding the governmental capabilities to properly plan for effective and efficient sustainability. Many infrastructure network pipe designs were based on forecasted water demands and historical unmanaged data. In most cases other unforeseen data wasn't taken into consideration to provision services. 
Socio-economic challenges are often directly influenced by population growth. In many cities financial issues limited the city to move forward with improving the design of aged infrastructure and led them to adopt outdated methods. One of the biggest issues faced by water industry in any city is the aged infrastructure. Statistics has shown that metallic infrastructure pipes have a range of 0.1 to $0.9 \mathrm{~km} /$ per (Gemma et al., 2014). The American water Association has estimated a restoration cost of over one trillion US Dollars in the next two decades (Gemma et al., 2014).

The Association has also estimated an overall loss of $40 \%$ clean water due to leaks, overflow, and sewer damages resulting in loss of 14 billion annually(Gemma et al., 2014).

In some instances illegal pipe connections within the network has caused loss of large amounts of water (Gemma et al., 2014). Cities have been facing challenges in provisioning water supply distribution, construction, and maintenance without being able to recover from hefty costs.

\subsection{Water Availability and Quality}

The world's water sources are ultimately coming to an end including rivers, lake water

and groundwater. In many growing cities, the watershed supply exceeds the demands of the city. Large cities rely heavily on distribution systems and supply to meet their water requirements. Complications are transparent with the scarce distribution of water over uneven space, placing more pressure on management of water sectors.

In less developed countries, water sanitation is the main source of diseases and health problems. More than $90 \%$ of untreated wastewater is released into rivers, due to lack of treatment plants (Gemma et al., 2014). This further decreases the availability of clean water in these places, making water an expensive liquid gold.

Many cities experience water stress relative to the climate change conditions, increase in water demands, and weak management planning. With the increase in water demand and lack of water sources, water scarcity will become a political issue in addition to human health. 
Figure 1 in Appendix A is a projected side by side comparison of projected water stress map of the globe. The figure demonstrates the change forecasted by 2025 (Gemma et al., 2014).

\subsection{Climate Change}

Changes within the climate is projected to decrease the frequency of floods in the coming years. The impact of change will differ from region to region. Furthermore, studies show a flood increase in Eastern Europe and Southeast Asia but decrease in North and South America (Gemma et al., 2014). The global conditions are anticipated to decrease water quality and infrastructure while threatening operation and maintenance services.

Various precipitations cause floods and or droughts depending on the region, the increase in droughts will have a negative effect on reservoirs. Cities with lower levels of rainfall, may experience system overload which leads to more flooding (Gemma et al., 2014). Sewerage system carrying a combination of stormwater runoffs and wastewater will be overwhelmed resulting in public health.

Established cities and cities on the rise are the most threatened by climate change and its impacts on water systems. Cities experiencing poor water management will be at higher risk due to intense water stress. Figure 1.2 explains climate change effects on urban water resources:

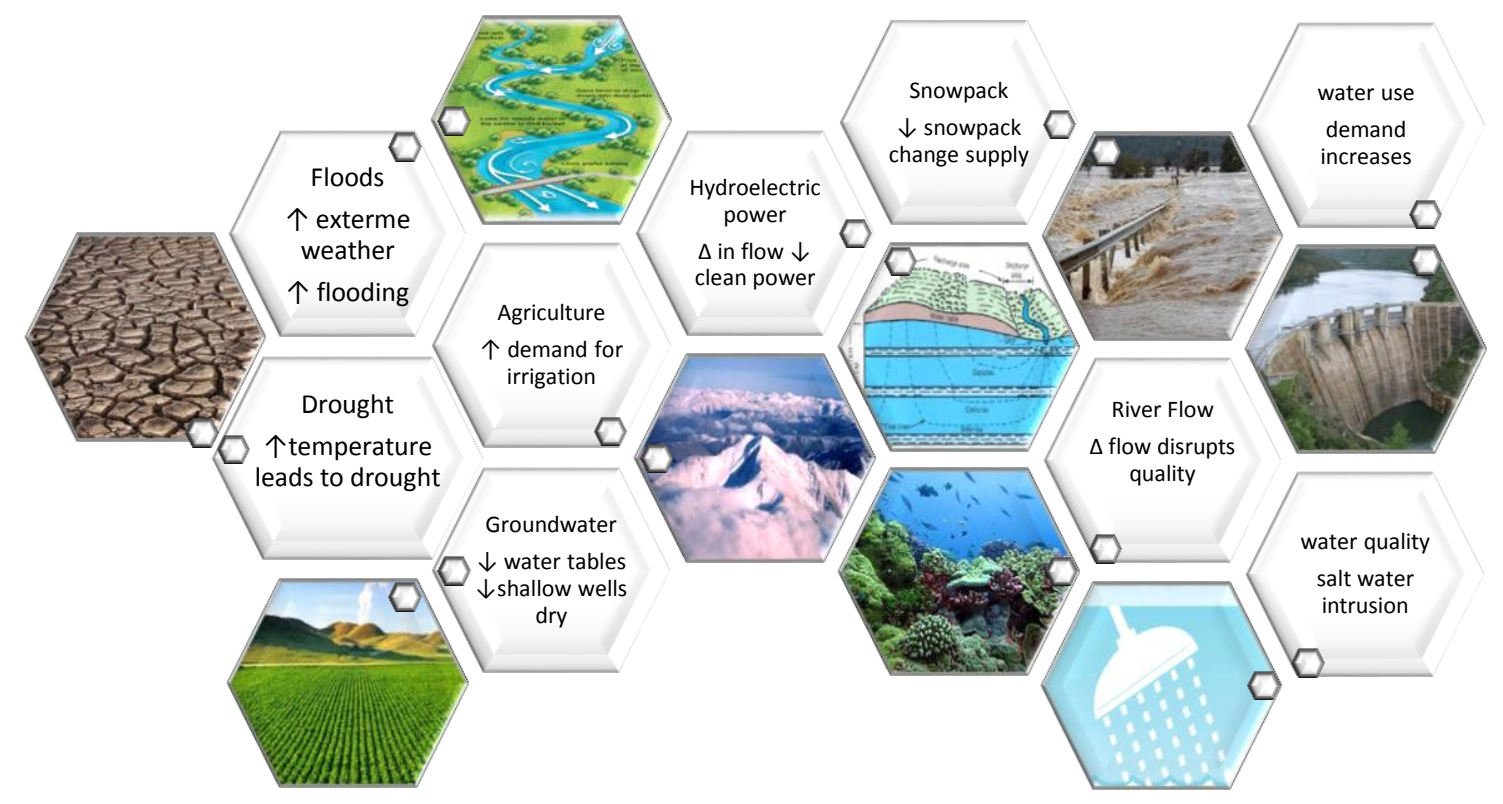

Figure 1.2: Climate Change Effects

Source: Adapted and modified from Gemma et al, 2014 
Most coastal cities are at risk of sea level rising, currently most of all large cities and half the world's population is considered coastal. Salt water contamination is bound to deteriorate groundwater sources, and decrease quality (Gemma et al., 2014). An increase in sea level suggests an increased probability of sewage pollution and reduces the ability to properly discharge CSOs. In summary all suggestions conclude climate change will exhaust the city's water vulnerability in terms of quantity and quality.

Aim of this comparative study is 1) to explore existing issues concerning sewer overflow in modern cities and 2) to offer practical solutions to tackle sewer overflow issue in the City of Toronto using smart water management technologies.

\subsection{Research questions:}

1. What is the City of Toronto's best practice in managing combined sewer overflows?

2. Does City of Toronto use real-time monitoring to manage combined sewer overflows?

3. What are some potential benefits of implementing real-time monitoring in combined sewers?

4. What are the environmental impacts on the Great Lake from combined sewer overflows?

5. Current best practices used in North American Cities monitoring CSOs in real-time?

6. How can City of Toronto apply existing real-time monitoring best practice to CSOs?

The following section explores the current state of CSOs in the City of Toronto, the Cities efforts in reducing CSOs, and the results from their initiatives. 


\section{Chapter 2: Literature Review}

System-wide monitoring of combined sewer networks detects water quantity levels, water quality and reduces runoff contamination caused by sewer overflows eliminates costly infrastructure improvement projects. Currently Canada releases over 150 billion litres of untreated wastewater into the Lake every year (Fan, Cao \& Li, 2014). In Canada alone, approximately $\$ 270$ million has been spent over the past 10 years by federal and provincial governments for wastewater infrastructure improvements in Canadian Areas of Concern (International Joint Commission [IJC], 2003). A recent study carried out by Environment Canada estimates $\$ 1.8$ billion dollars to improve the remaining wastewater infrastructure. Furthermore, a project completed under the Municipal Class Environmental Assessment determined, sewer separation in the City of Toronto has been examined to be costly. In addition, it does not achieve the water quality benefits and solve environmental problems (MMM Group, 2012). Even from a technical standpoint, sewer separation is impossible, even with a newly build separated sewer system, the City cannot stop stormwater from reaching combined sewers due to direct connections from private properties. Even though downspout disconnection became mandatory, it is nearly impossible to stop all direct connections from private properties. These technical and financial challenges encouraged municipalities to develop real-time monitoring systems that can evaluate the current infrastructure, optimize development in combined sewerage systems and control water pollution received by the Great Lakes. According to a field study at MIT, integration of real-time data with accurate analytical models can be used for different applications including optimization of pump scheduling, to detect leaks and implement an alarm system for overflow contamination (Stoianov, Nachman \&Whittle, 2008). All these applications require many distributed measurement sensors across the combined sewer system to accurately $\log$ the occurrences.

Currently, City of Toronto and some other municipalities collect data at high-cost and high-risk locations for billing purposes or treatment plants. The collected data is not integrated into a holistic sewer monitoring system. The main reason for the limited level of continuous monitoring is the prohibitively high price of traditional telemetry systems and in some cases high cost of ownership (Stoianov et al., 2008). 
This sections reviews City of Toronto's current best practices in managing combined sewer overflows (CSOs). Including City of Toronto's one-time monitoring verification, literature review of the City's CSO planning, and current practices to control CSOs at source, conveyance and end-of-pipe.

The objective of this paper is to understand the current best practices used in the City of Toronto to manage combined sewer overflows and investigate the potential benefits of managing combined sewers in real-time.

\subsection{City of Toronto's Combined Sewer Monitoring Plan}

\section{Background}

City of Toronto's impervious built surface area, increase in urban development and continuous changes in the climate results in wet flow events. In older North American cities, such as Toronto, highly urbanized core areas remain to be served by antiquated combined sewers collecting both sanitary sewage and urban runoff in a single pipe system (Joksimovic, 1999). Combined sewer overflows (CSOs) and treatment plant bypasses are products of wet weather flows (International Joint Commission, 2009). Each year there is a high volume of bypasses and sewer overflow discharges in Lake Ontario.

In 2013, in response to the adverse impact of sewage overflows and bypasses, new Federal Wastewater Systems Effluent Regulations were developed for Toronto Water. The Regulations report lists the Ontario Ministry of Environment requirements for the City of Toronto's Public Works and Infrastructure Committee (Toronto Water, 2014). With respect to Toronto's combined sewers, regulation requires annual reporting of the overflows. The one time identification and monitoring report was collected by the City in 2013 and 2014. In 2013, the combined sewer overflow outfalls were identified and monitored in the following year to meet the Ontario Ministry's regulations (Toronto Water, 2013).

Under the regulation, combined sewer overflows were monitored for number of occurrences, period of duration and volume released in the Lake. According to the report prepared for Public Works and Infrastructure Committee, “Toronto Water has not undertaken system-wide monitoring of all CSOs on a year-round basis" (Toronto Water, 2013, p. 8). Toronto Water has done some small monitoring projects just to satisfy the Ontario Ministry of 
Environment. As part of the assessment, they verify the sewer system performance based on data estimates and random flow measures. In order to have an all-year round monitoring system, the City has estimated a total cost of $\$ 6.3$ million a year to maintain the flow monitoring devices. There has been a great deal of push back from the City to eliminate unnecessary monitoring of combined sewer overflows, with Toronto's Wet Weather Flow Master Plan in place to reduce combined sewer overflows. The City also believes CSO data required to be provided under the Regulations provide little insight into the operation or condition of the sewer systems (Toronto Water, 2006). The City confirms CSOs happen during wet weather flow instead of dry weather. This statement may be true to an extent but sooner than later with urbanization and development, number of runoffs will increase. Despite all the disagreements, the Regulations require CSO reporting from the City.

Currently the City is using an estimation method, InfoWorks ${ }^{1}$ CS computer model and the use of hydrologic to collect rainfall data is norm for reporting during wet/dry weather. The City has yet to validate and confirm the InfoWorks model during dry weather (Toronto Water, 2006). This items remains outstanding till this day. It is important to note that InfoWorks model only estimates the volume of runoffs without giving real-time precise information.

Furthermore, the City believes the Wet Weather Flow Maser Plan (WWFMP) will suffice Toronto's CSO issue if properly implemented. WWFMP considers all aspects in the combined sewer system, including at source, conveyance and end-of pipe. But without real-time data, the plan to overcome combined sewer issues might fail. The City needs to consider the reality of climate change and increase in population to plan ahead for any type of infrastructure upgrade and end-of-pipe storage planning.

In summary, the City compiled a one-time CSO Identification Report to verify outfall locations. There were 309 combined sewer overflow locations reported across Toronto. Volume and number of occurrences were collected on InfoWorks Collection Systems computer model (Toronto Water, 2006). This model only collects volume estimates of the combined sewer

\footnotetext{
${ }^{1}$ Infoworks helps assess sanitary capacity to provide baselines for future growth and development. The model provides stable computed flows without unrealistic spikes (InforWorks Model Extension and Modification, 2012)
} 
overflows without having real-time volume information. The City will continue using this system until the Regulation demands precise data.

\subsection{City of Toronto's Combined Sewer Plan Development}

Toronto's combined sewers were originally built to service the City's under populated community. As Toronto's population grew and climate changed in the 1980's, issues aroused with the combined sewer systems.

In 1987, the City of Toronto was considered one of the main sources of pollution to the Great Lakes. The International Joint Commission (IJC) identified the City of Toronto as an area of concern to the Great Lakes due to poor water quality. The Inner harbour and the Don River had a negative impact on the waterfront due to overflows carrying both sanitary and stormwater (International Joint Commission, 2009). At the time the International Joint Committee verified Toronto as one of the ten areas degrading the Great Lake water quality. Other areas in the United States and some binational waterways are considered a threat to water quality. In total forty thirty Areas of Concern contaminated the Lake with undertreated wastewater, stormwater pollution and other contaminants flowing into receiving water.

In response to IJC's concerns, Canada agreed to work towards restoring the ecosystem by signing the Great Lake Water Quality Agreement. The Remedial Action Plan Agreement requires Canada to restore the drinkable water and to create a safe aquatic environment for fishing and swimming (MMM Group, 2012).

Later in 1989, the City revisited the Strategy for improvement of Don River water quality. The International Joint Commission, U.S. EPA and the Ontario Ministry of Environment conducted several studies to look at wet weather flows to understand patterns in combined sewer overflows. To conclude, after several experiments, the concentration of stormwater sewers and combined sewers were similar, except for the bacteria present in the raw sewage were by far higher. Michael D'Andrea, Executive Director of Engineering and Construction Services, City of Toronto, agrees water quality parameters are similar (Mulley, 2014). An Environmental Assessment completed by the City confirms polluted stormwater causes environmental problems in our waterways (MMM Group, 2012). Meaning the stormwater sewer carries the same bacterial concentration as the combined sewer overflows. The City continued their research to reduce CSOs but with the current infrastructure in place, they require a better plan. 
In 1997, the City of Toronto developed the Wet Weather Flow Master Plan to minimize the impact of CSOs by managing the watersheds. Area Watershed Management studies were originally done in 1980s. The progress to reform the structure has been very slow due to reorganization in Toronto Water Business Unit but the plan is to construct a city-wide strategy to meet Water Quality Objectives. The full implementation is estimated to take between seventy to a hundred years to just meet the target levels.

\subsection{City of Toronto's Current Best Practices in Managing Combined Sewer Overflows}

The City of Toronto adapted the Wet Weather Flow Master Plan since 2003. The goal of this plan is to reduce and potentially eliminate any type of wet weather flow during heavy rain, storm or snow. WWFMP's vision is to, "mange wet weather flow on watershed basis accompanied by a hierarchy of solutions starting with "at source", followed by "conveyance," and concluding with end-of-pipe (Toronto Water, 2006).

Wet Weather Flow Master Plan focuses on realities of urban development growth in City of Toronto, resulting in significant amount of sewage production over time. The plan considers human and environmental factors disrupting aquatic habitat, contaminating the Great Lakes and creating an unsafe condition for recreational beaches.

25-year plan focuses on different areas of improvement to reduce and potentially eliminate CSOs. Including public education strategies to help communities understand wet weather flow issues via multi-faceted advertisements sending a message through various mediums such as television. The purpose is to promote issues and enable Torontonian's to take individual responsibility in reducing wet weather flows.

WWFMP's goal is to have the community take part in reducing CSOs by playing a small role in the program. Torontonians need to recognize stoop and scoop helps the Great Lakes and our receiving waters. This communication channel advertises statements like, "Pesticides from your lawn end up in the lake" (Toronto Water, 2006). It informs the community of the direct linkage between individuals and lake contamination.

Toronto Water informs residents on avoiding use of chemicals and disposing anything into a sewer- not even coffee (Toronto Water, n.d). Residents have the power to contaminate the Lake by contaminating their lawns with pesticides. 


\subsection{Current and existing CSO problems}

The National sewage report card established in 1994 declared Canada's waters as a national disgrace (Holmes, 1999). In 1999 same results were extracted from concerned environmental groups on discharged sewage. The National Sewage Report Card simply assigns a letter grade to individual cities in Canada based on several criteria including raw sewage discharges, compliant level of discharge, and regulation compliance.

The report is indicative of some shockingly high volumes of sewage in our waters, a combined amount of billion liters of untreated sewage is dumped into our water every year. Raw sewage containing motor oil, paint thinner, grease, human excrement and a combination of toxic and industrial household waste is discharged into our Canadian waters. Sewage doesn't only contain human waste but it also has more than 200 synthetic chemicals, requiring extensive treatments. Since sewage contains chemicals as well as other human waste, transforming such content to drinkable water is not simple. As stated in the National Sewage Report Card, " one gram of polychlorinated biphenyls, a substance used in everything from cosmetics to pesticides, is enough to make one billion litres of water unfit for freshwater life" (Holmes, 1999, p.4).

Sewage is considered one of Canada's biggest environmental issues that has been neglected over the years. The measures taken towards protecting the environment from our waste is inadequately addressed. Even though issues of sewage has dragged on for years, proper justice hasn't been laid down on the municipalities by the federal and provincial governments.

The National Sewage Report Card gives an overall glance of the effort each Canadian City has taken towards improving the sewage issue. The main criteria used to evaluate the cities includes sewage treatment provided, discharged raw sewage, process used for disinfection, compliance and regulations (Holmes, 1999). The grades given is indicative of the City's efforts in committing to improvements and measures taken towards addressing the discharged sewage.

In 1999, Toronto's sewage sludge was identified approximately as 454.3 billion liters/year and 442.3 billion litres/year into Lake Ontario. One of the plants discharges 12 billion liters into Don River. In 1998, 4.5 billion liters of sewage bypassed secondary treatment. Secondary treatment refines and breaks down the solids found in wastewater. The process involves biological oxidation, which includes providing oxygen by breaking down organic matter. Oxygen is one of the main ingredients in the treatment process, high amounts of oxygen 
in sewage threats the environment, and break down of organic material helps decrease toxicity. Without oxygen availability, toxins are produced during an organic breakdown. Eliminating oxygen from the process harms the aquatic biota while producing compounds such as hydrogen sulphide and ammonia, some of many toxins. Unfortunately combined sewer overflow events still occur at least 30-50 times a year which results in an estimation of 9.5 billion liters of untreated sewage and runoff being dumped into receiving water (Holmes, 1999).

In 1999, Toronto received a split grade of C/B. C is indicative of the efforts Toronto placed on prioritizing sewage and B is a grade received for to-be future efforts in addressing CSO issue. This grade given is the results of Toronto's effort to remove phosphorous from sewage in the secondary treatment, facilities compliance with Certificate of Approval, implementation of UV disinfection on Main Sewage Treatment Plant as a pilot project and to shut down sludge incinerator. This grade also indicates issues the City is currently having with CSO release, raw sewage is discharged via the combined sewer overflows, an enormous amount of raw sewage and treated somewhat treated effluents is discharged into Don River, a severely damaged environment (Holmes, 1999). The discharge flow contaminated Lake Ontario, and is recognised as a contaminated ecosystem by both US and Canadian governments. Although Toronto has promised to make better plans in addressing CSO issues, no real progress has been made in the past five years.

In 2003, the City of Toronto found a series of harmful chemicals including extractable and volatile organics, grease, endocrine disrupting substance such as nonylphenols and nonylphenol ethoxylates, dioxins and furans (Sierra Legal Defence Fund Report, 2004). In this report the City of Toronto also reported additional problems with cross connectivity. Some stormwater pipes are connected to sanitary sewer systems and vice versa by mistake. The overall combined sewer overflow decreased from $27 \%$ to $16 \%$ since the last report in 1999. Even though there were some improvements, City of Toronto still discharges 9 billion liters of untreated sewage and run-off. In 2004 Toronto received an overall grade of B-, an improvement since the 1999 report. Based on the 2003 Sewage Report Card, Toronto generates approximately 455 billion liters of sewage per year, 9.9 billion liters of untreated sewage and runoff discharged into receiving waters each year. The 2003 report calculated an approximate 443 billion liters of discharge into Lake Ontario and Don River (Sierra Legal Defence Fund Report, 2004). 
Combined sewer overflow events did not change since 1999, there are still overflows occurring 30-50 times a year.

The City made some improvements on updating its Sewer Bylaw to include pollution prevention plans. Ever since the implemented plan, mercury has been reduced by $41 \%$ mostly because of the reduction of amalgam in the dental industry. City's Wet Weather Flow Management Master Plan was in place to eliminate negative effects of combined sewer overflows. Since the last report card the City made progress of reducing combined sewers from 27\% to 16\% since 1999 (Sierra Legal Defence Fund Report, 2004). The Water Efficiency Master Plan promised to achieve a 15\% reduction in the City's water demand by 2013.

2011 report card concludes, Toronto's lack of CSO monitoring between months of April and October, during the months there were approximately $42 \mathrm{CSO}$ events of various volumes in Don River and Central Waterfront watershed depending on the wet weather flow conditions. In 2011 the logged CSO volume was reported as unknown.

The assessment made in 2013 serviced an overall population of 2.7 million in the City of Toronto. There were approximately 80 combined sewer outfalls received by Lake Ontario and Don River at 97\% and 3\% consecutively Harbor (Ecojustice, 2013). In the 2013 report card, City's projects included upgrading the plants to replace the aging infrastructure to optimize plant operations, reduce usage energy and chemical usage. There were a few CSO storage facilities built to reduce combined sewers and volumes. Since the 2003 report card, the City addressed the outfall issues by recommending storage tanks and sewer upgrades.

Their future plan promised to address CSO and stormwater from a combined number of 50 CSO outfalls along lower Don River, Taylor Massey Creek and the Inner Harbor (Ecojustice, 2013). The recommended solution included tunnel installations, underground storage and remote storage tanks and a high-rate wet weather flow treatment facility.

In addition, Toronto has yet to publicly report the Combined Sewer Overflows during a wet weather flow, therefore Toronto received an overall grade of C. A lower grade compared to the assessment in 2003. 


\subsection{Controlling Combined Sewer Overflows}

\section{Source Control}

The Wet Weather Flow Master Plan focuses on controlling the stormwater at source before it reaches the combined sewer systems. The City's method of choice, includes downspout disconnection program, that in excess amounts have caused basement flooding as a result of combined sewer overflows. The program disconnected many downspouts in Leaside, sewershed tributary and Ashbridges Bay area showing the most basement flooding rates. Other initiatives include green roof application, a joint project with Environment Canada, Toronto Region Conservation and Ryerson University to collect stormwater at source (Toronto Water, 2006). Green roofs help reduce the stormwater at the time rain falls by routing it to green vegetation and plants. Other methods explore rainwater harvesting, a way to collect and harvest stormwater for on-site use. The goal is to collect stormwater to use towards toilet flushing for energy saving purposes.

\section{Conveyance System Control}

The City's municipal operations installed a monitoring program at one of the City's watersheds, the Taylor-Massey Creek, to track the outfalls hitting Toronto's surface waters. Also as part of the conveyance control program the City is looking at perforated pipe system, grass swale, roadside ditches and sewer separation anywhere possible.

WWFMP's conveyance measure focus on managing and controlling combined sewer flows in three steps. Perforated pipe system removes pollutants in stormwater by reducing runoff temperature in the filtration system. Another procedure is sewer separation of the combined single pipe system. This will reduce the combined stormwater and sanitary sewage from one single pipe. The volume of stormwater is reduced which results in much less volumes of combined sewer overflows and potentially basement flooding (Toronto Water, 2006). There are certain areas including Leaside and East York that were privileged to have combined system separation, other areas are also under consideration.

\section{End-of-Pipe Monitoring}

End-of-Pipe control is another major project the City has been looking to control larger facilities with excessive drainage. Depending on the area, and its surrounding environment 
including land usage and vegetation, facilities are selected to implement the Wet Weather Flow Master plan accordingly (Toronto Water, 2006).

\subsection{Wet Weather Flow Monitoring Plan}

The Master Plan considers various wet weather flow criteria; at source, conveyance and end-of-pipe. As mentioned there are number of methods to reduce combined sewers and ongoing runoffs to the lakes, as part of the initiative an environmental monitoring plan has also been implemented to report on the plan's progress. The monitoring plan includes environmental assessments and field work to evaluate the Master Plan. A "desktop" monitoring tool as well to add detailed value to ongoing technical studies. The monitoring plan came into place to effectively evaluate the Master Plan as it's moving towards its goals. The monitoring system in place tracks a set of criteria such as, end-of-pipe facilities built, downspout disconnections, etc. Even though there are a number of water quality measures, the City is implementing a 25-year implementation plan to track the water quality, but there is inefficient data supporting water quantity. An intensive monitoring tool was set up back in 1990 to 1992 to compile water quantity data to create a baseline. The plan only covers water quantity assessments within the study area. The Master Plan defined other monitoring programs to implement within the City and Toronto Waterfront. Assessment of water quality and quantity trends are only available at key stream location within the study area (Smith, 2015).

Similar pilot studies have been conducted in several cities in the United States. As part of this study, greater cities similar to Toronto will be presented in a case study format in the next section. 


\section{Chapter 3: CSO Cases Cities}

This experimental field project considers all flow entering the pipes and overflows in an outfall pipe. Initially it was assumed the primary source of combined sewer overflow is extracted from overflow pipes, other source of data is collected to support observations during the overflow. As a test to overflow, depth elevation was converted across to determine a baseline for compare between tides and regulators. Based on the experiment, tide gates and stormwater in an overflow pipe affect measurement and minimize assumptions on determining overflow from depth.

Data collected from entering and disposed wastewater, results in concluding incoming data should be used as a primary source of information when calculating overflow. Collected data from the outfall pipe should be used towards verifying the event, this is a different way from traditional method.

\subsection{Boston case study}

\subsubsection{Boston pilot project}

Combined sewer overflow in Boston has become an issue as the wet flow events become unpredictable with population growth. Therefore, the Boston Water and Sewer Commission designed a pilot project to identify overflow occurrences to update the public with real-time information. Boston's sewer commission took initiative to further investigate current technologies in use and identify exact time of sewer overflow and possibility of posting information to public in a timely manner.

The Sewer Commission appointed Environmental Services to conduct a pilot program for a spam of 2 years to fulfill the monitoring requirements. The pilot program developed in 2013 notified the public on real-time overflow data on a designated web page.

ADS Environmental Commission collects data from several locations, maintains and stores data on FlowWorks website. FlowWorks calculates and stores data while identifying overflow events (Keohan, Armes, \& Stevens, 2013). The tool has helped identify several number of storms by comparing various data to help understand the life of an overflow event from beginning to end. 


\subsubsection{Boston's Combined Sewer Overflow Background}

Metro Boston regional water authority, Massachusetts Water Reclamation Authority created a plan to control and reduce overflows from the Cambridge, Boston, and Chelsea and Somerville areas. The goal contained decreasing overall overflow to receive bodies of water and minimize pollution footprint in recreational zones. The pilot program was designed around Boston Harbor or Fort Point Channel where water discharges. The map below outlines discharge points in red:

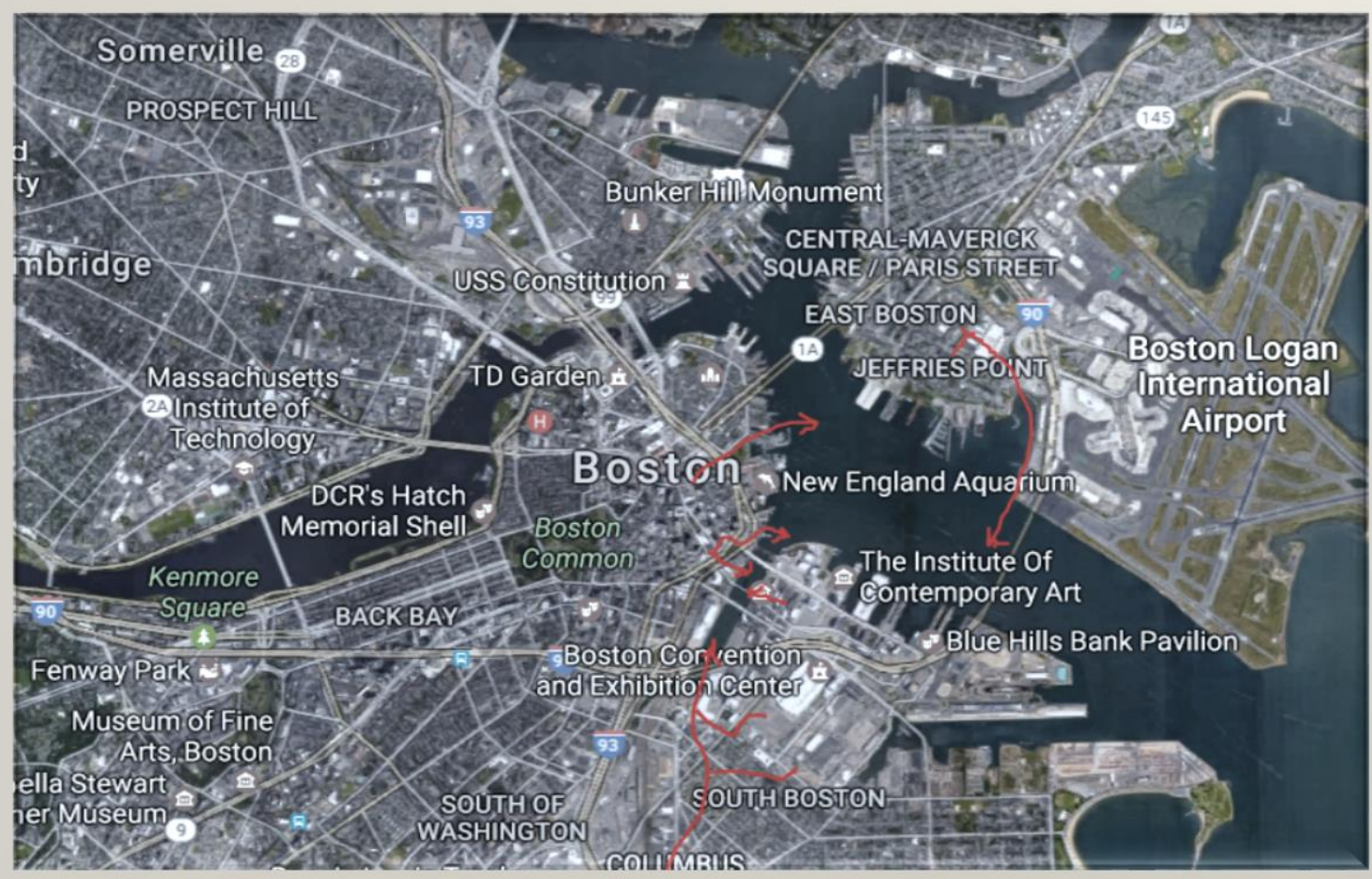

Figure 3.1: Boston Water and Sewer CSO pilot location map

Source: Adapted and modified from Keohan, Armes, \& Stevens, 2013

In the past many programs were designed to measure stage and velocity overflows near weirs or points of outfall. In some cases stormwater was present in downstream pipes of the regulator in the outfall pipes. In conducting this case study, overflow measurement was erroneous. However the FlowWorks system is designed differently to collect data based on stage and velocity in inlet pipes and downstream weirs (Keohan et al., 2013). The system polled data in 5 minute polling intervals to better understand the change during a wet event flow. The pilot 
project monitors tidal heights at the Harbor since regulators are impacted by height of the tides. Each location at the Harbor contained an established elevation baseline set for comparing water levels at the Harbor against sensors.

During the pilot project, several storms occurred varying between 1 to 4 inches affecting sensors ability to fully measure velocity data with high reliability. The tidal waves present in overflow pipes created havoc in the weirs, making it much more complex to identify overflows.

During the pilot study, inlet sensors were not affected by tides therefore combined sewer overflow measures were reliable. Stage and velocity data from inlet sensors were plotted to observe patterns via scattergraphs. Manning's equation was used to predict increase in depth and velocity in initial stages. However the intensity of the storm did not validate the equation (Keohan et al., 2013). While stage increased in pipes, velocity decreased. Also while depth of the storm increased, velocity decreased. During the storm, regulators were utilized to convey flow to nearest interceptors. Regulators are distinguished based on location and are given a certain capacity to identify overflow occurrences. When flow exceeds regulator capacity, it overflows into an 'overflow pipe'. The excess flow is discharged to overflow pipes to help minimize overflows. At the end of a storm inlet flow reaches regulators level, therefore flow is conveyed to nearby interceptors.

\subsubsection{Methods and Procedures}

Combined sewers have been measured using meter installations in overflow pipes to calculate overflows during storm events. Normally meters installed in downstream pipes have been compromised during heavy storms. Erroneous measurements are logged due to invert below mean tides during a flood. Positive and negative flows are captured by flow meter and registered. Therefore to correct the data, it became a requirement to measure all flows plus overflows entering interceptors. Figure (3.2) below explains regulators work to divert flow into an interceptor during dry weather. During wet weather flow is conveyed into a regulator that exceeds capacity of connecting sewer. 


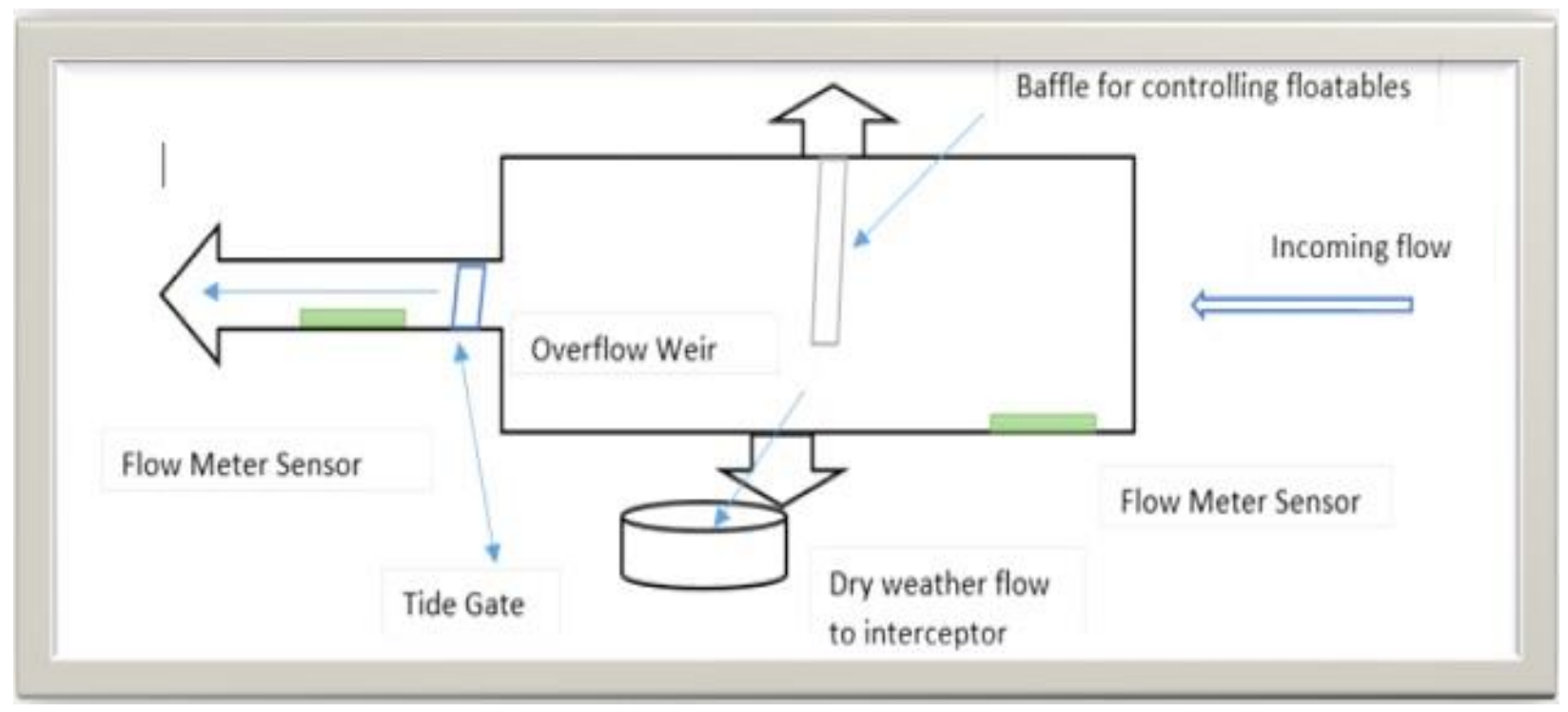

Figure 3.2: Schematic Regulator

Source: Adapted and modified from Keohan, Armes, \& Stevens, 2013

This simplified figure shows incoming flow entering pipe carrying sewer. During a dry weather flow, entered sewage drops into an interceptor with a small pipe connection. Dry and wet weather flow entering the regulator exceeds height of the sewer, weir and tide gate causes an overflow. Use of metering in all locations helped identify information on regulators.

CSO build scattergraphs are known to be one of the most complex types of graphs, they include free flow and backwater conditions within hydraulic conditions while considering the rules of gravity.

There are several trigger points causing wet weather overflow, which include flows exceeding capacity of the sewer connections, height of weir, elevation of the tide exceeds tide gates causing an overflow event. Applying meters at all locations will help provide accurate measurements on regulators functionality.

In this pilot study scattergraphs for combined sewer overflows are utilized to better understand the workings of flow during a dry/wet weather event. This method is said to be one of the most complex ways of measuring flow since hydraulic conditions are also being considered. Hydraulic conditions consist of backwater and free flows in pipes. 


\subsubsection{Results}

The results were logged in a graph and data analyzed helped in understanding patterns. During the first part of the storm empty interceptors had more capacity before getting affected by downstream pump blocking flow to enter. Observation was not verified by metering tools installed.

The scattergraph (figure 1) in Appendix B is evident of flow over a weir, with no sign of downstream tide affecting data collected. The study shows data points on scattergraph that exceeds weir height. It is an indication of overflow.

In Dec 2014 a counter clockwise storm flow event was seen in an overflow weir of $1060 \mathrm{~mm}$ that contained a flow rate of $0.13 \mathrm{~m} 3 / \mathrm{s}$. Based on known metrics, overflow rate was calculated by subtracting actual flow rate by known flow of $0.13 \mathrm{~m} 3 / \mathrm{s}$ during the storm event. Figure 2 in Appendix B is suggestive of yet another storm event showing a counter clockwise pattern in Dec of 2014. According to the chart any flow above overflow weir is considered overflow, any flow greater than the flow rate. The overflow rate is overflow volume minus all the volume points in a pipe during a storm event. This graph presents tides in Boston harbor in blue, while presenting incoming combined sewer volume in green, velocity in black, and overflow is marked in red.

The graph depicted in Appendix B (figure 3) illustrates a better visual of hydrograph. In this graph tides are shown in blue, incoming combined sewer depth is displayed in green, velocity is represented in black, and overflow threshold is red. The red marked letter points are showing the journey of a storm. Point (A) on the Iso-Q line is the initial storm flow at $0.13 \mathrm{~m} 3 / \mathrm{s}$ up to flow peak on point (B) at $0.22 \mathrm{~m} 3 / \mathrm{s}$ and decreases at point (C). The storm intensifies on peak point (D) at $0.44 \mathrm{~m} 3 / \mathrm{s}$ before reversing back to point (E), also known as initial stages of the storm. Storm overflow event was calculated based on any data point greater than $1060 \mathrm{~mm}$ and summarized in 5 minute intervals lasting in an approximate flow of six hours (Keohan et al., 2013). Scattergraph represents both clockwise and counter clockwise patterns of storm determining that each pattern is dependent on two independent variables affecting the measurements.

In summary, key points have been identified in letters to display overflow events. Starting from left to right, point A represents a peak then flows up until point B outlining another 
peak point in the chart. There is an increase in storm intensity at point D. Graph displays a 6 hour storm duration a 5 minute data points.

Based on data points presented in scattergraph, both clockwise and counter clockwise patterns were observed in 5 minute intervals to better evaluate the event. The pattern was deciphered for additional meaning indicating clockwise and counter clockwise patterns were dependent on two independent variables.

Velocity changes with depth in a sewer when there is impact from a slopped sewer. In normal gravity, flow will increase in velocity. With an increase in depth, downstream sewer results in a velocity increase. The exceptions are realized once downstream depth is controlled by any other factor such as tide, usual rule will change.

Scattergraph rotation guide in figure 3.3 explains the impact of the storm based on tides depth/velocity and pattern of the storm. In a sewer without any gravity force, velocity changes based on depth of sewage. In a normal situation where gravity plays a role in the sewer, an increase in depth results in velocity increase. This concept affirms the Manning equation. Based on the scattergraph rotation guide (Clock Wise Pattern) tide depth increase is directly related to measured flow rate. Clockwise Pattern also displays a decrease in tide, depth/second is directly influenced by decreased flow rate. In an opposite situation, Counter Clockwise Pattern with an increase in measured flow directly affects the tide decreasing depth/s. Furthermore the reverse is true with tide decreasing in depth/second and flow rate decreasing in a counter clockwise pattern. 


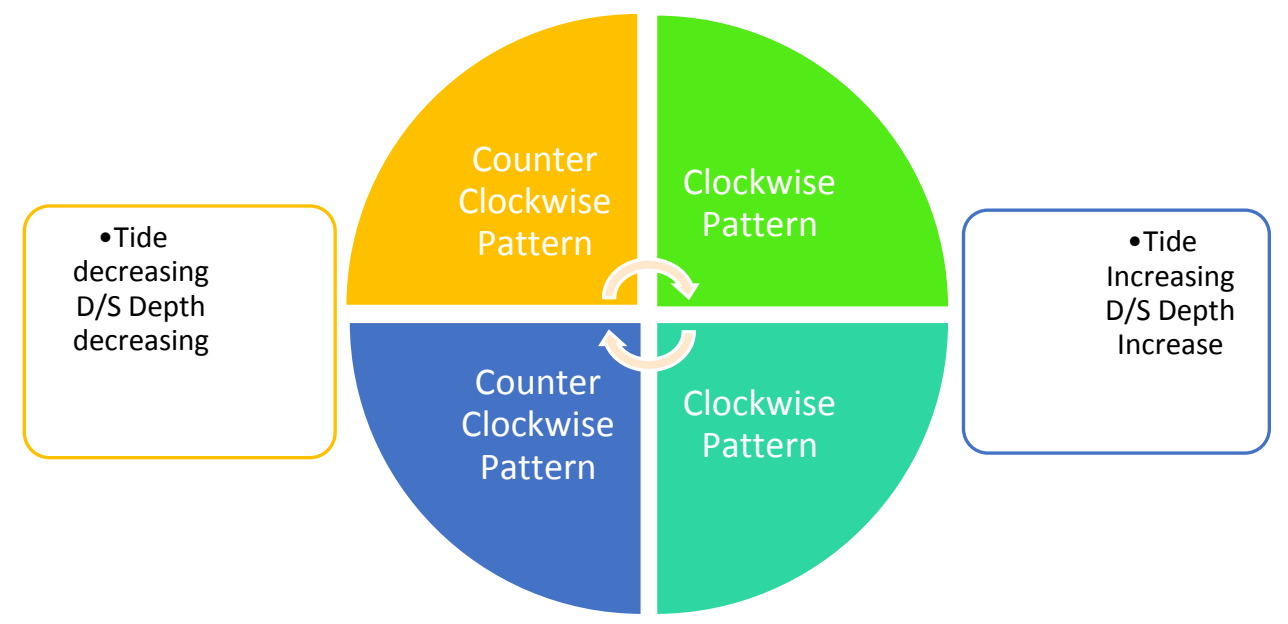

Figure 3.3 - Scattergraph: Rotation Guide

Source: Adapted and modified from Keohan, Armes, \& Stevens, 2013

\subsubsection{The Current Best Practices in Managing CSOs in Real-Time}

The City of Boston is investigating the use of wireless sensors to determine real-time monitoring data on water quantity and quality. A field study conducted in Boston carried by MIT (Stoianov et al., 2008) chose to monitor the water level in combined sewer outflows as part of their experiment. Their goal is to break barriers in monitoring large water operations with high costs or locations considered high priority. The main reason for the limited level of continuous monitoring is prohibitively high price of traditional telemetry systems and in some case high cost of ownership (Stoianov et al., 2008). MIT's experiments were not limited to a laboratory setting but extended to real-life conditions to explore Boston Water and Sewer Commission. MIT's objectives were to implement a system-wide wireless data collection application to assess wireless sensors in extreme conditions in sewers. Other criteria such as cost of deployment, maintenance and technical performance were considered during this 15 month experiment.

Combined sewer systems are currently using real-time control (RTC) systems to route flows, overflows and are designed to manage sewerage systems during wet-weather event. RTC management systems are computer-based models in use to avoid hefty costs of CSO reconstruction. This method proved to be a cost-effective solutions in managing overflows. Use of RTC systems had started in the mid-60s (U.S. Environmental Protection Agency, 1974), and with the latest technology development in wireless sensors, monitoring and automation are 
making real-time control a go-to solution. With recent developments RTC systems are designed to protect receiving waters from pollution by maximizing storage space and utilizing treatment plants. RTC components include sensors, automated gates and strategies (Field, 2000). In measuring combined sewers, required equipment includes devices to measure rainfall, water level, regulators in sewerage pumps and weir walls. There are some challenges in using RTC equipment in terms of reliability, due to corrosion or placing devices in inaccessible locations that are not within our reach. The equipment needs to be safely distributed or else it will ignite gases in sewers.

Their study of monitoring combined sewer outflows uses multiple sensor distribution to eliminate error by increasing redundancy. Use of multiple sensors reduces sensor fault, spatial sensor distribution in pipe allows for data collection and comparison. This process will eliminate data appearing to spike or is irrelevant when compared to other data. All data collected will be passed on to gateway or hub for processing, this all-in-one data collection gives user one view of the water levels. Furthermore, data sampling process includes precipitation/ rain gauges data as weather conditions change.

In terms of background information on system architecture of wireless monitoring study areas, to meet data collection objectives, it is mandatory to place demanding requirements in terms of bandwidth, long-distance communication and accurate tem synchronization, and local data processing (Stoianov et al., 2008). One of the main challenges with creating a system-wide monitoring data collection is access to power supply. In many cases these devices are in remote location without power, and must rely on battery power. During the system design there were a few constraints to overcome, including power access, communication from sensors to hub, choosing the correct bandwidth and data processing.

In response to these challenges a three-tier communication structure was developed. In this design, subsystems work dependently to collect and distribute data sensing points. First tier, underground pipe level tier forms a cluster to communicate short-range data and is battery operated. These energy-constraint sensor nodes transmit data from tier one, underground pipes to second tier, data gatherers. Data gatherers are installed at upper ground, and street levels on street lights or panels. They don't necessarily run on battery power but have solar grids attached to them as power supplies. Use of second tier solar power is very critical in this setup due to 
costs efficiency and overall feasibility of this project. This setup eliminates the need of digging up the pavements and maintaining power cables which is costly and risky in particularly in dense urban environments (Stoianov et al., 2008). Data gatherers have control over sensor nodes to schedule their sleep and wake times for data collection. Furthermore, they initiate communication to central hub via TCP/IP to establish a secure communication tunnel. SSH protocol guarantees confidentiality and integrity of data exchange between gateway and servers (Stoianov et al., 2008). Secure form of communication via TCP/IP carries a huge weight when implementing such systems; secure form of communicated data is a must for many industries to avoid hacks and lose substantial information and credibility. The setup at MIT ensures this type of communication throughout the subsystems then finally third tier displays data via a web browser. The web browser portion is supported on a web interface using Google MAP API to build and locate the sensors for viewing.

Boston Water deployment in collaboration with Boston Water and Sewer Commission was deployed in 2004 to formulate answers for any technical challenges, economic costs, maintenance, overall product reliability and durability. Monitoring system implementation successfully captured several overflow events, as the emergency power supply at one of Boston's treatment plant failed. Deer Island Sewage Treatment Plant did not capture 25 million gallons of untreated sewage released into Quincy Bay (Stoianov et al., 2008).

MIT's field experience demonstrates advances in wireless sensor networks, communication and sensing technologies could provide much needed increase in spatial and temporal of hydraulic water quality data for better understanding and monitoring large scale water supply and sewer systems (Stoianov et al., 2008). Their implementation of monitoring system using sensor network for duration of one year gathered continuous data with minimum technical assistance. This automated system only requires a 60 day battery replacement in severe weather conditions. Otherwise this system has proven to be durable and reliable when correct design procedures are followed.

\subsubsection{Summary}

In summary downstream sewers with an increase in depth directly results in increased velocity. If the downstream depth is controlled by other factors then results change. The rotation guide gives a clear condition rule of the changes flow rate has in respect to depth of pipe. 
This project is an example to measure flows entering each regulator and calculating overflow in a single outfall pipe. The calculations extracted from this project can be used towards better understanding flow regulators and also gathering enough data to support the production of hydraulic models. Interestingly enough the project was initially designed around primary CSO information gathered at the overflow pipes and any other data is just supporting the main source. The process was to convert data gathered from depth and produce a common elevation denominator to calculate overflow. Unfortunately this method failed to produce correct information as existing stormwater in overflow pipes influenced the final overflow measurement.

After many tests it became apparent that incoming data was much more reliable and should be used as the primary source of information (Keohan et al., 2013). The data from the outfall pipe should be used for verification, contradicting the traditional views.

Improvements were recognized in measuring flow technology to accurately report on depth and velocity information via wireless communication. With advancements in technology, any hydraulic changes in the regulator are accessible.

\subsection{City of Poughkeepsie New York case study}

\subsubsection{City of Poughkeepsie New York, Combined sewer}

City of Poughkeepsie located in southeast New York State founded in the late 1790s remains as one of the older cities with six combined overflow sewer infrastructures. The City of Poughkeepsie, located on the Hudson River discharges into Hudson River directly or via several river branches. Hudson River is one of the most crucial water resources due to its multi-purpose use of recreational activities and water supply. Furthermore the Hudson River accommodates industrial tourism shipment.

In the 1970's and 80's, Poughkeepsie initiated several combined sewer system projects. The City of Poughkeepsie's combined sewer system contains six overflow structure systems.

The diagram shown in figure 3.4 explains the City's Stormwater Management Model: Stormwater Management Model: 


\section{HUDSON RIVER}

PINE ST. PUMPING STATION

Capacity $=284$ liters $/ \mathrm{s}$

PINE ST. INTERCEPTOR
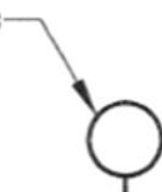

Rain Gauge and Treatment Plant

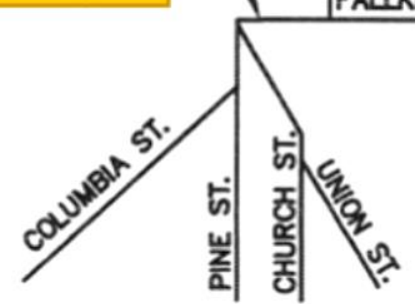

Capacity $=879$ liters $/ \mathrm{s}$

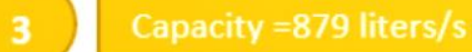

Figure 3.4: City of Poughkeepsie - Stormwater Management Model

Source: Adapted and modified from Van Gelder \& Barlow, 1995 
The combined sewer system contains six interconnected overflows, described in table 3.1:

Table 3.1: Stormwater Management

\begin{tabular}{|c|c|c|}
\hline \multicolumn{2}{|c|}{ Combined Sewer System } & Description \\
\hline 1 & $\begin{array}{l}\text { Pine Street Pump } \\
\text { Station }\end{array}$ & $\begin{array}{l}\text { Combined sewer overflow is located on the bank of the } \\
\text { Hudson River. The overflow contains a side weir, flow spills } \\
\text { over the weir during a spill over into the river. }\end{array}$ \\
\hline 2 & Pine Street & $\begin{array}{l}\text { CSO is located in between the upstream of Pine Street Pump } \\
\text { Station and downstream of Pine Street Trunk Sewer. The } \\
\text { overflow sewer contains a weir with a sliding vent, during wet } \\
\text { weather flow the sliding vent discharges excess flow into the } \\
\text { Hudson River. The pipe can hold less than } 10 \text { inches of flow } \\
\text { during a dry weather flow. Excessive flow from Pine Street } \\
\text { and Riverview is discharged into the River. }\end{array}$ \\
\hline 3 & Fallkill Creek & $\begin{array}{l}\text { The combined sewer overflow in FallKill Creek is structured } \\
\text { with a maintenance hatch located in the pipe bridge on the } \\
\text { bank of FallKill Creek. South bank's maintenance hatch has a } \\
\text { maximum overflow height of } 15 \text { inches, discharging into } \\
\text { Fallkill Creek. The FallKill Basin and Mill Street basin are } \\
\text { supported by a CSO that carries over } 800 \text { liters of discharge. } \\
\text { Other CSOs such as Mill Street and Albany are located close } \\
\text { to Fallkill Creek. }\end{array}$ \\
\hline 4 & Mill Street & $\begin{array}{l}\text { Mill Street CSO located at the base of the Mill Street Trunk } \\
\text { Sewer contains a hatch structure with a leaping weir. During } \\
\text { dry weather, flow falls into the underflow line while excess } \\
\text { flow is carried by a sewer discharging to the Hudson River. } \\
\text { Mill Street sewer is reserved for the Mill Street and Fallkilll } \\
\text { Basins, while discharging flow from Albany Street. }\end{array}$ \\
\hline 5 & Riverview Boulevard & $\begin{array}{l}\text { Upstream of the Pine Street Pump Station resides the } \\
\text { Boulevard CSO which includes two-chambered maintenance } \\
\text { entrance of the Pump Station. The CSO has a diversion weir } \\
\text { with a valve and a regulator controlling the gate beneath the } \\
\text { two chambers. Flow diversion is controlled by a } 10 \mathrm{~cm} \text { curb } \\
\text { which is directed to a bypass line shared with Pine Street } \\
\text { combined sewer overflow. The Riverview combined sewer } \\
\text { overflow serves the Church Street and Union Basins. }\end{array}$ \\
\hline 6 & Albany Street & $\begin{array}{l}\text { CSO located on Albany Street Combined Sewer Overflow } \\
\text { located in maintenance hatch containing a weir pipe } \\
\text { discharging flow to Mill Street's shared outfall pipe. }\end{array}$ \\
\hline
\end{tabular}

Source: Adapted and modified from Van Gelder \& Barlow, 1995 


\subsubsection{Model development}

\section{Model Selection}

Developed monitoring plan was based on two different approaches for reporting overflows. One main option contains installing permanent flow monitoring equipment on each of the combined sewer overflows. Data obtained from flow meter combined with the rainfall data is used towards reporting overflow volumes. Benefits of using a combined method eliminates uncertainties, measured overflow, and provides computerized estimates. There are some difficulties in maintaining and installing such an approach, including high cost in association with monitoring equipment as well as the limit set on estimating rainfall events.

The alternative approach, quantifying CSO discharge by using a computer model. The model is built to:

$\checkmark$ Allow Cities to report on overflow events by using local rainfall data while satisfying the permit requirements.

$\checkmark$ Reduce the need for automation and manual flow monitoring at the combined sewer overflow points.

$\checkmark$ Create planning software to allow evaluation of the current and future strategies.

To evaluate overflow rate, an appropriate model was selected to compute flow rates. The main requirement in model selection was dependent on regulating authority. Other important criteria included on flexibility to expand and improve model, perform single/multiple event simulations and to evaluate flow and overflows (Van Gelder \& Barlow, 1995).

Poughkeepsie's overflow and flow rates were evaluated by the Stormwater Management Model selected primarily due to its acceptance rate.

\section{System Definition}

Developing stormwater management model requires a defined description of system and a set limit for the drainage areas. The combined overflow system covers an estimated amount of 780 acres worth of City's sewer (Van Gelder \& Barlow, 1995). During field experiment, limitation such as modelling whole system at once was recognized due to element limitations. 
Furthermore, modelling every pipe infrastructure in the system wouldn't necessarily redefine results when comparing system models side by side.

\section{Model development}

The model was built based on qualitative and quantitative measures of the system. Major points of the infrastructure included critical contributors to overflow, sources of overflow and any critical point within the system such as major changes. Furthermore, nodes were placed at key points in the system for expanding the model.

\section{Data Collection}

A significant amount of requirement gathering was required to prepare an accurate model system. Without conducting a survey or completing tedious investigations, the City's system was readily available by the engineers. The City Engineer provided full reports on infiltration issues, numerous treatment plans and efforts to develop a baseline for the system. Drainage system areas were provided and used for mapping out the system model.

The biggest challenge in developing a system model depends on collecting flow information to construct a model. In order to calibrate the model, an extensive plan was designed to capture required data for the monitoring program. To obtain overflow quantities, both inflow and overflow pipe had to be monitored. Utility services of New Hampshire, was designated as a monitoring site for metering information. Installed metering equipment contained dual sensor meters, one designed to record depth of flow and velocity and other positioned to record flow only. The collected data was stored digitally onto a computer. Weekly maintenance allowed for proper operations to obtain depth of flow and velocity measurements. The City's rainfall data was collected via a bucket rain gage in the sewage treatment plant to record rainfall precipitation data during wet/dry event logging period. It's conclusive to use one rain gauge based on historic data to evaluate rainfall for the entirety of watershed (Van Gelder \& Barlow, 1995).

Monitoring was performed during months of summer in 15 minute intervals for sewer overflow and main line data. Data was summarized based on minimum flow, daily flow, peak flow, and total amount of rain, intensity of rain and peak flow. To provide precise data, additional data was retrieved from upstream pipes to develop models. Metering data collected was used as a base flow to accurately model a system for proper flow distribution. Depth of flow in pipes were measured manually then later used to compute pipe flow. Base flow distribution 
helps verify assumptions made in earlier stages of monitoring, this method used helps identify flow monitoring measurements (Van Gelder \& Barlow, 1995).

\section{Model Structure ad Calibration}

To simulate similar stormwater infrastructure network, two types of computational blocks were used to recreate the system. Dedicated blocks, RUNOFF² Block for hydrologic computations and a TRANSPORT ${ }^{3}$ Block routed storm flow.

The main criteria for the model relied on its dependency to meet the requirements of the six overflow structures. Five out of six were structured as weirs. Weirs were modeled to divide flow based on dry weather flow capacity structure. Historical data from dry weather capacity had been previously measured and stored for usage by the City.

Technical reports created for the City, included capacity information to use towards field experiments. Some adjustments were made when historical capacity measures were compared to structured modeled capacities.

A dedicated spillway pipe was introduced as a sixth overflow device. The sixth overflow device built within the pumping station, ultimately was controlled by flow capacity within pumps. This device model incorporated a flow divider at the pumps to divert flow.

To complete model calibration, aspects of Stormwater Management Model were in need of completion. The model required several adjustments to overcome issues such as:

1. RUNOFF Block Scratch Files: there were issues seen in using the incorrect NSCRAT file, once NSCART $(2)^{4}$ was assigned, the program operated normally. On the contrary if NSCART (1) was assigned an error would occur while reading the file (Van Gelder \& Barlow, 1995).

2. Units: Pipe slopes in RUNOFF Blocks expressed in percent while Overland slopes within RUNOFF Blocks are calculated in feet. Proper unit must be used while tracking and storing data. Data needs to be entered properly into the system. Human errors are reduced once these units are entered consistently into the system (Van Gelder \& Barlow, 1995).

\footnotetext{
${ }^{2}$ RUNOFF Block is part of the SWMM model, its sensitive to changes in the runoff volume and the pipe conditions

${ }^{3}$ TRANSPORT BLOCK routes flows and pollutions through the sewer system

${ }^{4}$ NSCART(2) file type created and used by SWMM model
} 
The calibrated model was equivalent to metered overflows. Iterative processes were required to adjust the model. To reduce error it was critical to avoid adjustments outside of the expected ranges. Adjusting control variables outside of normal ranges is an indication of a flawed model, and system parameters were wrongly defined.

The calibrated Poughkeepsie model was adjusted based on adjusting drainage within the RUNOFF Block. Adjusted parameters as shown in table 3.2 included:

Table 3.2: Adjusted Control Variables

\begin{tabular}{|l|c|c|}
\hline \multicolumn{1}{|c|}{ Description } & Original Value & Adjustment \\
\hline Depression storage availability & $0.35 \mathrm{in}$ & 0.65 in \\
\hline Overland areas (Manning's n) & 0.35 & 0.45 \\
\hline Effective impervious areas \% & $40 \%$ & $60 \%$ \\
\hline Subcatchment area width (effective) & 225 & 316 \\
\hline
\end{tabular}

Adapted and modified from source Van Gelder \& Barlow, 1995

Variables were chosen instead of being assumed, and the model was calibrated according to total discharged volume at each overflow. The model report was based on logged volume to calibrate model. Rainfall event logs were used towards the model due to significant amount of rain. The chart below summarizes monitoring data from May31st's heavy rainfall event in 1993 resulting in the greatest overflow.

The rainfall event produced a substantial amount of rain with a significant amount of volume. Incorporating additional rainfall data in the model was prevented due to limited monitoring data on rainfall events. Calibration data is summarized in Figure 3.5: 


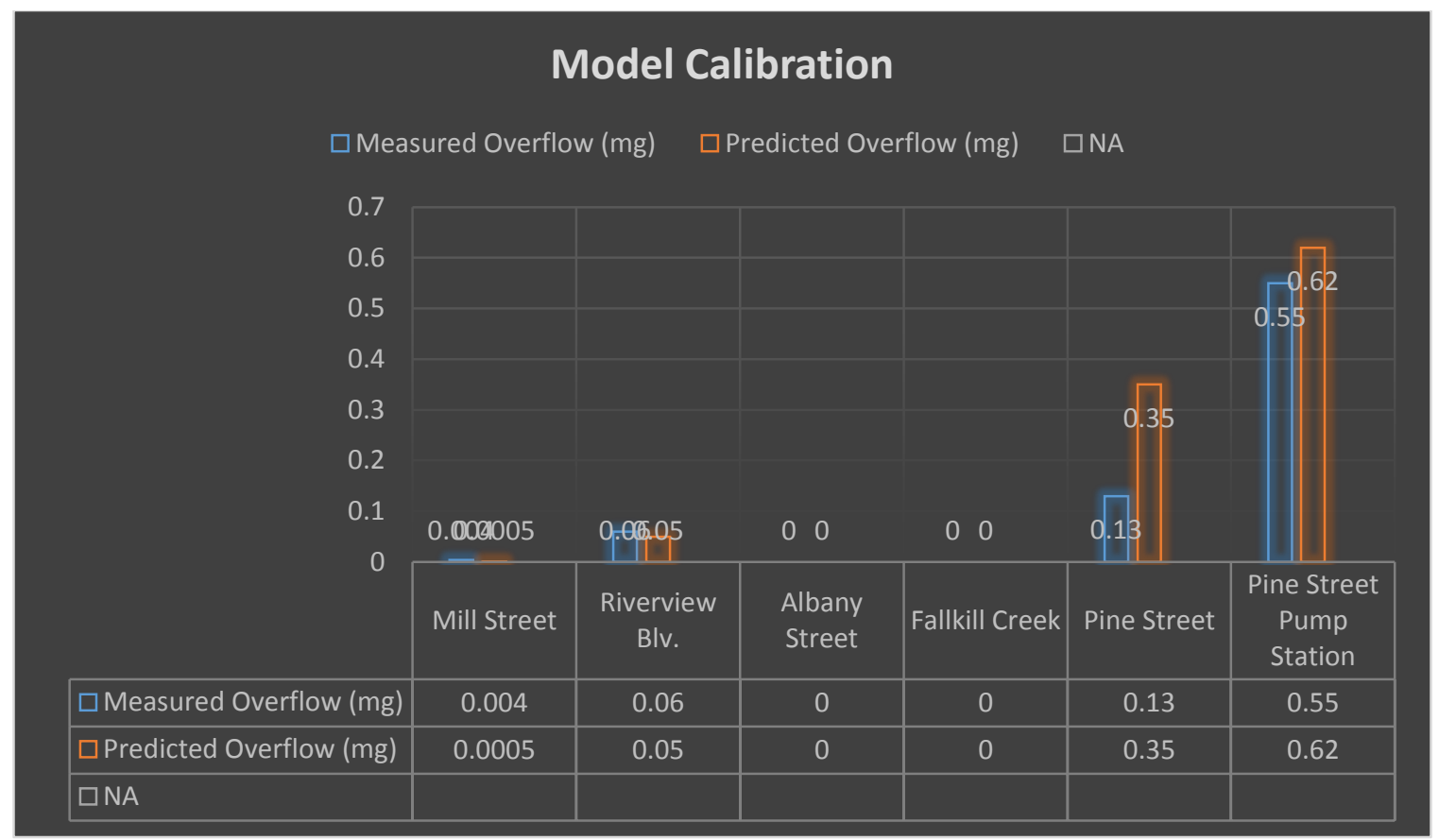

Figure 3.5: Model Calibration Results

Source: Adapted and modified from Van Gelder \& Barlow, 1995

Albany Street overflow calibration faced monitoring issues. Due to a blockage in the main pipe, downstream flow data monitoring caused flow recorder to report overflows during dry weather events that were mistakenly being recorded as overflow periods. Limitation of the model assumes overflow only during large storm events and computes overflow data as a small portion of combined sewer overflow. Due to minimal rainfall, results of the model were in conflict with measured data reporting overflow. Albany Street CSO had an advantage in monitoring and reporting due to its small drainage area.

Three of the calibrated combined sewer models were developed within 2-11\% ranges of measured flow. The erroneous monitoring measures in Pine Street and Albany Street combined sewers resulted in modifying calibrated parameters which affected performance in downstream sewer (Van Gelder \& Barlow, 1995). Furthermore, data provided by other calibrated model sufficed in providing beneficial metering data. 


\subsubsection{SWMM Model Simulations}

\section{4-hour Storm Events}

Hypothetical storm event reporting was a requirement to meet Poughkeepsie's permit conditions. Several overflow volumes were collected for storm event stimulation, based on hundred years of historical data. Due to an existing gap in collected rainfall data in previous years, storm stimulations were required for model calibration.

To generate data, simulation was required to feed input into the RUN-OFF Block model. Rainfall data collected from Rainfall Frequency Atlas of the United States helped initialize and develop the hyetographs. Hyetographs were calculated from total rainfall amounts (Van Gelder \& Barlow, 1995).

Stormwater Management Model ran against different storm events, results were plotted for each of six overflow structures.

\section{Estimating Curves}

The Storm Management Model served the City as a way to collect and compute overflows for reporting purposes. CSO estimating curves were developed for six different overflow structures to estimate the combined sewers.

Below is a summary of Poughkeepsie's total rainfall amount collected from a rain gage at the City's sewage facility and incorporated into the CSO. This information as shown in table 3.3 is a result of rain gage data installed at the City's sewage treatment.

Table 3.3: Mill Street 24 hour stork CSO Curve

\begin{tabular}{|c|c|c|}
\hline Year & $\begin{array}{c}\text { Overflow } \\
(\mathbf{m g})\end{array}$ & Rainfall (In) \\
\hline $\mathbf{1}$ & 2 & 3 \\
\hline & 4 & 4 \\
\hline $\mathbf{5}$ & 6 & \\
\hline & 8 & 5 \\
\hline $\mathbf{1 0}$ & 10 & \\
\hline & 12 & 6 \\
\hline $\mathbf{6}$ & 14 & \\
\hline & & 7 \\
\hline $\mathbf{8}$ & 16 & 8 \\
\hline & 20 & \\
\hline
\end{tabular}

Source: Van Gelder \& Barlow, 1995 
Historical rainfall data collected by Northeast Regional Climate Center at Cornell University was also used to develop the curves of the SWMM model. Historical data was provided by Cornell University from 1970-1992, as they maintain a gaging station (Van Gelder $\&$ Barlow, 1995). Storm data with various intensities, durations and rainfall amounts were used towards SWMM model.

SWMM simulation contains volume of overflow and rainfall amount. Graphs were plotted based off of a DCA ${ }^{5}$ module due to its variable plug in capabilities, three different variables including peak intensity, overflow and volume (Van Gelder \& Barlow, 1995). SWMM model generates CSO estimating curves, it provides number of combined sewer overflow events and volume of the event is recorded by wastewater treatment plant.

\subsubsection{Summary}

Poughkeepsie's stimulation field experiments resulted in understanding the benefits of developing CSO models to log CSO discharges instead of permanently installing flow monitoring devices. In this case, CSO discharge models are a recommended method if conditions are reasonable due to cost efficiency. The model works in favorable conditions but doesn't guarantee accurate results in complex sewage storm systems. Furthermore in instances of complication it is highly recommended to install permanent flow monitoring for best results.

Computer modeling has proven to require limited monitoring data for model calibration. It is vital to utilize accurate data to represent the existing system model for proper calibration. SWMM model crafted provides accurate computed data for CSO discharges since it was calibrated on system response. To successfully apply the model for reporting purposes, an extensive investigative effort was required to ensure calibration. Without quality assurance, data accuracy collected for CSO computation would have been debatable.

\footnotetext{
${ }^{5}$ DCA (David C. Arnold) module in Autocad supports variables (overflow, volume, and peak intensity) (Van Gelder \& Barlow, 1995).
} 


\subsection{Riverside and Evanston, IL case study}

\subsubsection{Monitoring and analysis of combined sewer overflows, Riverside and Evanston, Illinois}

\section{Background}

State of Illinois, U.S. Geological Survey and U.S. Army Corps of Engineers investigated methods to determine the best solution in resolving northeastern Illinois's CSO issue. As part of their Chicago Underflow Plan and Reservoir plan, flood-control design solution is intact to store combined sewers (Lyanders \&Welch, 2012) from Des Plaines and Mainstream tunnel systems. Their goal is to reduce combined sewer overflows in the receiving water and control flood damage. The sewer system is designed to transport sewage from Des Plaines and Mainstream Tunnel to the reservoir at times of excess flow to West-Southwest Water Reclamation Plant.

Engineers collected and analyzed flow data in combined sewers for 12 locations. Their main focus was to determine volume of combined sewer flowing through Riverside and Evanston from March 1997 to December 1999. Two corporations shared the same vision in designing a cost-effective system; a system that determines quality and quantity of water entering reservoir during large rain storms (Waite, Johnson, \& Hornewer, 2002).

Furthermore, while designing a cost-effective solution, it's important to factor in water quantity and quality during a wet storm event. The Metropolitan Water Reclamation District of Greater Chicago collected biochemical oxygen demand and other water quality samples at the Riverside (Calumet pumping station) and Evanston (Racine pumping station) combined sewer locations.

These locations are two of many locations with flow runoff, other areas of concern exist in the reservoir during heavy rain. Analyzing two locations is the baseline to determine combined sewer overflow estimate for other locations around the reservoir. In order to understand biochemical oxygen demand, qualitative and quantitative data must be collected using flow data monitors.

Purpose of the effort is monitoring combined sewer overflows by analyzing flow data collection to report on the status of CSO in Evanston and Riverside. This report includes a 
description of flow-monitoring tool chosen, location of combined sewer overflows, equipment used for measurement and procedure of data collection and analyzed (Waite et al., 2002).

Due to complexity of data flow analysis in the sewer system, many assumptions were made while estimating the volume of water entering the interceptor sewer, such as effect of infiltration and velocity required to make an accurate determination. Other unforeseen causes such as random inflow or backwater were also accounted for in this analysis.

In terms of look and feel of the sewer system design, sewer system infrastructure consist of circular elliptical siphon pipes ranging up to 10.0 feet in diameter. The sewer system is built on concrete or brick material with smooth and rough surfaces. Des Plaines and Mainstream systems transports; dry-weather flow, including domestic and industrial wastewater, stormwater, inflow and infiltration are transported in these tunnels (Waite et al., 2002). Des Plaines tunnel system covers almost 20 residential communities with an estimate population of 263,000.

Mainstream tunnel system covers 21 residential, commercial and industrial communities with an estimate population of 2.7 million (U.S Army Corps Engineers, 1998).

During the analysis period Riverside announced a total inflow sewage of 721,000 cubic feet in April 1999 and an outflow of 132,000 cubic feet to the Des Plaines River at Riverside. Also Evanston reported approximately 6,000,000 cubic feet during the month of April in 1999.

\subsubsection{Combined Sewer Overflow Monitoring Overview}

This section describes a general methodology of combined sewer overflow monitoring and complexities encountered during the monitoring process when examining the combined sewer overflow locations. The sewer infrastructure is complex due to its pipe configuration and overall pipe junction and chamber implementation, at times there were occasional reverse flows in the pipes. In this field study water levels and flow data was collected in two to five minute intervals. Constant velocity measurements were required since at times water flow velocity was either too slow or too fast to be measured by flow-monitoring equipment. In cases with water turbulence estimates were made in unreasonable circumstances.

Metropolitan Water Reclamation District of Greater Chicago (MWRDGC) collected water quality data at two different locations including Calumet and Racine pumping stations as well as Riverside and Evanston. Water quality sampler program were set up to automatically collect water samples at tide gates with water falling into receiving water during rain storms. 
During wet flow events water quality data was collected but to understand volume of pollution entering the receiving water, quantity was determined as well. The process in place used to find constitutes loading based on flow modeling and random water quality sampling but due to sewer system hydraulic complexities at the two locations, they decided to collect flow data and water quality data. The goal is to calibrate a computer model based on water quality and quantity collected concurrently in the same location.

\subsubsection{Equipment and Maintenance}

Equipment used for this study consisted of a flow monitoring device with depth and velocity sensor and automated water quality sampler to collect samples in parallel during periods of wet flow events. American Sigma meter installed in the combined sewers of Riverside and Evanston collected flow data in most of the sewers.

In terms of Sigma meter, this device consists of a probe with an Ultrasonic velocity meter and a pressure transducer to measure flow velocity and depth. The meter also contains a data logger to allow remote monitoring of collected flow data. For the purpose of this study Sigma meter 920 (see Figure 5 in Appendix B) was used in conditions were one probe was required to collect data and multi-probe sigma meters were installed in location required one or more flow and depth measurement.

In this field study, Sigma meters were configured to collect data every 5 minutes. The probe was programmed in 5 minute intervals to collect accurate measurements in the combined sewer.

During wet flow events, water depth and velocity changed in matter of minutes, in order to capture change, the probe's settings were programmed to collect accurate measurements in 5 minute intervals.

Proper location of probe is an important factor, to obtain most accurate velocity measurement possible, various items need to be considered. Vertical drops, bends in pipe and unexpected turbulence can cause incorrect measurements (American Sigma, Inc, 1996b). Probe placement changes depending on the condition of sewer system, if the probe is right at an outfall, then it should be implemented 10 times away from high water flows. Also if the probe is 
installed in a backwater pipe then it should be 10 pipe diameters away from all water turbulences.

In this study, stainless- bands were used to mount devices to pipes and bolt part of the strap to the wall. Other techniques were used to suit different situations to accommodate sewer infrastructure designs (Waite et al., 2002). For example, at one location the probe was first mounted to an I-beam then dropped into a pipe. Technicians weren't able to mount the probe to pipe surface due to its deep location. The I-beam carried weight that prevented movement of the Sigma meter probe during water turbulence.

Furthermore, additional instruments used to measure flow consist of probes capable of measuring velocity, distance and an internal thermistor. An instance of Unidata Starflow Ultrasonic Doppler was used to measure average velocity instead of discrete velocity.

Starflow meter will only report a good flow as the last flow if two conditions are met in water. For accurate velocity data, a certain amount of particulates must exist in the water. If the water is too clear or pooled then an accurate measurement cannot be made. Starflow meter is programmed to log data one probe detects water. Therefore, Starflow meter only functions to log data during water flow, as soon as water stops flowing, the meter discontinues logging data (Waite et al., 2002). This method is also known as event-based logging sequence. The probe was programmed to collect distance using stage sensor, velocity and water temperature in 2 minute intervals.

In addition to installed meters, Rain-O-Matic rain gage was also installed near pipes where the probes were installed at Riverside. Rain gage helped compare rain fall water quantity in watersheds with flow in combined sewers. Rain gage operated with a funnel carrying rain drops as it drained itself into a spoon (Waite et al., 2002). The spoon would tip once full as a $\mathrm{HOBO}^{6}$ contact-closure event data logger logged the rain quantity.

In terms of operation and maintenance, it was necessary to clean up debris, grease and oil from accumulating on flow meters in site locations. Monthly visits were required for cleaning probes to avoid loss of velocity signals due to accumulated debris. Additionally, Sigma meter also required monthly visits to retrieve monthly data and replace batteries. Sigma meter used

${ }^{6}$ Device logging data 
"wrap" memory data logger, meaning new data replaced old data, once memory became full. In order for technicians to enter pipes on monthly basis, permits were filled prior to entry and protocols were followed according to American Industrial Hygiene Association (1995) (Waite et al., 2002).

\subsubsection{Combined sewer overflow analysis of data}

This section describes Riverside and Evanston's combined sewer study areas.

\subsubsection{Combined sewer overflow at Riverside}

\section{Description of study area}

Riverside is a village located along the Des Plaines River with an estimated population of 8,800 (Waite et al., 2002). Combined sewer system used for this study consisted of 2 Sigma meters containing 4 probes in the Riverside sewer system pipes. At outfall pipe, Starflow meter was installed based on calculations made using laser on Des Plaines River at Riverside to determine measurements. The meters were programmed to associate dry pipe conditions with stage number ' 0 '.

Riverside Gage Street brick pipe connected to an interceptor sewer by a weir is conveyed to Stickney. During dry weather flow, flow is carried from weir and diverted into an interceptor pipe and then to Stickney. But during wet weather flow, flow exceeds capacity of the diversion weir then enters into chamber 1, at this point flow can take on two different paths. If flow enters path 1 , or long pipe then water enters chamber 2 given it's almost the same elevation. In case of backwater conditions then flow enters Des Plaines River by passing a tide gate which alarms as it activates. Activated gate signals its alarm to Stickney and opens sluice gate. Chamber 1 and 2 are connected by a combined sewer during wet flow events, combined sewer is monitored when it's entering chamber 2 (Waite et al., 2002).

In addition to sewage running into chamber 2 from long pipe, there is also a brick pipe combined sewer which contributes stormwater into chamber 2 during wet weather flow events. In dry weather, flow is diverted to an interceptor Gage street pipe by a diversion weir. In stormwater conditions, flow passes the brick pipe and enters chamber 2 passing the mounted probe, placed half way between the diversion weir and chamber 2 . 
From chamber 2, flow can either enter chamber 3 without any known estimation on monitoring or it can enter Des Plaines River via outfall pipe through tide gates. During dry weather periods water is diverted by a closed sluice gate. In this condition with a closed sluice gate, a backwater condition will result from stage increase in chamber 3. During a wet flow condition, water can even backup in chamber 2 through a tide gate. Alarm activated tide gate signals to Stickney as soon as gates open sluice gate. If the backwater condition continues water can back up into chamber 1 into Des Plaines River.

With tide gate in chamber 2 opening, flow falls into the outfall pipe then Des Plaines River. This pipe contains Starflow meter, the probe monitors data as soon as water is sensed. When tide gates open in chamber 1 and 2, the sluice gate is also opened by Stickney personnel to let the flow into the deep tunnel. With sluice gate opened, sewers flows vertically into the deep tunnel, this will help reduce sewage discharge in Des Plaines River.

The sluice gate opening to the deep tunnel transports the combined sewer overflow to Stickney; the sewage under goes treatment before getting released. The deep tunnel also works as a storage tunnel in case there is excessive water flowing towards Stickney and capacity is reached.

Deep tunnel storage capabilities allows treatment plant to continue functioning under normal conditions until its ready to release water. Patrick Connolly, Metropolitan Water Reclamation District of Greater Chicago communicated in 2000 (as cited in Waite et al., 2002), under circumstances, with Stickney's capacity and deep tunnels storage capabilities are reached maximum load, then sluice gate closes to avoid hydraulic surging In wet flow events with sluice gates closed, stormwater moves upstream of gates and causes tide gates of chamber 1/2 to openly discharge into Des Plaines River.

\section{Flow monitoring: storm volume}

This section describes methods used to determine the flow data from the initial point of Gage Street Pipe running to the sluice gate on April, 1999. In Riverside there were a limited number of flow meters used therefore assumptions were made to calculate an estimation of flow and volumes. 
During a dry weather event all the water is diverted by a diversion weir into an interceptor sewer at the Gage Street pipe. Monitoring probe was not installed within the interceptor sewer to track flow data, therefore an estimated assumption was made on quantity of water diverted by the weir to account for overflow during storms.

To determine flow from Gage Street into interceptor sewer, three stage rises were used to determine water does not reach threshold of the weir height. If water was not detected by the probe installed in long pipe then the value was true. This confirmed flow entering Gage Street Pipe is diverted into an interceptor pipe. An estimation was made that anything below the $3.75 \mathrm{ft} 3 / \mathrm{s}$ was properly diverted into an interceptor sewer without any overflow, but anything exceeding the maximum average of $3.75 \mathrm{ft} 3 / \mathrm{s}$ was considered an overflow.

Assumption was made based on downstream flow conditions, in cases of backwater conditions, estimated number changed. There is a high chance the weir would accept less than estimated average amount of $3.75 \mathrm{ft} 3 / \mathrm{s}$ of stormwater. In stormwater conditions more water will flow over weir than the estimated amount. But since interceptor sewer was located vertically it allowed for free-orifice. Meaning the interceptor outlet was a free outfall and not sub-merged (Waite et al., 2002).

Water arriving at long pipe due to an overflow condition is detected reaching probe in weir within a 10 minute spam. Velocity and depth of water is calculated as flow increases. Sewer overflow is detected accurately: as flow exceeds Gage Street pipe at above $3.75 \mathrm{ft} 3 / \mathrm{s}$, the probe located in long pipe sensed overflow water. Calculated volume of 357,009ft3 overflowed "Gage Street" weir during April 1999 storm (Waite et al., 2002). Figure 6 in Appendix B shows water detection of overflow in "Gage Street pipe" in 5 minute intervals as well as the "long pipe".

During storm of April 1999, long pipe probe detected overflow water combined with the brick pipe water in chamber 2. Combined sewage flowed into chamber 3 via short pipe. Causing a backwater condition to occur while reverse flow was seen calculating negative velocity. Excessive water flow may have caused turbulence in the entire sewer system resulting in extreme negative velocity magnitudes. At one point, these negative velocities led analysts to assume flow in entire pipe traveled in reverse direction from 5 to $7 \sim$ feet (Waite et al., 2002). But in reality there was a lot of turbulence around the probe during time of flow causing negative flows with 
lower magnitudes recorded. However due to unstable flow conditions magnitude and velocity data were accepted to complete data analysis.

Other assumptions were made during this field study, velocities in the long pipe were considered noisy reducing probe's signal quality causing fluctuation in recorded data. These recorded velocities were later confirmed to be faulty since a pattern wasn't seen in brick and short pipe. To minimize erroneous measurement, the sensor was replaced and relocated to a new location, consisting of an opening letting water infiltration in during dry weather and wet weather conditions. Location of new probe did not help the situation as it was attached to a downstream fall with water dripping into the pond of water causing 'noisy water' and faulty velocities. Therefore once again the probe was moved 2 feet lower than the original location, and problem was resolved.

The relocation of the probe was proven to be successful during the storm in 1999. In one case the water flow in brick pipe increased and combined with water inside the long pipe then flowed into short pipe (Waite et al., 2002). Water from chamber two and three were filled up and sluice gate closure caused the water to flow back to chamber two. Water turbulence in brick pipe was confirmed with fluctuating velocity. These velocity measures are most likely erroneous due to infiltration near the probe.

Negative velocities in brick pipe were mostly incorrect during the storm event. Most of recorded velocities were negative due to turbulence in sewer system. Measured velocities ranged between negative and other.

Storm velocity at a rate of 'zero' or negative is due to high turbulence in the sewer system. Storm starting on April $22^{\text {nd }}$ recorded negative velocity data due to infiltration then on April $23^{\text {rd }}$ continuation resulted in a velocity change of zero during stage rise. During stage recession due to infiltration, velocity data changed from 0.123 feet (Waite et al., 2002). Pattern displays velocity data changing from negative to positive once sluice gate opens and then returns to zero during constant stage. 
Additionally, rain gage at Riverside's Fire Department building indicated incorrect water flow data since rainfall ended hours before. During this time the probe was still showing negative data even though there was no water contributing to the flow rate.

Only suspected water having a reverse flow into the pipe is the leakage entering chamber 2 from high stage of Des Plaines River, including two other inflow sources. It's been noted that these inflow sources were not a contributing factor to water volumes since it only accounted for 4 percent of the total water volume in the entire system. Furthermore, no negative velocity measurements were recorded in the outfall fall. Also velocity data collected from brick pipe and long pipe before massive storm in April show noisy velocities and after the storm those numbers were exaggerated. Exaggeration of number was only seen during the storm confirming affected infiltration in probe.

Figures 7 and 8 in Appendix B are indicative of 'no negative' velocities recorded in the outfall pipe.

During the storm, stage normally increases as storm is at maximum flow but towards the end, stage decreases as it falls from brick pipe to sluice gates. Joe Prell, American Sigma communicated in 1999 (as cited in Waite et al., 2002), in still water, an internal change is automatically made to detect the smallest movement in water. When stage decreased, two negative velocities were detected indicating some turbulence in the sewer system. Negative velocity confirms water was pooled versus reversed.

Recording throughout the storm summarizes positive velocities during stage rise and then once chamber 3 fills up, short pipe and rest of the sewer system fills. Once the system was filled, some constant velocities maybe indicating sudden stillness in water and some negative velocities indicate reverse flow. Towards end of the storm positive velocities were recorded indicating a stage decrease. Also confirming sluice gate was opened for flow to enter the gate into deep tunnel.

In chamber 2, as soon as water rises to a certain level, water flows out of the sewer system into Des Plaines River from an outfall. Starflow meter implemented detects flow movement. When Des Plaines stage rises over gaging station, flow is detected by Starflow meter before reaching the river via outfall pipe. Rise of Des Plain river stage was reflective to the rise 
of velocity recorded by meter. Turbulence in the river caused negative velocities to be seen on Starflow meter. Data collected was verified by calculating mass balance entering chamber 2 from long pipe and brick pipe (Waite et al., 2002). Also outflows were calculated considering short pipe and outfall pipe. Gage Street pipe volume wasn't used towards mass balance, it was only used to verify the amount in long pipe. Water quantity in short pipe was verified by flow inside sluice gate entering deep tunnel.

Same method of calculation was used throughout the year to estimate storm volumes. There were some variations seen and fully described to account for estimations. During the June storm the Starflow meter recorded no data due to technical difficulties.

Another instance of variation was recognized during December's storm were the volume of water detected at Gage Street weir exceeded water flow recorded by the long pipe probe. Long pipe probe should have reported water exceeding Gage Street weir, because the long pipe probe reports on a combination of flows from Gage Street weir and inflow pipe. Negative velocities were recorded during December's storm indicating reverse flow. Magnitude of the recorded velocities in long pipe seemed very unreasonable (Waite et al., 2002). Evidently in sewer pipe there must have been turbulent behavior to have the probe generate faulty measures. For data analysis these velocity measurements were reduced to one tenth of the recorded magnitude.

\subsubsection{Combined sewer overflow at Evanston, Illinois}

\section{Description of study area}

Evanston, located in Chicago, Illinois holds an approximate population of 73 thousand, with most of the city falling between the North Shore Channel and Lake Michigan. Evanston field study covers a residential/ commercial area feeding into a combined sewer system. The study includes, six flow meters along with nine probes installs in the sewer system. Three of the probes were at Lake Street in siphon pipe, new pipe, short pipe and chamber 3 ledge and floor. Probes were measured to be installed using a laser level to elevate probes in pipe.

In terms of the Lake Street pipe description, the pipe is a circular concrete pipe with a drainage area of 1,738 acres. In dry weather, flow is diverted into siphon pipe by an interceptor 
sewer into the North-Side Water Reclamation Plant. In a wet event, flow can exceed height of the weir and overflow into chamber 3.

Chamber 3 has three possibilities of experiencing overflow, from sluice gates, it transfer water to deep tunnel. During dry events, sluice gate remains open very few times and the other gate is closed. With one sluice gate open, water is collected in chamber 3 quicker than it can flow from the sluice gate. Another path includes the rise of flow in chamber 3 causing reverse flows in short and new pipe. Lastly once the sewer system reaches maximum capacity, it then flows through the tide gate into the North Shore Channel.

New pipe is used as a storm-relief sewer built from concrete with a drainage area. New pipe functionality includes water storage during wet weather flows during times water is backed up from chamber 3 (Waite et al., 2002). If water is flowing from new pipe to chamber 1 and then chamber 2, then the flow is going towards a positive direction. Continuous positive direction continues from chamber 2 as water flows into chamber 3 then finally enters into chamber 1. A concrete pipe also enters chamber 1 to provide storage during wet event flows.

Short pipe in the sewer system is built to convey stormwater from a vertical outfall into chamber 3 , also plays a role of a storage tank to minimize water backups from chamber 3 .

Floor probe installed at the bottom of chamber 3 detects water flow entered from Lake Street pipe and short pipe. Due to turbulence near vertical outfalls this probe was only used to measure stage, velocities recorded were not considered.

Reverse flow was detected in short and new pipe in chamber 3 as stage exceeded threshold of approximately 3 feet. As chamber 3 stage rises, water is stored in pipe entering chamber 1. In severe conditions, water is reversed from short pipe to chamber 2.

Outfall pipe located down from tide gates of chamber 2 flows through gate into outfall pipe in North Shore Channel as the stage exceeds. With tide gate alarming Stickney to open sluice gates.

When chamber 3 is filled with water, tide gates near the top open. A probe installed on the ledge is upstream of tide gates, activated when an alarm goes off to open the sluice gates. In 
case the stage in chamber 3 is high, tide gates allow flow through gate opening and into the North Shore Channel via outfall.

With the sluice gate opening, water from chambers goes into deep tunnel. Sluice gate stops water from discharging to the North Shore Channel.

\section{Flow monitoring: storm volume}

This section describes methods and assumptions for data analysis during the storm of 1999 in Evanston. A detailed description is given of flow from the initial point, Lake Street pipe, towards the sluice gates. Limitations of flow meter are factored in the assumptions during analysis.

In Lake Street pipe, Sigma probe was chosen for installation due to debris accumulation. Three Sigma probes were mounted on C-channels and were prone to most fouling and debris accumulation. Velocities measured at probe were recorded as zero but probes installed on downstream pipe weren't as sensitive to debris. Two installed probes included a Keppler stage/velocity and a standard stage/velocity. Keppler probe is meant to be used in clear water, the velocity sensor in a Keppler probe has "larger crystals and, therefore, a greater beam/return signal sensitivity to reflectors in the water" (Joe Prell, American Sigma, Inc., oral commun., 1999). In a combined sewer pipe velocities recorded are higher than actual flow velocity, Keppler probe is sensitive to particles in water, especially in water containing combined sewage with high particulate matter (Waite et al., 2002).

In instances with highly different velocity recordings, it seemed best to take the standard probe recordings into account. It is recommended by manufacturer to take the number into account represented by standard velocity/stage probe. It is proven to be more accurate for data analysis.

Data analysis report recording consist of two installed probes in downstream pipe. Probes were used in parallel, since Keppler probe recorded high velocity data due to particulates in water compared to standard probe. The standard probe was utilized if differences between two recorded velocities were greater than $0.5 \mathrm{ft} / \mathrm{s}$. Otherwise if recorded data was less than $0.5 \mathrm{ft} / \mathrm{s}$, average recorded numbers were taken into consideration. 
Lake Street pipe connected to two different inflow pipes, located on opposite sides of the Sigma probe were not measured or concluded for reporting. Only during dry weather events, estimated quantity entering Lake Street Pipe was considered as flow measurement. During dry weather events, relatively low flow rates were recorded as assumed with understanding of rates being higher during wet weather events. For reporting and analysis purposes, $0.50 \mathrm{ft} 3 / \mathrm{s}$ was added to each instance of Lake Street pipe flow recording (Waite et al., 2002).

In dry weather condition all flow from Lake Street pipe is diverted from siphon pipe sewer to North-Side Water Reclamation Plant. Estimated time travelled by flow from Lake Street pipe to siphon is recorded stage peaks. Furthermore no correlation between stage peaks at two locations were found. Therefore time correlation seemed irrelevant in this case.

During storm, siphon pipe mostly recorded positive velocity/stage rises, but on a storm event stage dropped significantly and velocity increased. It has been concluded, sudden change in stage and velocity was directly influenced by release of water to the treatment plant. Zero velocity was also recorded, debris accumulation is an unlikely cause to block velocity signals. Probable cause could have been due to treatment plant exceeding capacity volumes. Water might have stopped moving and wasn't able to handle additional flow. Therefore creating reversed flow throughout the plant. Negative velocities recorded are an indication of treatment plants reaching its maximum capacity and not handling any additional flow, resulting in reverse conditions and turbulence. During storm at one point siphon pipe was rejecting any flow incoming from Lake Street pipe. At this point weir overflowed into chamber 3. Several sets of data was verified during storm and got accepted to report in data analysis. 

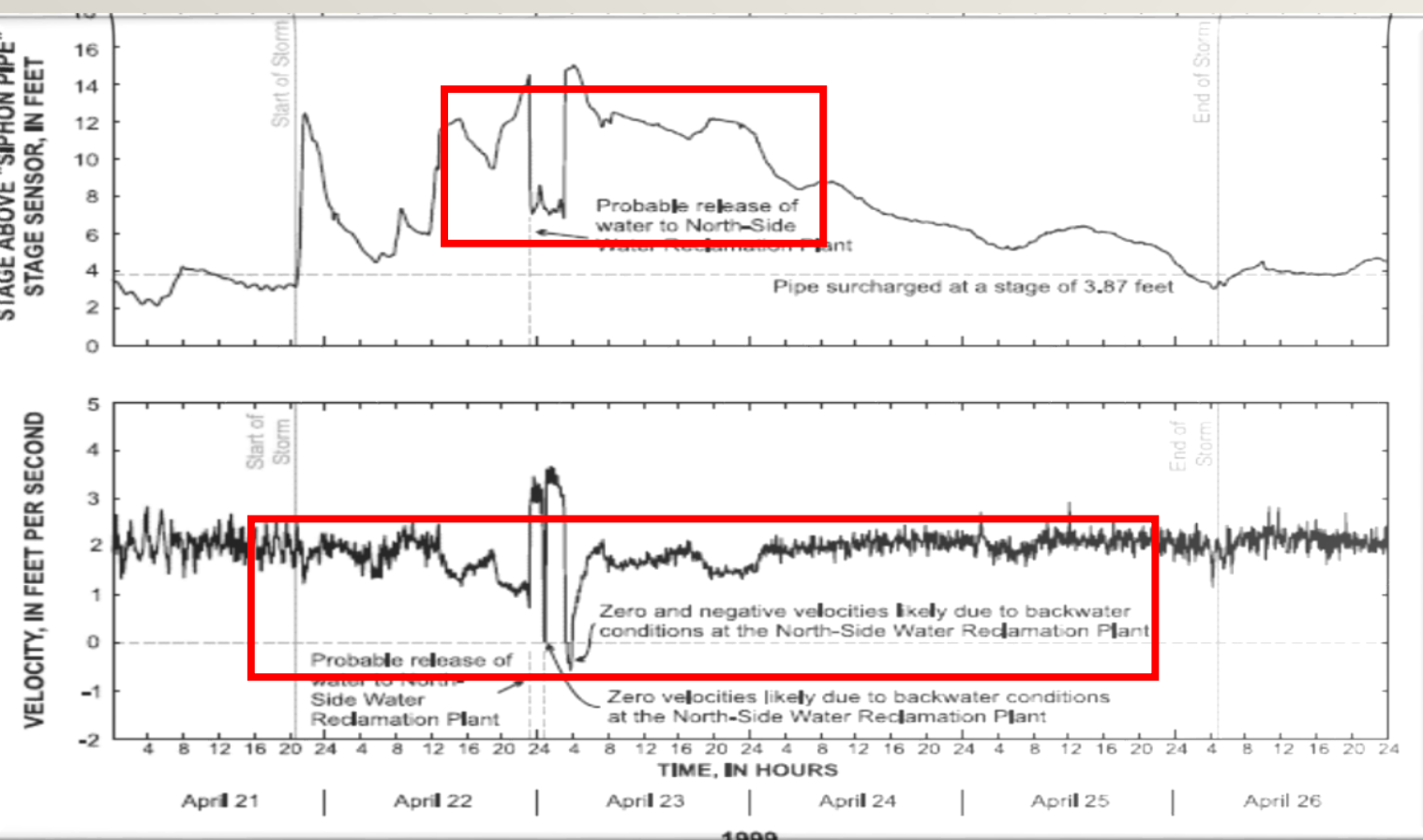

Figure 3.6: Stage and velocity at the "siphon pipe"

Source: Evanston Waite, Johnson, \& Hornewer, 2002

Figure 3.6 demonstrates height of stage decreasing as water is released to the North-Side Water Reclamation plant. Velocity graph shows 'zero' and negative velocities being recorded due to backwater conditions experienced in the North-Side Water Reclamation plant. Graph indicates correlation between zero/negative velocities and backwater movement (Waite et al., 2002).

Estimated difference of water volume in Lake Street's pipe diversion weir and siphon pipe was taken into consideration to estimate flow entering chamber 3 . A calculated volume overflowed from diversion weir and entered chamber 3.

Lake Street pipe and new pipe overflows were received by chamber 3. There were some limitations in the short pipe probe therefore data from new pipe was used in data analysis. It was recommended to place probe 10 pipe diameters away from the drop, but due to limited pipe length, it became impossible. 
Flow was affected by the drop and velocity in the baffling walls. Therefore, short pipe's flow calculation was not used to determine stages within the sewer system. This data would indicate the status of the tide gates.

New pipe probe located in concrete storm-relief pipe received storm and backwater flow from chamber 3. Manhole access, in new pipe's probe path, included a bend which could have caused turbulence affecting data. But the bend was small enough not to be considered. In addition, located downstream of the short pipe probe, chamber 1 caused some disturbance but the distance of the chamber data was assumed.

Three different stage rises were reported in the new pipe during the storm in April. The rise was linked to the upstream sources and reversed flow from chamber 3. Positive velocity measured as stage increased in the beginning of each rise. Positive velocities are an indication that flow entered new pipe from upstream sources. Right after each rise, velocities were recorded as negatives. Negative velocities are an indication of backwater flow, reversed flow from short pipe and new pipe. A peak points, stage became steady and velocity turned to zero. In this situation, zero velocity was not an indication of steady flow it was due to water overflowing into chamber 3 from Lake Street pipe. During storm, assumptions indicated zero flow was less than the detected probe limit. Stage was changing constantly in the sewer system evidently indicating water movement in system. Recorded zero velocity was changed to $0.125 \mathrm{ft} / \mathrm{s}$. for data analysis purposes (Waite et al., 2002).

In dry weather, sluice gate in chamber 3 opened five percent of time. Sluice gate opens once tide alarm goes off at Stickney. It must be noted, exact count of gate openings are unknown. During storm events, with stage decrease in new pipe, and water flow in chamber 2 and 3 sluice gate was slightly open. Water had access to deep tunnel from sluice gate while stage was decreasing, even though were no positive velocities detected in new pipe probe. During stage recession, zero velocities were recorded. Record shows, stage had decreased by a large amount before positive velocities were recorded by new pipe probe. Velocities below 0.20-0.30 ft/s were not detected by Sigma meter (Waite et al., 2002). The meter is configured to detect velocities above mentioned limits, otherwise zero velocity gets recorded. In situations with stage fluctuation, at times it becomes impossible to determine if velocity was positive or negative 
based on stage rise or drop. During stage rise, it can be said water was being removed from the system to sluice gates from tide gates in chamber 2 and 3.

Floor probe initially installed verified stage peak at the ledge but short pipe was used for this verification instead.

Flow rising greater than vertical drop in chamber 3, resulted in reversed flow in chamber 2. Stage rises as flow moves in tide gates into outfall pipe leading to downstream pipe and North Shore Channel. The North Shore Channel stage increases, water flows from the river into the outfall pipe which prevents flow into the sewer system.

North Shore Channel backs up the pipe, as the outfall pipe stage rises. Stage rise is directly linked to stage rising in North Shore Channel, therefore zero velocities were logged during April storm. Also during storm period positive velocities were logged in outfall pipe because of tide gate openings. Additionally inconsistent positive velocities were also seen due to turbulence from the North Shore Channel, but data wasn't used for analysis. CSO stage on upstream side of gate was compared to downstream side of stage in North Shore Channel. During storm period, stage rose in North Shore Channel in comparison to stage in sewer system, therefore it was decided to exclude inconsistent positive velocities as part of data analysis. In addition, flow could have went back in to sewer system from North Shore Channel via chamber 2 during periods when North Shore stage was higher than stage in sewer system. Same condition was seen in chamber 3, this occurrence validated the happening in chamber2. Confirmation received is valid since both tide gates are approximately at same elevation, making reverse flow a valid assumption.

During wet event flows, stage will rise in chamber 3 and water normally exceeds ledge probe at gates in chamber 3. Flow is detected by ledge probe, running through outfall pipe is logged during storm periods.

During storm in April, velocities were positive, an indication of flow running through tide gates. However as storm flow increased negative velocities were also detected, indicating turbulence effects near probe. Another similar incident detected first logged positive velocities then negative, indicating turbulence near probe. For data analysis negative velocities were replaced with zero velocities based on assumptions, water wasn't flowing back through gate. 
Second set of flow caused water inside sewer system to decrease water was still high enough to cover ledge probe but not high enough to open gates. Positive and negative values were recorded indicating signs of turbulence near ledge probe. Recorded period wasn't included in data analysis, assuming water did not flow through gate opening. Another stage rise was seen indicating water flow in gates (Waite et al., 2002). Followed by rise in the stage, sewer system decreased below tide gate levels. Due to high levels in North Shore Channel, water from North Shore Channel accumulated around edges of the gate causing reverse flow.

Flow measures collected from ledge probe is affected by turbulence due to its location. According to vendors, the probe should be installed 10 times away from the depth of the flow obstruction however this was not permitted due to space limitations. Installing ledge probe close to flow obstruction did cause turbulence as flow entered Lake Street weir directly near ledge probe.

Since there weren't any probes installed in sluice gates, volume was measured at Evanston using mass balance in chamber 3 by using short pipe. Flow entering chamber 3 includes Lake Street weir, new pipe, and seepage around tide gate. Outflow calculation is based on outfall pipe, the ledge gate and sluice gates.

Similar type of assumptions were used in all three storms in 1999. There was a variation at new pipe, around August period, the probe in new pipe was moved $3 \mathrm{ft}$ up the side of pipe to minimize debris accumulation. Adjustments were made to elevate probe, $1.09 \mathrm{ft}$ above the bottom of pipe. Water had to reach the $1.09 \mathrm{ft}$ of probe until it was detected. It was estimated that $0.60 \%$ of the total volume of the storm had gone undetected by the probe after six hours of overflow (Waite et al., 2002).

\subsubsection{Summary}

During 1999 storm events in Riverside and Evanston, U.S. Geological Survey and the U.S. Army Corps of Engineers collected data in the combined sewer systems. The Metropolitan Water Reclamation District of Greater Chicago collected data at Evanston, Riverside, Racine and Calumet pumping station during the 1999 storm event (Waite et al., 2002). The monitoring field study completed in Chicago provides data analysis towards designing a flood-control reservoir as part of storm relief plan. 
Sewer system consists of various pipes ranging in size as small as $0.83 \mathrm{ft}$ to a maximum of $10.0 \mathrm{ft}$. They vary in shape, elliptical siphon pipes, ledges, and sluice gates. Stage and velocity were collected in different points in Riverside and Evanston during storm event in 1997 - 1999 at 12 locations. Instruments such as the American Sigma ultrasonic flow meters and a Starflow ultrasonic Doppler instrument were mounted on to stainless bands, I-beams, C-channels and steel straps (Waite et al., 2002).

During the experiment, maintenance and operation was required on monthly basis to ensure probes were free of debris accumulation and fouling. At Evanston and Riverside sewer systems, flow mass balances were used to determine amount of water quantity flowing into receiving waterways through on sluice-gate and deep tunnel.

Due to complexity of sewer systems, data-collection and flow/stage data also became more complicated than expected. Therefore, many assumptions were required. During times of stage decrease in pipes, if velocity was below Sigma meter then one-half of average minimum detection was applied (Waite et al., 2002) for reporting and analysis purposes. Furthermore, it is assumed unquantified volume of water might have found its way into receiving water without going detected at a site in Evanston. Effects of undetected volume has unknown results on final analyzed amount. Other assumptions were made such as estimating volume from Gage Street pipe into the interceptor sewer at Riverside, affected probe at Riverside and logging velocity and stage data with error. Corrections were made during analysis.

\subsection{City of South Bend case study}

\subsubsection{City of South Bend}

\section{Background}

City of South Bend collaborated with CSOnet Emnet group to reduce wet weather overflow of sewage into the river by controlling network infrastructures in sewer system (Lemmon \& Montestruque, 2015).

CSOnet's approach differed from typical solutions such as separating sanitary and stormwater systems, creating impermeable surfaces, expansion and construction of treatment plants and tunnels. All of these approaches are expensive and disruptive. Straightforward solution in eliminating CSO systems do not scale well. 
Therefore CSOnet defined an in-line storage approach to store excess storage in the city's sewer temporarily during a storm (Lemmon \& Montestruque, 2008).

Sensor data collected by Supervisory and Data Acquisition (SCADA), takes a long time to gather all information which delay time to control. The system is viewed as a nonlinear control problem which can be addressed as quadratic approaches (Lemmon \& Montestruque, 2008). An alternative approach tackles a distributed solution to CSO control events introduced by Ruggaber et al. Sensor-actuator network resulted in a cost reduced solution in controlling CSO events. A WSAN solution was also introduced by Wan et al. to build upon Ruggaber et al WSAN solution for the City of South Bend. The case study simulations showed \%20 CSO reduction compared to the existing systems in place (Wan \& Lemmon, 2007).

Architecture

CSOnet sensor-actuator network architecture consisted of local WSAN's connected to one WAN via gateway devices. Four different types of devices are at play, described in figure 3.7. The prototype below created by Ruggaber et al describes each device by an alphabetical symbol. 


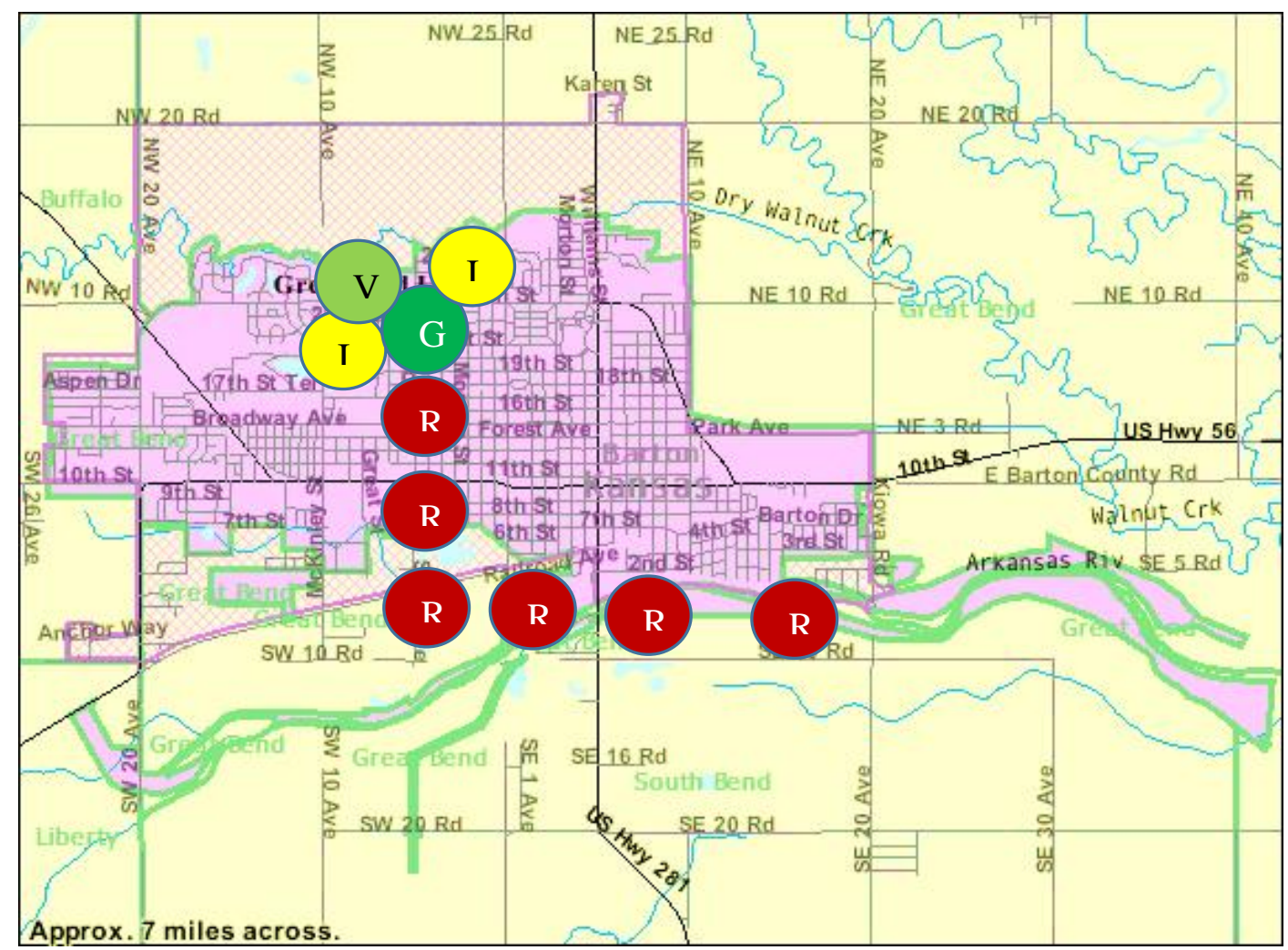

Figure 3.7: CSOnet Architecture Prototype

Source: Modified and adapted from Lemmon \& Montestruque, 2008

ANode marked by a ' $\mathrm{V}$ ' connected to valves control water in the system to receive sensor signals from INodes, which are responsible for receiving measures and processing data by forwarding it to destination gateway via radio transceivers. INodes marked by 'I, are dispersed in the river system to monitor CSO discharged and to monitor levels in retention basin (Lemmon \& Montestruque, 2008). Information gathered is then transferred to RNodes (marked as ' $R$ ') which serve to enhance connection in wireless networks.

To scale CSOnet to City of South Bend, a hierarchical architectural method with multiple WSANs provide reliable quality of service for large networks. Multiple WSANs are required to support large networks due to wireless network limitations. Therefore it is required to have consistent number of WSAN's to forward data to GNodes then forward it to other WSAN's in the system (Lemmon \& Montestruque, 2008).

\subsubsection{South Bend's Sewer System}

South Bend's sewer system conveys combined sewer trunk lines into interceptor sewer. Before 1972, combined sewers landed into rivers but under the clean water act, cities were 
required to treat lines before releasing sewer into rivers. To remediate the issue an interceptor sewer was built along the river. Figure 9 in Appendix B highlights the working of South Bend's interceptor sewer and CSO system.

Sewer intercepts sewage flow from combined sewer trunk to wastewater treatment plants. During dry weather condition, flows were small to be handled by wastewater treatment plant but during wet weather flow, flow volume would exceed WWTPs, overflowing to the river.

CSO diversion structure connecting sewer trunk and interceptor contains control points. Currently in South Bend Indiana a passive thresholding control is used to control flow. Once below the set threshold, it gets diverted to interceptor sewers. But if flow is above threshold then it gets dumped into the river. By implementing a WSAN in the combined sewer trunk line above CSO diversion structure, actual flows into interceptor are estimated to formulate optimized capacity decisions for WWTP. Based on estimations, best place to install ANodes is at the sewer diversion points to divert water into interceptor sewer line. Adaptive functionality requires flexibility compared to original passive conservative scheme.

As shown in figure 3.8, CSOnet is a collection of WSANs forwarding flow measurements in a sewer trunk to their respective CSO diversion structure. Diversion structure contains a GNode and ANodes, ANodes help to divert flow into interceptor line and GNode works as a gateway between WSAN and other WSANs. Figure 3.8 is a system with WSAN controlling two diversion structure into interceptor line (Lemmon \& Montestruque, 2008). 


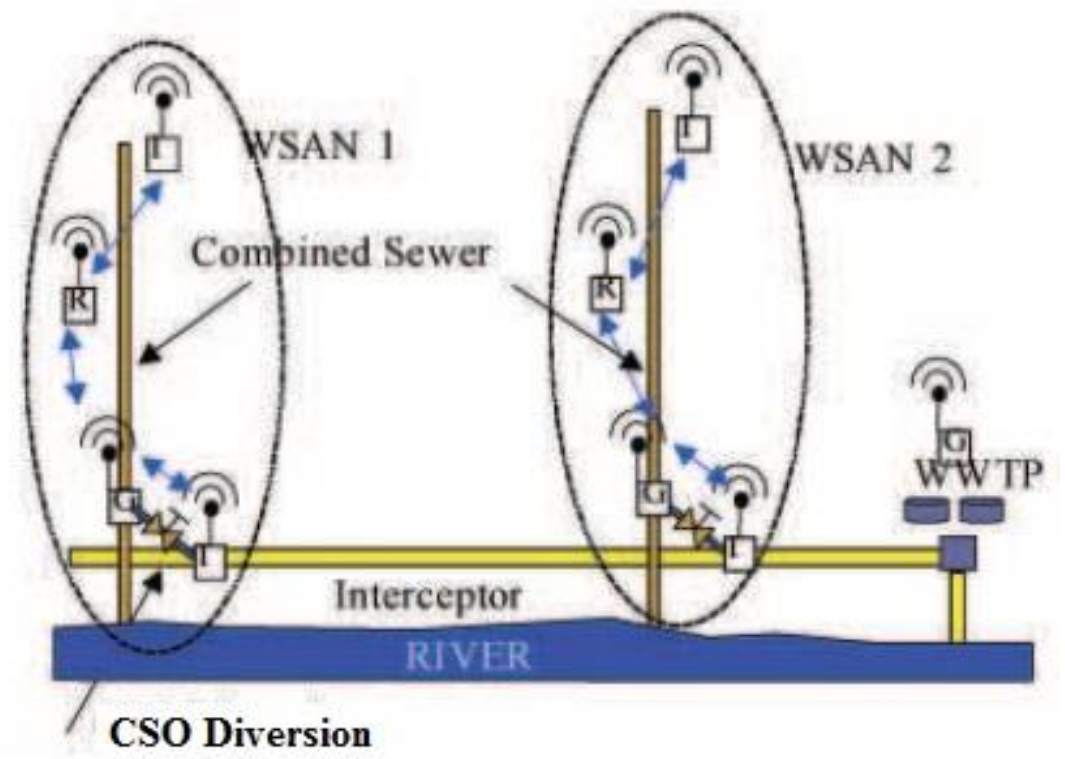

Figure 3.8: The CSO Diversion System.

Source: Lemmon \& Montestruque, 2008

GNodes placed in the diversion structure swap information with the WWTP to control flow in the city's sewer system.

\subsubsection{CSOnet architecture and material}

CSOnet's hardware is based on variations obtained from Ruggaber et al. Most sensors in an academic setting are based on variations of U.C. Berkley's MICA2 (sensor). MICA2 processor integrates with other MICA2 sensors via radio transceivers (Ruggaber, Talley \& Montestruque, 2007). However MICA2 did not suffice to endure environmental circumstances, therefore Chasqui wireless made industrial sense. Chasqui developed for CSOnet by Emnet LLC addresses limited radio range. In addition to wide range of transmission frequency, battery life lasts for years by using MOSFET by switching off sensor before it requires change (Lemmon \& Montestruque, 2008). Chasqui uses smart technology to activate while in use and go into deactivation mode with a real time clock. Another benefit of Chasqui processor involves its rough sensor subsystem.

INode, is a sensor management system and RNode only forwards data without use of sensor management. INodes implemented within sewer system is connected to flow senor. INode forwards data to RNode. CSOnet contains GNode for data transmission between the WSANs (Lemmon \& Montestruque, 2008). 
WSANs are controllers distributed geographically to fulfill network control system processes. WSANs help with measuring the environments behaviour by measuring performance using a feedback system. The feedback system finds difference between what is expected and what happened in the environment then adjusts itself to environmental measures. Feedback system minimizes sensors sensitivity to environment after getting adjusted.

CSOnet controls amount of water getting diverted into sewer trunks from interceptor lines. Control points are addressed at CSO diversion structure by diverting water into interceptors to minimize total CSO discharge. Control must be done properly to formally address capacity of the treatment plant and secondly to avoid flooding or discharge of interceptor lines.

\subsubsection{Future of CSOnet: Distributed Storm Water Management System}

The future of CSOnet relies on wireless network controlling sensors implemented within sewer system network. With use of wireless controls we can understand wastewater flow measures in real-time in order to maximize wastewater treatment plant capacity, to better divert water into treatment plants during wet weather events to minimize overflow.

\subsubsection{Architecture of CSOnet}

CSOnet uses existing conveyance and storage structure to its advantage to divert flow in the system with high tidal while other points of the system is empty and some parts are overflowing. During wet storm events parts of the system are loaded while other sections are running on empty, therefore understanding the highs and lows of the pipe help with diverting flow in areas that are overwhelmed versus areas with less of a load (Montestruque \& Lemmon, 2015). To implement a solution, real-time monitoring is required to collect data during a storm event.

CSOnet sensors include sensors and ultrasonic velocity flow at 5 minute intervals. Initially CSOnet was designed to use multi-hop wireless network but in this design CSOnet uses a gateway device (WAN) connectivity to establish accessibility at all times. This benefits the network by enabling data availability and accessibility at all times (Montestruque \& Lemmon, 2015). For power conservation, the gateway has a sleep/ awake functionality to enable network synchronization to allow for multi-hop interconnectivity. 
System performs dynamic actuator controlling CSO collection system. Actuators in the system include valves and gates etc. which are controlled electronically. As part of the CSOnet initiative, gate actuators were installed even though some actuators were part of existing infrastructure. To configure CSOnet, set points need to change in sewer system to accommodate flow load in the system. During a wet-weather flow event, actuators understand precipitation patterns by load balancing pressure points in the sewer system. Distributed architecture is used due to major storm conditions and communication systems in wet-weathered events (Montestruque \& Lemmon, 2015).

After implementing several control schemas, it became apparent interceptor line was not balanced properly. Interceptor line running through the City collects water from different watersheds and transfer it to the wastewater treatment plant. Therefore, the sewershed would accept maximum flow and any excess flow is redirected into the river via the CSO diversion structure (Montestruque \& Lemmon, 2015). This original structure contains a throttle line to divert flow during dry weather from sewershed to interceptor and weirs once throttle line capacity exceeds.

Original plan did not meet real-life requirements since it never rained evenly throughout the city. Some points were overflowing while others were not. Throughout storm event, interceptor line was never at full capacity. Furthermore an additional actuator, an extra throttle line was added to accommodate extra flow entering the network into interceptor when it senses available capacity downstream from the valve. To avoid flooding, valve gets closed once capacity is reached (Montestruque \& Lemmon, 2015).

The Pontryagin principle is used to switch interceptor to balance flow in interceptor sewer by managing the points of hydraulic constraints (Montestruque \& Lemmon, 2015). Control is focused on throttle valves where gateway nodes reside. With nodes communicating via WANs with one another.

Advancements have been made throughout the years in predicting amount of runoff entering the sewer system by using probabilistic controls (Montestruque \& Lemmon, 2015). South Bend's stormwater detention basin is an example of probabilistic control usage. The basin 
serves as water detention plus a body of water for aquatic life. The pond must be at a minimum level to serve as an aquatic life, but it also must have capacity for stormwater before it enters the surrounding water. The probability control system predicts forecasts of future rainfall, therefore control system determines amount of water required to drain based on the distribution function. Furthermore the lake is able to retain its minimum level to support aquatic life while reducing risk of overflows.

\subsubsection{CSOnet: Implementation}

CSOnet monitoring system installed initially in 2008 and then implemented in 2010 consist of 110 locations with 150 wireless monitoring nodes with 36 discharge locations and 28 sewer points. The system is subdivided to five sections for connectivity purposes. CSOnet controls weirs and valves.

Normally the communication between wireless nodes works all times. Communication patterns do change during winter, with lower hop counts whereas during summer time with constant patterns. During winter time sensors increase number of retries to send messages due to snow and slush.

The system has been a success in reducing overflows by controlling valves and weirs by extending hydraulic performance of the collection monitoring system. Sensor network has the ability to adjust and detect areas that are out of the ordinary based on historic data.

\subsubsection{CSOnet: Results}

Based on table 3.4 simulations overflows were reduced by $25 \%$ based on the rain precipitations in 1995. The performance index shows the total yearly CSO volume in comparison to the total yearly amount of precipitation.

Table 3.4: CSO comparison to total yearly amount of precipitation

\begin{tabular}{|c|c|c|c|}
\hline Year & $\begin{array}{c}\text { Total Precipitation } \\
\text { (in) }\end{array}$ & $\begin{array}{c}\text { Total Overflow } \\
\text { (Mgal) }\end{array}$ & $\begin{array}{c}\text { Performance Index } \\
\text { (Mgal/in) }\end{array}$ \\
\hline $\mathbf{2 0 0 6}$ & 45.0 & 2111 & 46.9 \\
\hline $\mathbf{2 0 0 7}$ & 42.0 & 1432 & 34.1 \\
\hline $\mathbf{2 0 0 8}$ & 48.0 & 2054 & 42.8 \\
\hline $\mathbf{2 0 0 9}$ & 36.5 & 1199 & 32.8 \\
\hline $\mathbf{2 0 1 0}$ & 29.5 & 804 & 27.3 \\
\hline $\mathbf{2 0 1 1}$ & 41.9 & 890 & 21.2 \\
\hline $\mathbf{2 0 1 2}$ & 29.4 & 445 & 15.1 \\
\hline $\mathbf{2 0 1 3}$ & 35.8 & 715 & 20.0 \\
\hline
\end{tabular}


Source: Adapted and modified from Montestruque \& Lemmon, 2015

Figure 10 in Appendix B shows performance during 2014 prior to the CSO implementation based on rain data, the top shows overflows and the underflows (blue section) indicates flow directed to treatment plant.

Figure 11 in Appendix B shows overflow and underflow after the CSOnet implementation with the sensor network.

\subsubsection{CSOnet Summary}

CSOnet has been a success in reducing CSO events and helped with building a solid foundation in feeding data into systems on smart city environment. The CSOnet system plan reduced the CSO cost by $\$ 150$ million (Montestruque \& Lemmon, 2015).

Based on the data analysis, more opportunities presented itself to reduce overflows in the sewer system. It soon became apparent that an interceptor line running can be linked via three small connections that were initially disconnected. Use of CSOnet and advancements in technology permits improvements to monitor system infrastructure. 


\section{Chapter 4: Smart Water Management in Cities}

Water management is defined in proper management of water resource demand and development while protecting the environment and effectively allocating cost. Furthermore, water management is in charge of ensuring public health, access to services, managing stormwater and combined sewer runoffs. Allocation of resources and implementation is of a concern faced with climate change and aged infrastructure. With the growth of technology in the past decades, valuable information can be extracted with provisioning the correct technology against water resources challenges to improve water management.

In order to resolve various water challenges, different sectors have identified and developed highly intelligent tools to address water issues. According to the recent studies in OECD, optimizing smart water systems has been an effective and efficient method in dealing with aged infrastructure and wastewater management. Utilizing such technologies has been trending in the market to recognize the issue faced (Gemma et al., 2014).

Developed technologies offer to improve on providing productive and efficient solutions to contribute to sustainable water resources. These technologies are utilized to ensure continuous real-time monitoring of water networks to better compile valuable information to use towards decision making.

Hefty investments made towards technology enabled tools targets to manage the remaining water resources left on the planet. It evaluates the steps to take towards future implementation to manage and protect water resources (Gemma et al., 2014). A concept known as smart water management is based on integrating technologies, solutions, and expanding sustainability while protecting the environment.

Smart water management in cities is utilized to plan for water supply and distribution by protecting the environment and planning for better sustainable efforts. 
Use of information communication technologies in smart water management helps with water distribution, reduce water loss, and improves on waste water management. Role of smart water management can be summarized in:

- Customer centric: with the use of smart water meters customers are given detailed information on water conservation. The technology can be utilized to allow them to understand waste water management.

- Go green systems: green water systems follows the same concept as green roofs. Information technology enables us to capture water before it enters the sewer systems.

- Increase water quality: use of sensor technology distributed across the city helps detect water impurities. Sensor installed switches store and transfer data with neighbor watersheds.

- Reduce operational costs: smart systems remotely diagnose issues to prevent problems in existing infrastructure.

- Eliminate leaks: smart water systems help assure water reaches its destination via fault management, it enables utilities to repair unwanted leaks.

Utilizing smart water technology improves upon water efficiency in the water sector, contribute to economic sustainability and cost recovery from illegal pipe connections. 


\subsection{Potential Benefits of Smart Water Management Technologies}

\begin{tabular}{|c|c}
\hline $\begin{array}{c}\text { Combined sewer } \\
\text { overflows }\end{array}$ & $\begin{array}{c}\text { optimized levels of volume are predicted based on efficient } \\
\text { management systems. }\end{array}$ \\
\hline $\begin{array}{c}\text { Smart agricultural } \\
\text { water usage }\end{array}$ & sustainable water usage by leveraging commercial use. \\
\hline $\begin{array}{c}\text { Smart water supply } \\
\text { management }\end{array}$ & managing water resources to ensure supply and quality. \\
\hline Smart water & sensors to ensure water quality. \\
\hline $\begin{array}{c}\text { Smart waste water } \\
\text { management }\end{array}$ & manage wastewater quality and volume. \\
\hline $\begin{array}{l}\text { Smart water } \\
\text { distribution }\end{array}$ & monitoring water for distribution and managing of asset. \\
\hline
\end{tabular}

Figure 4.1: Current smart water Management technologies and tools Source: Adapted and modified from Gemma et al, 2014

According to figure 4.1, Current Smart Management and technologies and tools, potential benefits of smart CSO consists of understanding optimized levels of volume based on efficient management systems. In addition, proactively monitoring water distribution and management of asset, use of sensors to ensure water quality, manage wastewater quality and volume, manage water resources to ensure supply and quality and sustain water usage by leveraging commercial use (Gemma et al., 2014).

Utilizing smart water technologies in cities, improves on decision making based on optimized and reliable data. Once applied to cities, information technology tools in support of smart water management are developed to contribute to next generation infrastructure systems while enhancing performance and reducing environmental footprints. Here is a handful of smart technologies and its use: 


\subsubsection{Enterprise Monitoring}

Utilizing enterprise monitoring systems in sensor based networks enables device management. Using a centralized tool for monitoring sensors offers an overall pane of glass displaying sensor's health performance. Sensors deployed to monitor depth and velocity in a combined sewer system require a monitoring software to evaluate their network connectivity. In other words to monitor device availability.

For the purpose of monitoring CSO sensor devices, it is required to implement a software capable of providing performance data. Monitoring software have the capability to be leveraged via software as a service (SaaS) or installed on premise (Gemma et al., 2014).

Monitoring services will gather performance information on all available ports and servers to determine the root cause of any network failure. An implemented software solution ultimately provides real-time root cause analysis in case of a device failure in the infrastructure.

\subsubsection{Smart Pipes}

Within smart pipes live multifunctional sensor nodes, they measure velocity and quality while continuously monitoring flow during service, inspection and distribution. In the upcoming generation of technology this will enable water managers to receive real-time data via wireless connections and antennas to provide and process data for optimized decision making.

Smart pipes have been in the industry for years servicing the oil, gas like industries. Their need has been transparent in the water industry to better supply and distribute water resources as water has become even more of a limited resource. Smart pipes informs water managers and service providers' with real time data on potential leaks and issues (Gemma, Sang et al., 2014).

\subsubsection{Wireless Sensors}

Wireless sensor technology within cities is used to control water supply while accurately taking measures and monitoring the water supply system. Wireless sensors have been advanced to use acoustic metrics for data analysis in pipe leakage. An indication of a pipe leakage is determined by the amount of water is absorbed by the ground. If the daily noised created exceeds the norm, acoustic signature of a pipe increases. Many companies have seen value in water sensors and have used information communication technology and strategies to develop many ranges of sensors for infrastructure water networks. Smart sensors are capable of reducing the 
risk of a pipe break by detecting an early leak. Data retrieved on pipe flow is then associated with an alert to send a notification to respective parties. This will allow sufficed time to locate and potentially restore any damages (Gemma et al., 2014).

Sensors are capable of assessing the water quantity and the quality of treated sewage within cities. Other benefits of these sensors are seen in automating water sampling for chemical dosage which is collected manually. Furthermore real-time data collection and analysis helps close out the time gap between the time of data retrieval and assessment to sending out notifications based on the analysis. Without proper provisioning data can become meaningless if not delivered effectively to warn affected members (Gemma et al., 2014).

Real-time water monitoring has been adopted by many water resource and waste water management. Water quality monitoring via smart sensor networks is being utilized to improve on delivering water quality information on time by performing various measurements.

\subsubsection{Smart Sensors Specification}

Other forms of technologies are blended in with the network sensor technology to reduce power consumption and cost.

These sensors have network connection interface with wireless or wired networks for data retrieval and storage. This type of network topology is easily expandable to broader ranges if need be. Technology is integrated to ensure automation across control, pre-treatment, measurement, and data analysis based on collective data.

Smart sensor monitoring include but are not limited to these tasks:

- Monitor change in water quality over time for existing and potential issues

- Compile information for analysis, developing pollution prevention and potential remediation measures to control and respond to sewage leakages and etc.

- Use collected information to determine the existing gaps between the actual pollution footprint and the regulations in place. 
Integrating sensors within smart pipes optimizes the operations in the infrastructure by enabling more metrics such as velocity rate, backflow, and quality, quantity of water or sewage and pressures placed in the pipe (Gemma et al., 2014).

\subsubsection{Smart Metering}

Smart meters are more common in governmental use to measure user consumption. These devices contain embedded advanced infrastructure metering enabling online measurement of natural services. In the case of water consumption, the meters contain a controller, a long life battery of 10-15 years, and wireless transmitter without any type of power supply. The meters are interconnected to a network to log data for continuous water monitoring in a city. Data is transmitted bi-directionally between the meter and the central network receiver.

Smart water meters are designed to collect consumption data, pass it to the local area network which then gets passed over on the wide area network. Consumption data is sent to the local area network then transmitted to home area network allowing customers to view their consumption rates. Within the local area network resides a measurement function of the meter which collects information to display through a user friendly interface. Due to high energy consumption presumed by home networks, local area networks have replaced data collection giving users web access to usage with the wide area networks. WAN gives utilities the tool they need to track and bill consumption (Gemma et al., 2014).

Smart meter implementation in an infrastructure water network enables utilities to better

service customers by providing transparent consumption data while improving on collecting and delivering real-time data, detecting leaks and alerting on new connections, while predicting peak consumption points. With increased communication and transparency customer-provider relationship improves through increased communications. Use of communication technology in water resource management allows customers to have alarm and alerting options on consumption rates, leaks and change in consumption rates.

\subsubsection{Communication Modems}

Communication modems include and are not limited to Bluetooth technology used for remote access and reading of sensors and smart meters then transferring real-time data to a central management system. Stored data is available for customers to review, manage data for supervisors to enhance decision making. Integrated communication modems with smart sensors 
provide alerts. Most recent communication solutions is built to cover a wide range of areas and larger distance compared to traditional ways of collecting data manually consuming great amount of time.

\subsubsection{Geographic Information Systems}

GIS systems capture, store and display information on underground assets and decision making. GIS integrated systems are applied to different sectors and can improve data management while processing big data with high quality results to display.

GIS integrated systems will allow users to view water resource activity while linking geographic information and displaying detailed descriptions (Gemma et al., 2014). GIS provides valuable information on day to day water resources and potential mitigation of floods by identifying areas at risk. GIS is utilized in creating maps based on areas at risk as well as planning for potential remediation plans while offering cost reduction, efficient and effective analysis.

\subsubsection{Cloud Computing}

Cloud computing is a series of external computing resources such as servers, database, networks to run application and programs. Cloud computing enables users to access, manage and deliver services on multiple networks without any human involvement (Gemma et al., 2014).

Cloud systems increase efficiency and utilization by load balancing through multiple

applications, providing a large range of storage and modelling. Water managers are given access to many possibilities in modelling based on collected data.

It's important to fully understand the various measures taken towards ensuring security and privacy before implementing cloud computing system.

\subsubsection{Supervisory control and data acquisition- SCADA}

SCADA integrated within the water management system tools provides various communication computer controlled systems for water monitoring, distribution, wastewater collection and water treatment. The system acquires and manages data within the system by processing and sending commands. SCADA uses connections, wired connections and other communication methods such as telemetry methods. 
Utilities have utilized the SCADA system tool for managing close to real-time events by generating alarms on plant networks.

Enhancements in SCADA systems provide optimized solutions and propose predicted models. These systems have the capability in providing peak time, identify leaks and determine bill rates.

SCADA systems have shown value in reducing costs of utilities, and improving water distribution globally by monitoring and managing water infrastructure to prevent sever degradation. Statistics have shown SCADA helped reduce water loss by $20 \%$, increase energy saving by $30 \%$, and $20 \%$ decrease in water reduction (Gemma et al., 2014). Disaster preparation methods against storm and disaster recovery of storm management and support operations and monitoring of water resources.

\subsection{Optimization Tools and Decision Support Methods}

Modelling applications supporting water management improve quality and quality while improving operations costs. Modelling software supporting monitoring of water quality, management and relevant decision making information are stimulated based on real world data to report and visualize results.

Optimization tools aim to provide solutions based on various methods and formulas supporting the most efficient and effective environmental, technical and financial models. These tools have added value in developing various optimal models based on various dynamic variables in managing water resources while planning towards better decision making.

Optimization tools have added value in providing and determining solutions for water resources in order to calculate and forecast consumption and reduce costs by providing the most optimized plan based on informed strategies.

\subsection{Web Based Information Tools}

Knowledge management and decision making revolving around water sector are important in sustaining energy. The main issue experienced by water utilities exists within managing large data without having an effective tool to efficiently structure and display for 
decision making purposes. Web-based tools provide solution to structure and fragment data to effectively manage, display information required by water utilities.

Web-based server offers integrated information from silo data sources, while offering assessments of issues such as water resources, sanitation and health with innovative tools and assessment in order to manage water.

Web-based communication and information systems enable users to access the most up to date processed data while delivering relevant and transparent information on water resources. Visible information distribution enables various groups such as water utilities, customer and the government to deliver and distribute relevant information required for trust and relationship building. In addition to providing visibility into water resource information, it is highly recommended to present the data using intuitive user-friendly interface.

Relevant information is sent via the communication systems with associated alarms to notify the public, governments and utilities of any warnings. Additionally water resource managers make informed decisions.

It's critical to address any prior security and data system before implementing any webbased communication tools within utilities water infrastructure in cities (Gemma et al., 2014). 


\section{Chapter 5: Smart and Sustainable Water Management in Toronto}

\subsection{CSO Background in the City of Toronto}

As discussed in Chapter 3, city of Toronto's Wet Weather Flow Monitoring Network explored the baseline conditions at two different periods in time from 1990 to 1992 and 2008 to 2011 with an automated system. The baseline criteria factored in water quantity and water quality to find mean contaminate concentration in dry and we weather flow, contaminant in watercourses and annual contaminate discharge. This monitoring study was organized to capture the quantitative and qualitative data to form a remedial design for implementation. The Monitoring Network Plan was established in 2007 to understand the benefits of implementing the Master Plan within the next 25 years. This is used as a benchmark to evaluate the cost/benefits of real-data. The automated monitoring system implemented in 2008 was located in 14 different stations at the mouth of all watersheds located in central and north border of Toronto. Wet weather and snowmelt data was collected hourly in a 42 hour period and dry weather data was collected hourly in 24 hour period. There were over 50 samples collected by the end of the experiment at all the 14 watersheds to sample event duration, maximum rainfall and rainfall event numbers. It was concluded that there is a need to understand the contaminate load that exists outside of the city while considering the use of any new technologies. All watercourses were contaminated at different levels and most importantly further investigation must be done during snowmelt or rain. As part of the experiment several recommendations were made to better service the city's combined sewer system. According to Derek Smith, Field Coordinator of Surface Water, “...further investigation into the relationship between rainfall intensity/volume and watercourse loadings must be done. This indicates that without having solid monitoring baselines, the implementation and assessment of the Wet Weather Flow Plan is bound to be inaccurate" (Smith, 2015).

\subsection{Combined Sewer Overflows Environmental Impact on the Great Lakes}

In 1987, Toronto was identified as an Area of Concern by the International Joint Commission as one of the areas in direct contact with the Great Lakes. The growth in population, development and change of land use was an evident sign of lake contamination. Vast, growing urban clusters surrounding major cities such as Chicago and Toronto were perceived as having significant impact on Great Lakes water quality through increased discharges of sediments and contaminants from urban watersheds, runoffs from impervious surfaces and direct discharges 
from storm and wastewater treatment (International Joint Commission, 2009). Many studies have validated urban areas and development have a significant impact on human health and the overall ecosystem.

In terms of background information on the status of the Great Lakes water, in 1964, Lake Erie captured a lot of attention for its large pollution. The main scientific concern at the time and even to this day is the increase in development in urban areas in the area surrounding the Lake. Increase in development has direct link to abundance in the volume of sewage in the receiving water. In 1970, the International Joint Commission made a recommendation to both Canada and US government to implement water quality measurement system to better understand the status of the Great Lake. Their objectives were to investigate pollution in the Great Lakes from various land use activities and study of water quality in Lakes Huron and Superior (International Joint Commission, 2009). Their study proved increase in land use and imperviousness has led to changes in the surrounding environment.

There were several other findings in the upcoming years in reference to Great Lake water pollution;

In summary: In 1997-1999 International Joint Commission (IJC) made a statement that the phosphorus levels entering the Great Lake are out of control and non-point sources of pollution remain an issue. Also lack of data on pollution sources and their impact on the environment provides incorrect remedial action plans or strategic planning for future growth. Furthermore, in their findings IJC concludes, new technologies combined with improved land-use planning will be necessary to meet targets and continue the progress (International Joint Commission, 2009). Without having proper monitoring tools to report the exact amount of discharge there will always be an issue with strategic planning and expansion strategies to reduce runoffs. IJC's continuous reports in 1999- 2001 were somewhat similar to the previous years. The non-point source of pollution remain in the out-of-control status. Pollution from land activities have also increased due to population activities, increase in population means increase in urbanization. Their recommendation to governments were to utilize pollution control technologies to overcome costly replacements of sewage pipes and upgrading. At this stage IJC requests governments to adopt a reactive plan to budget for any type of infrastructure maintenance. 
In 2001 to 2003, the list of findings grew larger, there was an increase in development, sewage, and budget for research to evaluate the runoffs and its effect on the habitat. Other findings to reduce runoff quantity were described as the 'four elements': compact development, mixed uses, short blocks and respect for natural system. In IJC's 2003-2005 report, there were significant concerns about stormwater management and lack of infrastructure planning (International Joint Commission, 2009). Stormwater has been found to bring numerous loads of pollution into the Lake, in comparison to runoff from forestland, stormwater has been estimated to carry ten times the amount of phosphorus, five to eight times of nitrogen, four times the amount of suspended solids and sixty times the bacteria load (International Joint Commission, 2009). The Commission recommendations were for the state/provincial and local governments to take appropriate responsibility, create appropriate plans to manage sewage outflows, combined sewer outflows and stormwater discharges. The City of Toronto's Wet Weather Flow Master Plan is a provincial initiation to reduce sewer outfall and combined sewer overflows.

In 2011, the International Joint Commission released a report naming Toronto's Ashbridge's Bay wastewater treatment plant the number one surface water polluter in North America (International Joint Commission, 2009). Then again 2013, one of the worst seen storms in Toronto overwhelmed the City's infrastructure and an estimated one billion litres of raw sewage entered Lake Ontario. Toronto's sewage problem is known to the public community living in the City of Toronto. Especially by those living in the Downtown Toronto area, they have experienced this in one of these forms; basement flooding, release of litres of sewage from the treatment plants or water runoff to the natural environment (City of Toronto, 2012). Torontonians spending time in the lake with recreational activities have also noticed the change in the lake color after a wet flow event. Unfortunately some became aware of the issues after experiencing an illness. The City of Toronto has failed to issue any form of public warning (Lake Ontario Waterkeeper, 2015). The City currently does not have a real-time monitoring sewage data collection to alert the public on sewage runoff/bypass issues (Tully, 2014). The Ontario Waterkeeper calls the treatment plants to collect data for public awareness.

In order to raise public awareness, the Lake Ontario Waterkeeper requested from the City to publish water quality and wastewater treatment plant bypasses in real-time. According to the International Joint Commission, Canada and Ontario have committed to make "publicly 
available environmental monitoring information for evaluating environmental recovery and adjusting remediation strategies" (International Joint Commission, 2003). The real-time information released by the City is based on estimated amounts of bypasses that enter the lake, considering the treatment plant experiences no power outage. As a result of a power outage, bypass information will not get logged. Therefore, without proper data there won't be any supporting information to help decision makers formulate a remedial plan. Furthermore, this information is valuable to those using the Lake for recreational activities. Research has shown, large amounts of wastewater overwhelm the system once a month without informing the public (Hamilton, 2014).

Currently only bypasses are available to the public, but combined sewer overflow amounts released in to the Lake are yet to be available. Recently the Ontario Waterkeeper submitted a Freedom of Information request to Environment Canada to release CSO reports (Lake Ontario Waterkeeper, 2015).

\subsubsection{Smart Water Management Integration: Potential Benefits}

Parallel water resource management solutions are implemented across various water initiatives addressing issues in water sectors. Innovative initiatives involve one or many integrated technologies stated above. In this section there are several examples providing innovative solutions related to water management, wastewater management and flood management. It's important to understand the solutions used towards addressing each issue can be used towards different initiatives.

\section{Intelligent solutions in water management}

Aquadapt Monitoring Solution

Utilities utilize Aquadapt solutions in their management monitoring systems for data analysis to help make better operating decisions in order to reduce energy. Aquadapt solution not only reduces cost but it also improves water quality at the same time (Gemma et al., 2014). 


\section{Water Resources System Australia}

Australian Bureau of Metrology in charge of providing nationwide water resource information build an Australian Water Resources Information System in charge of managing and displaying data. The Bureau intends to deliver water resource data and deliver highly secure data to the public. Their system is focused to deliver high quality data and securing water data repository. AWRIS the Australian water resource tool is meant to improve Australia's decision making process, ensure compliances are met and water resources are efficiently and effectively managed (Gemma, Sang et al., 2014).

\section{Aquadvanced Innovations (Utilize IT as Solution)}

Innovative Aquadvanced solution enables water network operators to view intuitive real-time water performance data in a user friendly interface. The technology helps by reducing cost in operations, control and save water energy via a comprehensive view.

Aquadvanced integrated technology is a blend of data from GIS, sensors, SCADA feeding complex data into one single pain of glass for management's decision making. The advanced technology is flexible in monitoring most activities in the network infrastructure such as water quality, quantity, and pressure and flow velocity to detect any abnormalities. The software collects data to analyze and stimulate possible interventions to continuously provide remediation plans with optimum strategies (Gemma et al., 2014).

\section{UrbanWater project (European Commission)}

The European Commission funded a collaborative project to provide an intuitive water management system for management level decision making. Advanced web-based water solution is designed to provide real-time data for utilities to make informative decisions.

The initiative collectively utilizes tools to provide customers, utilities and the government with the correct information by analyzing water availability inputs and outputs via weather and surface waters. Furthermore, it obtains data on household consumption, distribution, predicts patterns and creates baselines to help provide end-user customer billing capabilities (Gemma et al., 2014). 


\section{Improvements in pipe scanning}

A Norwegian Enterprise, the owner of Brievoll Inspection Technologies, a provider of pipe condition assessment developed a pipe scanning technology to provide pipeline analysis reporting. Scanners have a built-in acoustic technology with cameras to feed real-time raw data to the system for further filtering.

This platform has the potential to provide reliable data on internal as well as external water pipe conditions to model predictive optimized solutions and integrate with other software to improve data and reduce cost (Gemma et al., 2014).

\subsection{Wireless Mobile Sensors in Underground Pipes}

Wireless sensors are an integral part of Internet of Things (IoT), a term that refers to the expanding interconnection of smart devices, ranging from appliances to tiny sensors (Stallings \& Brown, 2017). The main component of an IoT-enabled system is sensors for measuring some parameters of physical, chemical or biological entity (Stallings \& Brown, 2017). In addition, IoT is the core component of today's smart city arrangements. Collecting sensor data and delivering it to a cloud network for further analysis is a continuous process of today's modern city planning and development including smart water management.

Wireless mobile sensors in underground pipes is designed to monitor issues related to water distribution. The technology is used to identify any leakage based on a mobile sensor placed in pipes. The solution is shipped with a watermole sensor which collects data once identified by a spectra.

\section{Global remote monitoring solutions to urban wastewater management}

\section{SolidAT and Holon (Israel)}

In order for Holon municipality to address and remediate the sewage blockage issue seen within the city's infrastructure system, several sensing gauges were installed across the sewer system to control and manage flow. SolidAT helped improve alerting using a webbased platform to provide reliable monitoring information when levels reached the thresholds. Additional enhancements were made to the device as it proved to survive the methane environment due to high resistance (Gemma et al., 2014). 


\section{Delta Regional Water Authority (Delft-FEWS and Hollands)}

Netherland's pilot project is focused on extending its research on an already implemented

SCADA technology by providing a unified national system to link Wastewater Treatment Plants. Currently each municipality has ownership of maintaining operations within their boundaries, unfortunately water does not understand boundary limitation therefore, and their strategy fails once the wastewater reaches surface water. The system shows vulnerability once storm events contaminate bodies of water. The pilot project investigated the potential benefits of automating the control of the system with a centralized method of control that would result in linking the regional SCADA systems with the Water Treatments Plants to develop optimized models. Holland's Delft-FEWS was fed real-time data from the SCADA systems used to calculate optimal pumps. DelftFEWS real-time forecasting software was used to send calculated data back to the SCADA systems to control sewer pumps (Gemma et al., 2014).

\section{Technologies for urban flood management}

\section{INFLUX Predictive Modeling System}

INFLUX is a predictive based system providing the overall status of the sewage system based on baselined data, trending meteorological data and acknowledging the sewer in a wet and dry event while proposing an optimized strategy. The system aims to process the maximum amount of sewage volume in the treatment plants before releasing the wastewater into surface water. Their strategy aims at reserving as much wastewater volume within the systems and limiting flooding during a storm event. During wet weather conditions city operators are in charge of utilizing the wastewater system assets while protecting the environment, people and the natural environment in compliance with the rules and regulations. It's mandatory for operators to make the best use of all the assets within their system to maximize capacity by filling and strong wastewater and load the stored volume into treatment plants (Gemma et al., 2014).

\section{RainGain Radars}

RainGain uses radars a light, manageable device to collect data to improve flood protection programs. RainGain, a transnational project seeks to provide detailed and 
reliable rainfall data from radars to water managers to establish a robust storm protective city.

Four European cities; London, Paris, Rotterdam and Leuven were under pilot study to investigate the value of each radar technique. New polarimetric X-band radars were implemented in Rotterdam and Paris in addition to the previously installed X-band radar, while acquiring four rain gauges in the City of Leuven (Gemma et al., 2014).

Furthermore the project covered the Greater London by upgrading the C-band radars for testing. The pilot intends to investigate:

- Utilize the system to warn against early signs of flood prediction in the City of London.

- Maximizing rainwater storage while assessing real-time operational data on pumping station strategies in Paris and Leuven.

- Assessing and upgrading the capacity of water system based on the experiments running against Rotterdam.

\subsection{Smart Water Management Opportunities}

Integrating smart water management technologies within water and wastewater distribution networks realizes values almost immediately with measurable results. Even though there may be some challenges, it's important to have realistic expectations, implement with measurable timeline and processes. Smart Water Management programs can improve water network sustainability with appropriate involvement, investment and technologies. The benefits of implementing a smart water monitoring system increases water supply safety, enhance water infrastructure robustness, minimize flooding while decreasing energy, lower cost but create a customer rapport by increasing transparency and trust.

Utilizing the latest technology in implementing water management monitoring systems fosters the conditions required to increase sustainability in water management resources while facing aged infrastructure networks, climate change and water resource scarcity. SWM implementation has the potential to address the following:

- Easily collect real-time data via network sensors and information communication technologies 
- Utilize integrated water resource data sources to make better analytical informative decisions

- Improve efficiency while effectively increasing performance and optimizing infrastructure management systems

The outdated approach in place by the water resource sector has traditional silo data collection systems in place to make long and short term decisions. Wastewater and stormwater management is faced with daily pressures with the independent traditional approach. However, through integrations and connectivity of multiple sectors via smart water management networks, allows for sustainable water management systems. Advancements made in smart water management systems has the ability to extract data from multiple data sources to feed into other innovative intelligent software for analysis. This approach enables decision makers to view water resources and all the external influences in a holistic view while formulating their course of action. Single pane of glass views of the collected data facilitates a more informative approach, thus overcoming the challenges faced with the traditional methods and decreasing pressure at the management level.

Smart Water Management has various benefits such as environmental, socio-economic while ensuring sustainability in water resource management contributing to the well-being of residents. Benefits associated with wastewater and water management include:

Cost saving: using Smart Water Management reduces cost by recognizing leaks and any connection made illegally in the infrastructure pipes, increasing revenue to maintain the network pipes. Water management promotes water use, while reducing operational costs in distributing and treating water resources.

Service improvement: smart water management improves relationship between water utilities and the customers by providing real-time time and transparent information. Implementing monitoring prevents potential interruptions and common disruptions in the water networks in events of overflow and sewage. During periods of water scarcity, better management reduces pressure on water resources. 
Wastewater management improvement: effective and efficient economic improvements are associated with monitoring enhancements to help prevent infrastructure overload of the wastewater treatment plants.

Efficient treatment: water quality improvement through the system is utilized via sensors, creating resource pollutant controls while using natural resources thus, reducing water treatment required for water supply system and potentially separate pollutants in wastewater networks.

Enhancement and protecting the environment: improvements in environmental monitoring helps restore and maintain a healthy ecosystem.

Reduce foot prints: less energy is consumed for treatment, processing and distribution of water resources, helping reduce carbon footprint.

Flood and storm management: managing drainage systems and stormwater has become more effective with improved weather awareness and predictive intelligent models to plan for an effective flood prevention strategies.

Greater resilience: reliable data improves decision making, reduces predictions and uncertainty surrounding the situation and creating better strategic water investments. Operational infrastructure maintenance is prioritized to improve control and monitoring. Utilizing concepts of smart water management inspires better decision making in centralizing sewers and treatment plants.

Utilizing smart water technology improves upon water efficiency in the water sector, contribute to economic sustainability and cost recovery from illegal pipe connections. Smart water management tool examples can be summarized in the list below:

$>$ Enterprise monitoring software managing sensors.

Acquiring data via senor networks and smart pipes and integration of the retrieved data. 
$>$ Publicizing data on the internet and use of radio transmitters.

$>$ Improving and assessing water resources with modelling and analytics.

$>$ Storing and processing data using software as a software and cloud computing.

$>$ Managing and controlling water resources with optimization tools.

$>$ Use of information system tools to visualize for supporting decisions.

Provide data to cities services and end users using Internet Technology (e.g., Web).

Figure 5.1 below, outlines the efforts of this study to offer a functioning smart monitoring system for City of Toronto.

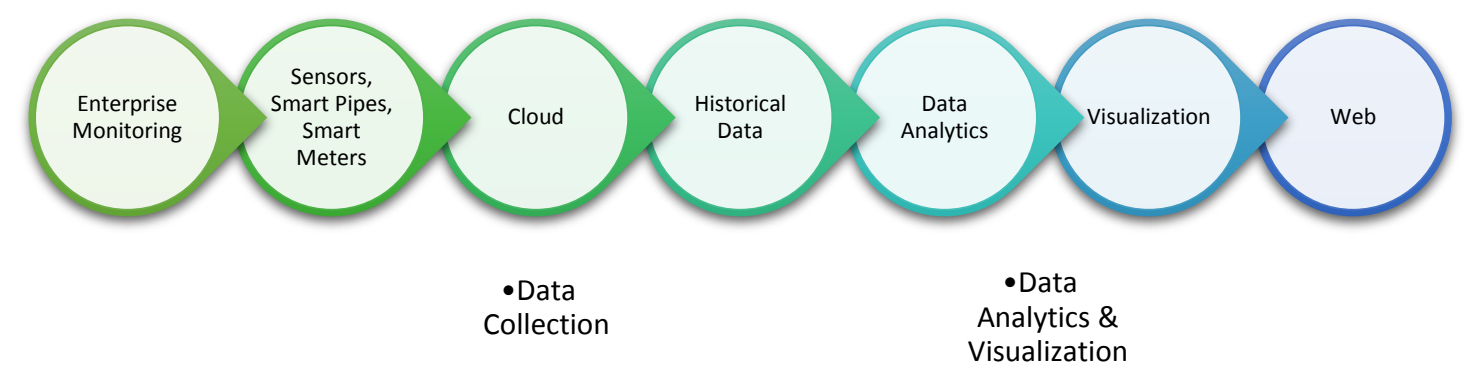

Figure 5.1: Representation of smart water management technologies and tools

\subsection{Monitoring System implemented in the City of Toronto}

The City of Toronto's initiation to address combined sewer overflow at Don River and Central Waterfront was built to respond to several issues:

I. Wet weather flow events

As mentioned previously, in 1987, the International Joint Commission defined the City of Toronto Waterfront as an Area of Concern in the Great Lake Basin (don river/water report). This was mostly related to the poor water conditions in the Harbour leading to destructive habitual environment for the fish. It was identified that both sanitary and stormwater were the main cause of the problem in lake contamination (MMM Group Limited, 2012). 
During a heavy rainfall, the lake expects approximately 100 sewer outfall discharges, from which 50 contain combined sewer overflows while the others are just stormwater. The Don River and Central Waterfront Class EA adds on to the Wet Weather Flow Master Plan initiation from 2003 by finding the most feasible solution in treating combined sewer overflows (MMM Group Limited, 2012).

The study is designed to investigate better ways to address issues surrounding the 50 outfalls containing combined sewer overflows.

II. Dry weather flows

The other component of this project is set to address the dry weather flow issues:

- Accommodate future capacity growth with proper dry weather flow systems

- Increase security measures for maintenance and potential repairs

\subsection{Current state of Smart Pipes in the City of Toronto}

The City doesn't find the need to install smart pipes in the City of Toronto or any type of real-time monitoring device due to unnecessary hefty costs. However as part of the Don River and Central Waterfront project, a geotechnical investigation was required to monitor groundwater levels. Monitoring wells were installed at each borehole location to monitor groundwater levels. Furthermore hydraulic conductivity testing was performed.

\subsection{Use of Cloud in Smart Monitoring Systems}

Smarter cities cloud analytics has been implemented in one of the fourth largest cities in Indiana to proactively help reduce combined sewer monitoring and control its sewer infrastructure.

The cloud network provides storage and processing capabilities for massive amounts of data generated by IoT-enabled devices. Cloud serves also as a platform for applications that (1) interact with and manage sensor devices, and (2) analyze the IoT-generated data (Stallings \& Brown, 2017: 447).

With the help of IBM's Intelligent Operations Center (IOC) for Smarter Cities, softwareas- a- service (SaaS), South Bend is promised to save millions of dollars in managing its 
water system. In 2012 South Bend was announced as the first city to use cloud computing to manage its water system (IBM, 2012).

Implementing IBM IOC for proactively monitoring and managing combined sewers has reduced wet weather flows by 23 percent while eliminating dry weather overflows from 27 percent to 1 percent within the first year. IBM IOC for Smarter Cities has improved storage and water conveyance while eliminating hefty infrastructure costs and helping the city avoid hundred thousand in government fines.

Utilizing IOC as a service for SmartCloud, enables South Bend to utilize the service without the initial balloon payment costs by saving on infrastructure costs. The pay-as-yougo business model gives Cities such as South Bend the ability to utilize the software-as-aservice mentality, enabling faster project initiation. Use of SaaS enables faster procurement compared to finding funding to initiate an IT infrastructure project (IBM, 2012)

Benefits of implementing IBM IOC for Smart Cities has helped:

$>$ anticipate and prevent incidents before they occur

$>$ view aggregated data in real-time using IBM SmartCloud helped predict incidents, followed by protect citizens of South Bend

$>$ creatively collaborate using the smart city solution to resolve problems that did not seem obvious without having data

City of South Bend's Board of Public Works has seen tangible benefits to implementing IBM IOC services. Gary Gilot continuously sees the endless benefits of implementing such service by continuing his partnership with IBM. Mayor Pere Buttingieg of City of South Bend shares similar thoughts as Gary, believing that with strategic collaboration in place while using smart technology and great human resources will extend the beneficial outcomes via innovations (IBM, 2012).

Implementing such technology benefited South Bend by reducing cost and avoiding unnecessary spillage. The City has a faster response rate to basement backups by sending a cleaning crew to areas in need of assistance. With the new monitoring system in place, South 
Bend has reduced water flow in its plants by millions of gallons by keeping river water out of its system.

The newly implemented SaaS solution generated for Smart Cities in the IBM SmartCloud sector has shown to manage cities by using intelligent technology to help prepare, manage and response to problematic issues while maintaining efficiency without bottlenecks.

\subsection{Use of historical data for the future}

CSOnet in South bend Indiana is a perfect example of a successful monitoring system saving millions of dollars in CSO cost. According to MCcorvey writer of Fast Company, South bend saved 100 million dollars just by tracking its sewers. Mccorvey a Consultant for McKinsey declares his understanding of the value in data to shape information into answers (MCcorvey, 2013). South Bend used this theory to become the first city ever to populate its collected data into the cloud and save millions of dollars in sewer costs (IBM, 2012).

City of South Bend real-monitoring deployment includes outfalls, interceptors and retention basins to monitor for end result CSO control locations. The final results determine the locations required to control CSOs without needing pre-existing infrastructures, relying on tower lines or communication to work or need for command center (Montestruque, 2017). The data is transferred from sensors to a server wirelessly from a remote location.

CSOnet uses simple application designed to monitor sewer system and CSO monitoring solutions. The solution allows for monitoring of water quality and quantity by gathering and reporting data. The capabilities provide the current systems operations, identify the areas that require improvement or storage tanks, evaluate system, and detect sewer problems. Furthermore, monitoring with wireless communication enables cities to identify potential areas for cleaning in real-time. The City of South Bend collected useful data in the system to identify flows in main lines, evaluate in-system levels, levels in retention and overflows, along with water quality overflow locations and industrial discharge (Montestruque, 2017). 


\subsection{Benefits of visualization in Monitoring}

City of South Bend's CSOnet application allowed the city to visualize monitoring by creating a topology view of the City-Wide sensors. The City was able to plan accordingly for electric valves, gates and inflatable dams (Montestruque, 2017).

CSOnet real-time management control solutions have proved to reduce overflows by utilizing the existing infrastructure system while using flow information from implemented monitors installed in the system. A case study conducted in the City of South Bend proved to show interceptor optimization utilization due to the fact that rain does not fall uniformly. The service areas identified in the City of South Bend have various sizes and capacity, therefor outfall flows reach the lake at different times. The outfalls overflow at different times and the interceptors have shown to run at various capacities. The optimized solution minimizes the overflow by maximizing utilization of the interceptors. The optimize solution dynamically changes the outfall points to divert water into interceptors while capacity exists (Montestruque, 2017).

Interceptor optimization is an integrated control solution within a Storm Water Model Management. The interceptor has shown benefits based on three factors at play, including a given storm at a given sewer system with number of control points.

South Bend's 2005 storm event lasted for approximately 7 hours but prior to the storm, the City was experiencing dry weather events for 3 days. The results collected were translated to understand the existing system and the CSOnet in place. The estimated overflow volume while using the CSOnet was reduced by 24\% (Montestruque, 2017). Furthermore, overflow volume reductions were reduced to $\sim 37 \%$ in recreational areas while maximizing wastewater treatment capacity. The CSOnet also reduced almost 10 storm events (Montestruque, 2017).

South Bend's CSOnet conducted two phases; phase 1 and 2 included the implementation of 110 sensors which monitored 36 outfalls in which 18 of them were controlled, 5 retention basins with control storage, 27 interceptor locations and 42 trunkline locations in the system (Montestruque, 2017). 


\section{Analysis Benefits}

South Bend CSOnet has shown to eliminate dry weather overflows and standardize Storm Water Management Model in already existing infrastructure systems. Furthermore CSOnet is built around utilizing inline storage areas to eliminate basement backups and increase flows to Waste Water Treatment Plants. Financials implications have shown to reduce CSO budget by \$110 million (Montestruque, 2017).

CSOnet's adaptable solution has shown to handle unplanned flow increase cycles by flushing cycles in an effort to eliminate dry weather overflow. Implementation of proper operations and efforts to maintain outfalls has maximized flow into WWTP for treatment, reduce dry weather overflows, efficiently and effectively monitor CSO impacts and controls while notifying the public of any events (Montestruque, 2017).

As mentioned above, the aim of this is to implement a real time monitoring system for sensor network based on South Bend's innovative sewer system by incorporating a cloud architecture composed of five distinct yet interrelated components: the sensor network (see figure 5.2 for details) at the bottom followed by data management system, cloud layer, CSOnet controller or management layer, and finally the Web 2.0 user interface.

\section{CSOnet Controller}

Implementing massive IP-based sensors across the city for real-time data collection and analysis requires not only the availability of high speed network infrastructure, high performance servers and storage devices, but also such an infrastructure should be able to support the QoS required for sensitive data delivery. In this context, communication between various sensors and access points as well as the central management unit should be designed in such allowing sensitive applications to operate more efficiently within boundaries of the cloud while maintaining quality of service (QoS) delivery (Foster, Zhao \& Raicu, 2008).

Implementation of CSOnet, will enable sensor monitoring and controlling. Sensors probing for multiple data becomes seamless to manage by defining rules and thresholds, acceptable baseline data is collected in real-time. CSOnet offers an effective and fast system for time-sensitive, time-varying applications, networked sensor systems operate in various operational conditions. (Chrysostomou, Pitsillides \& Sekercioglu, 2009). However, real-time data collection produces increases network traffic resulting in congestion, therefore specifying 
quality of service levels prior to data storage is accomplished via the management layer. Core component of the management layer contains, estimating real-time data errors for further processing. In an IP-based hybrid cloud system CSOnet is implemented as a means of quality control mechanism for data collection (see figure 5.2).

As mentioned above, in contrast to hard-wired sensors, smart sensors are IP-based sensors with the following features:

a) IP based agent for collecting water based data

b) It is multiplatform agent with multifunction capability

c) Wireless

d) Energy efficient devices, Solar powered devices

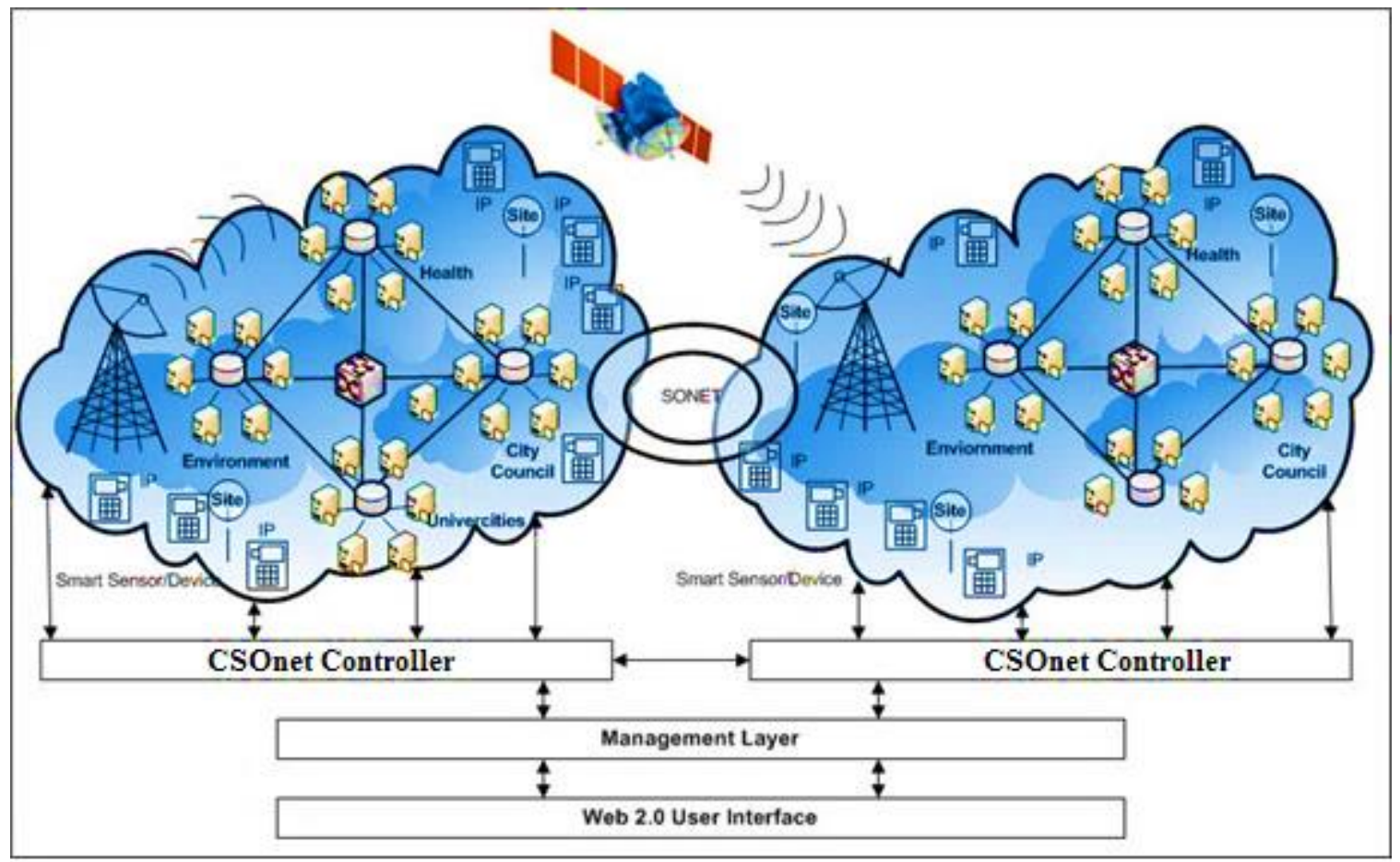

Figure 5.2: A high level schematic of Sensor Networks for Smart City

The City of Toronto and other cities with problematic CSO control and monitoring can utilize cloud computing services such as IBM SmartCloud. Cloud platform can be integrated with inexpensive CSOnet solution using the existing infrastructure (wireless, satellite and 
$\mathrm{SONET}^{7}$ fiber optic connectivity) to control and manage a city wide sewer flow in real time. The monitoring system claims to provide simple plug-and-play functionality with fast installation to provide reports to end-users. The city cloud connects not only the sensor network but also it is capable of delivering collected data to various applications including the existing GIS system. Using the Web 2.0 interface managers and city planners are able to track quantity and frequency of CSOs in real time and respond to it in real time. It offers also the opportunities for future evaluation and optimization of the sewer system.

\footnotetext{
${ }^{7}$ SONET Synchronous Optical NETwork: device used in multiplexed digital traffic, use of optical signals and synchronous structure (Cisco, 2005)
} 


\section{Chapter 6: Conclusions \& Recommendations}

One of the greatest challenges in the upcoming century will be supplying water to the global population. Rapid population growth and uncertain climate change places pressure in the existing water resources and creates competition in the fast-paced environment. To meet socioeconomic and environmental goals, it becomes a must to meet demands and respond to challenges before demand overtakes supply. It's mandatory for antiquated infrastructure to get upgraded with smart solution systems, to reduce cost and optimize the existing infrastructure while mitigating challenges.

Smart water management helps transform cities in the making and already developed cities by implementing sustainable policies, increase stakeholder involvement and integrating it into planning. Smart water management enables city's growth via real-time monitoring systems, enhance decision-making, performance and efficiently increase operations. Furthermore advantages of smart water management include an increase in utilities, create rapport between utilities and customers, and reduce operational cost to address challenges.

Initiatives taken towards an effective implementation of smart water management is more effective once integrated within a wider strategic approach. Collaborated efforts are required to build across various sectors in water management field. Creating a coordinated efforts to tackle water resource management and wastewater should be a cross sector effort between all parties including researchers, water managers, and utilities in order to overcome obstacles and provide opportunities.

In order to maximize contribution and increase innovation, it's mandatory to understand importance of technical and non-technical innovations while breaking innovative barriers in effective water management. Acknowledging importance of information technology in business model utility is vital for success of smart water management systems.

Implementing proper policies and considering corrective measures are effective in deploying smart water systems. Standardizing software used in smart water management and practicing common standards encourages use of best practice methods to acknowledge water management field issues. 
Currently the City of Toronto is using estimation methods to determine quantity and frequency of CSOs at random. According to Toronto's Wet Weather Flow Master Plan, real-time monitoring of CSOs are costly and insignificant to reducing overflows. The City lacks a continuous system-wide monitoring method to evaluate CSO outfalls during wet/dry weather conditions.

This comparative study offered innovative methods using existing ICT infrastructure to better understand the potential benefits of implementing real-time monitoring systems to reduce and manage CSOs by reviewing use of technology in various North American Cities experimenting.

\subsection{Gaps to be addressed}

Water managers need to fully understand the benefits of implementing the appropriate water intelligence tool within their network for maximized potentials of leveraging information technology to increase capacity and control the pipes. Experimental field studies have shown the possibilities with implementing integrated solutions however, lack of having a set of standardization within the water sector utilities develops problems with future solution integration within the system.

Challenges faced by water utilities can affect the proper implementation of smart water management tools around the world. Some of the challenges faced are categorized and explained further below:

\subsection{Policy and standardization}

Information technology innovations in the water resource sector are a result of a complex and highly changing environment. It is essential to implement a set of standardized tools and systems to effectively and efficiently use monitoring product tools. A set of standards contains technical and specific criteria to provide consistent rules and guidelines. Adopting a source of reference ensures clear roadmaps containing technical specifications, reference to quality and reliability. Following a set of standardization ensures product tools are aligned with the service provided to serve a purpose for compatibility as a form of best practice. 
Smart water management is a newly developed form of a management tool in a growing market creating double standards. As a new initiative, innovations within this sector can either maximize value or delay further developments. However in this fast paced world of technology it must be mentioned that providing valuable experimental field studies in a timely manner is essential in bridging the gap in research and innovations. Therefore standardizations serves as guideline to strategic implementations of smart water management.

Smart water management highly depends on interoperability and solution integration. Without interoperability many restrictions affect growth in use of ICT in the water utility sector. Interoperability is defined in the ability of product integration without having serious user involvement. Therefore standardization is required to assure sustainability across tools and systems is implemented.

Standardization organizations developed various sensor networks to eliminate risks of incompatibility via testing and verifications. With the current pace of technological advancements and developments, further research, field studies and standardization must be in place.

Standardization provides a guideline to measure ICT product quality to ensure policy security. Proper policy implementation will effectively support water management solutions used by developing countries.

Many initiatives to deploy smart water policies were targeted against smart water developments, resulting in mixed outcomes. In some cases further research was done to innovate the water technology market or question the investments made to development.

Research invested countries such as Canada, Singapore and Israel supporting innovation have launched new smart water companies as a result of investing in intelligent water technologies. These companies have mostly invested in sustainable, environmental and other forms of initiatives to target smart water systems. 
Challenges faced by innovative investors always remains the same, as questions are raised about the required types of policies in development of Information Technology Management in the water utility sectors, implementation of these policies, determining the tradeoff and benefits of ICT in water management and the objectives of the focus driven sectors.

Since the water initiative is fairly new, it's vital for policies to be adaptable nationally and internationally to reflect the actual intentions of the chosen technology deployment. As a result there are limited integrated research innovations being pursued in the smart water management industry.

In summary, it's advised to place in policies in a timely manner to address water management issues. It's vital for governments and organizations to fully support integrated systems to support smart water management technology. Collaboration between governments, policy makers and water utility technologist ensures effective policies. Cross reference across sectors enables policy makers to develop sustainable tools.

As a result, decisions made towards implementation must be strategically thought out before any smart water management initiative. Guidelines and a properly organized strategy is required to effectively develop an innovative policy. Standardization and policy development can only succeed if there is enough research and innovation to support a strategic initiative customized based on protocols and standards.

\subsection{Future research}

This study can be a very small part of future studies looking to reduce the effects of CSOs by providing some context around the potential benefits of implementing a monitoring system across the combined sewers. Data collected from monitoring systems can potentially help analysts with supporting document on benefits of having real-time monitoring data to compare in estimating CSO data.

Research is required to understand better ways of implementing real-time devices with lower costs and maintenance for more effective and efficient monitoring. Evaluating stored data in establishing a baseline and providing predictions can help decrease and further manage CSOs. 


\section{Appendix A}

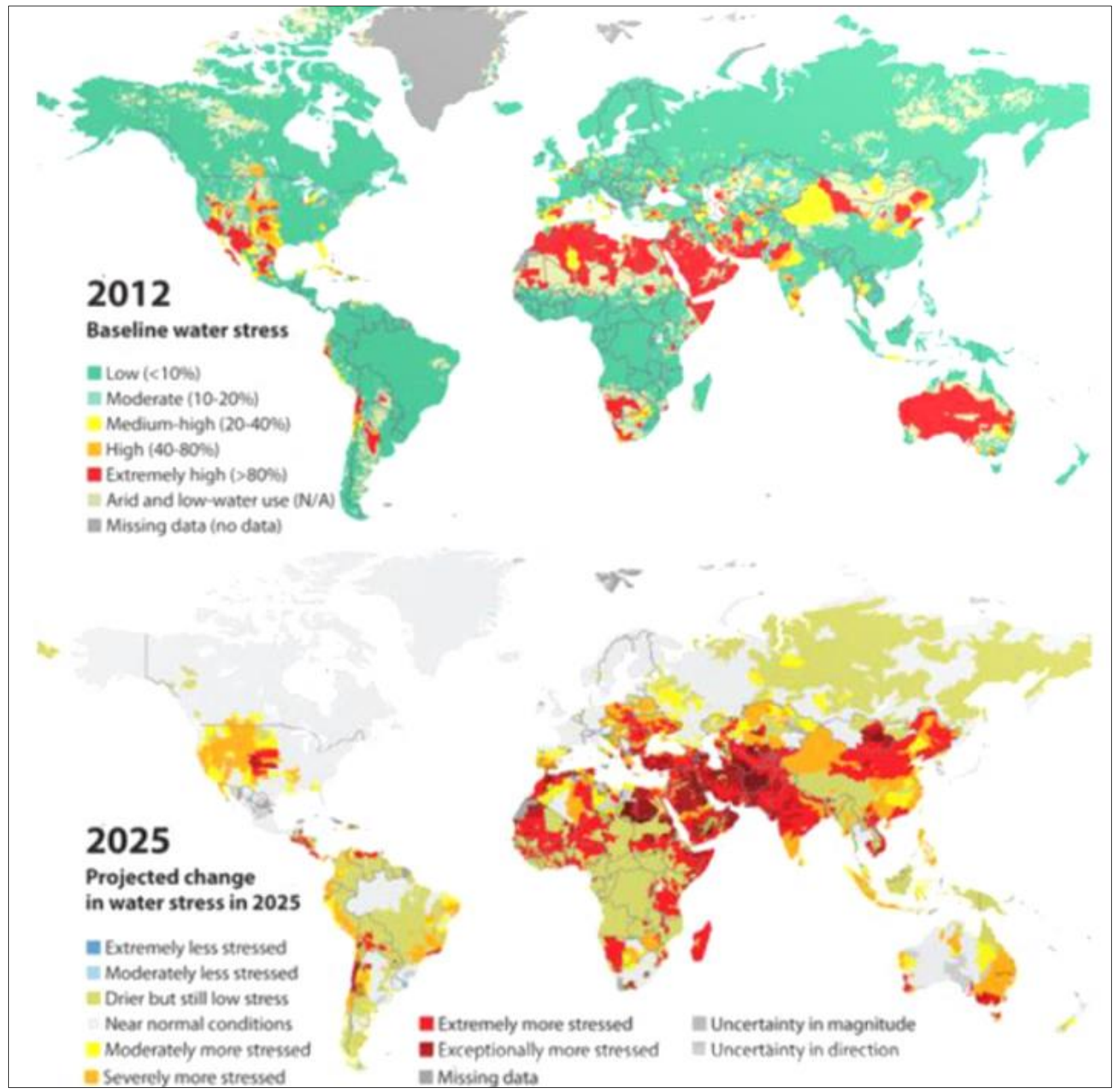

Figure A1: Projecting Water Stressors. Source: Gemma, Sang, Mc Intosh \& Ospina, 2014 


\section{Appendix B}

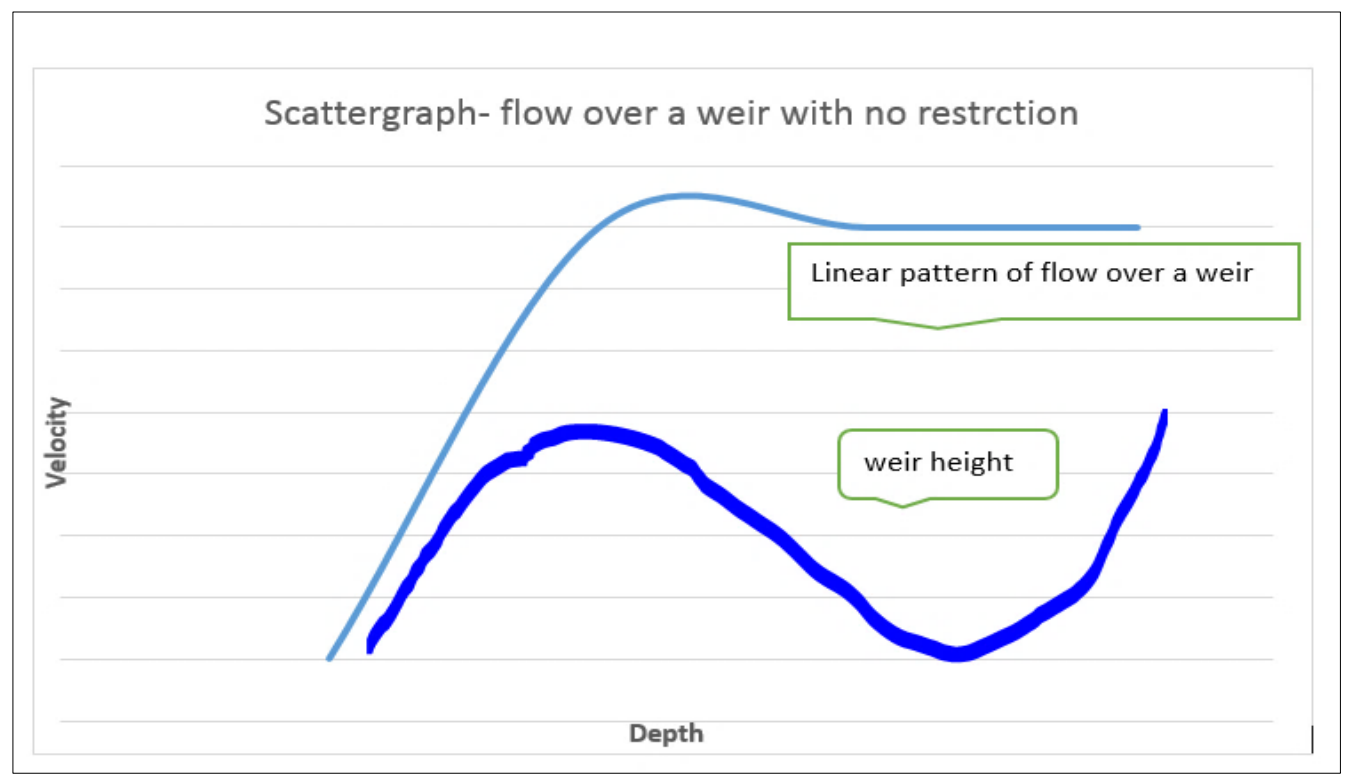

Figure B1: Scattergraph: Flow over a weir with no restriction. Source: Keohan, Armes, \& Stevens, 2013

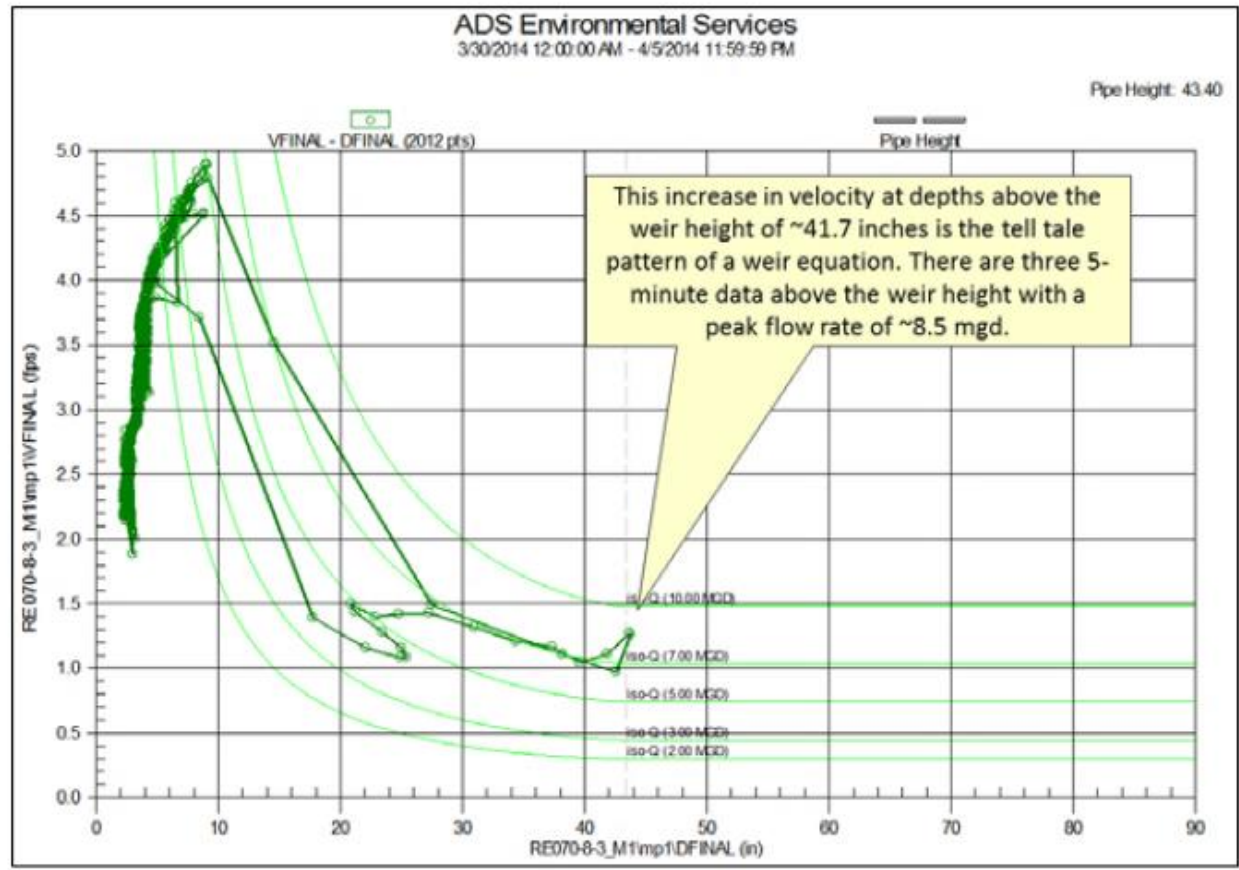

Figure B2: Scattergraph: Mar 302014 Storm Event. Source: Keohan, Armes, \& Stevens, 2013 


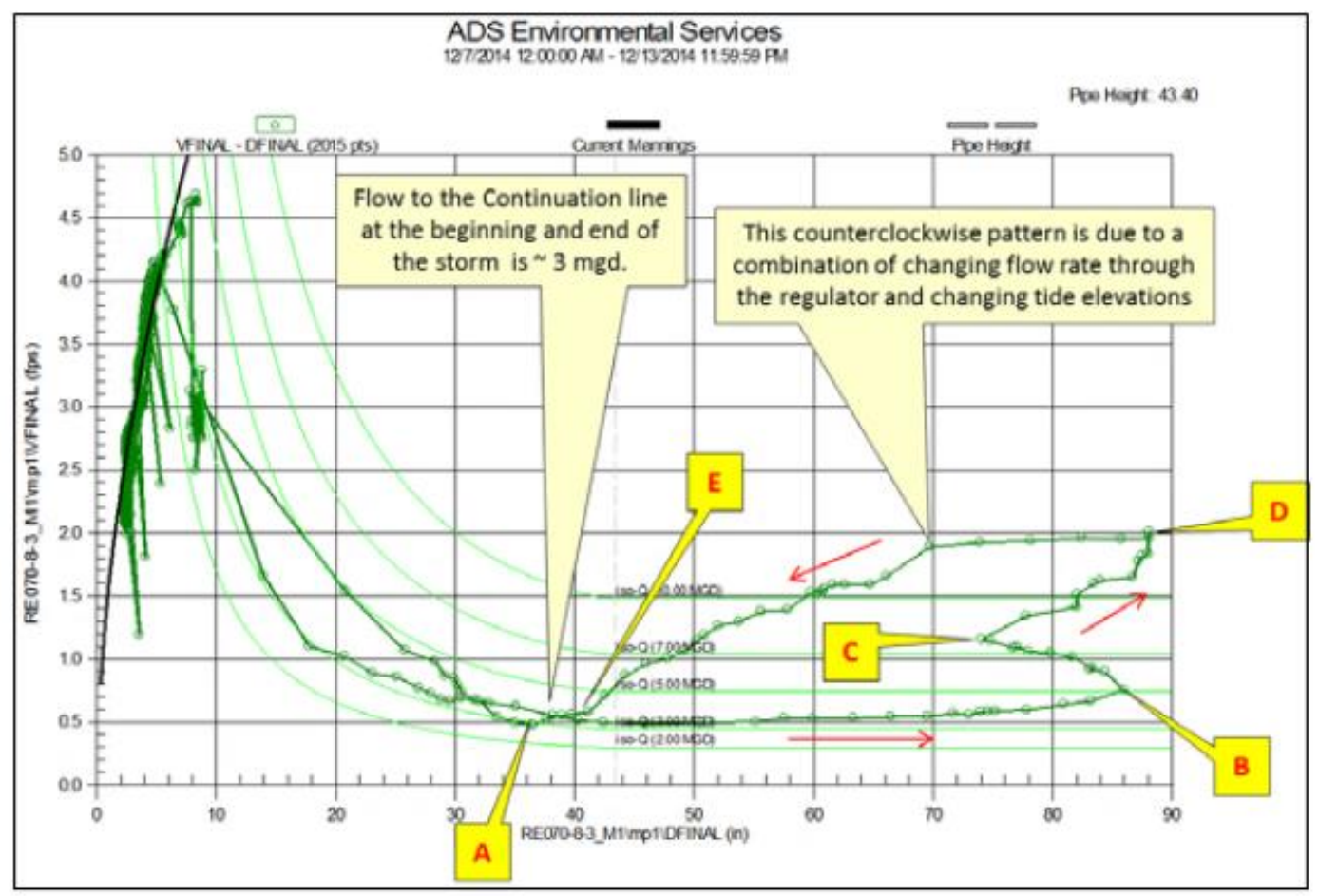

Figure B3: Scattergraph: Dec 92014 Storm Event. Source: Keohan, Armes, \& Stevens, 2013

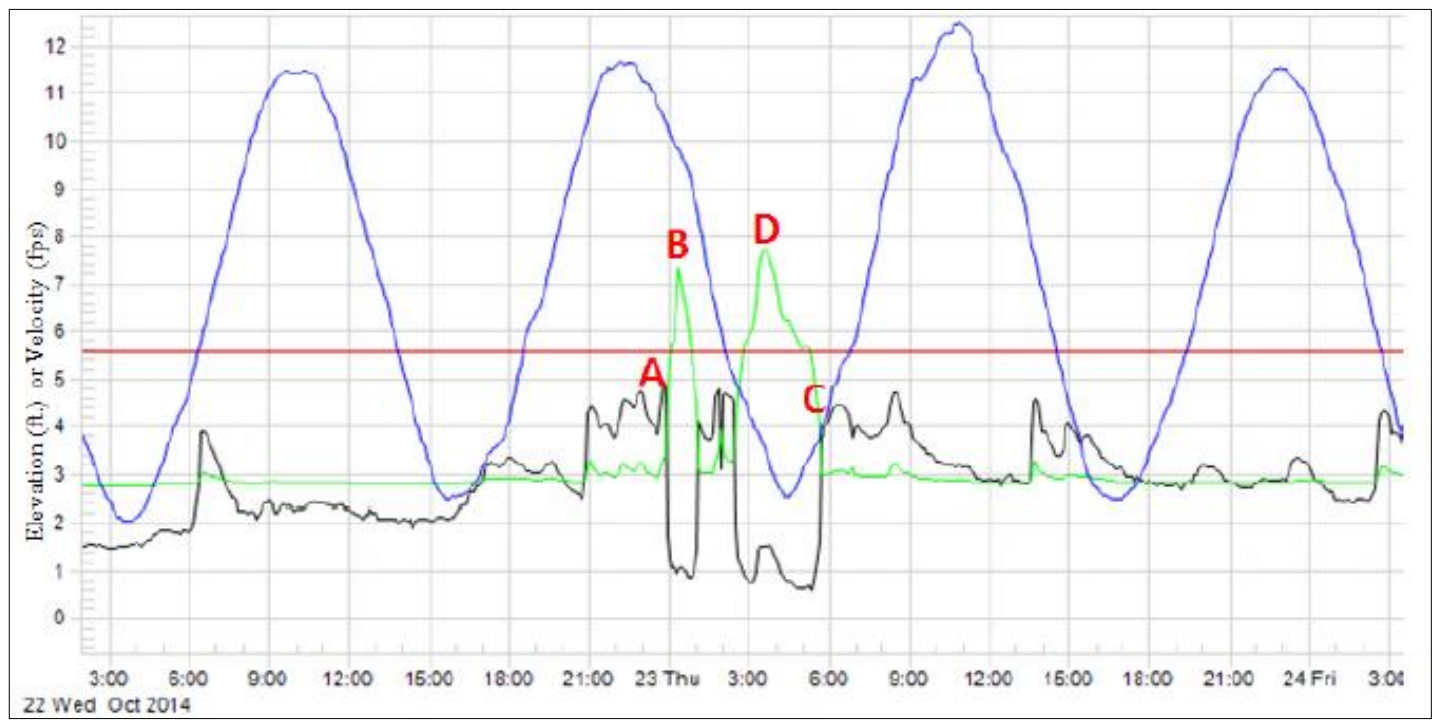

Figure B4: Scattergraph: Oct 232014 Storm Event. Source: Keohan, Armes, \& Stevens, 2013 


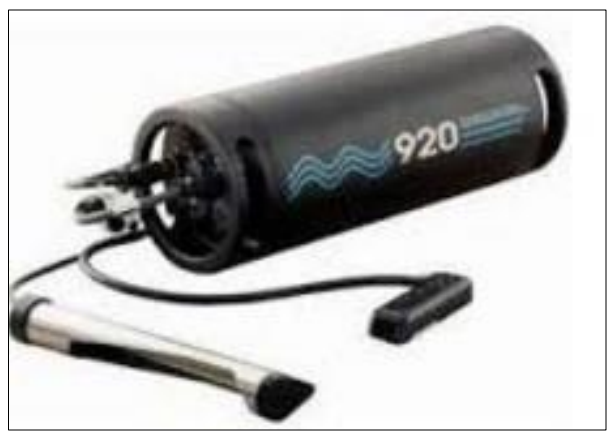

Figure B5: American Sigma 920

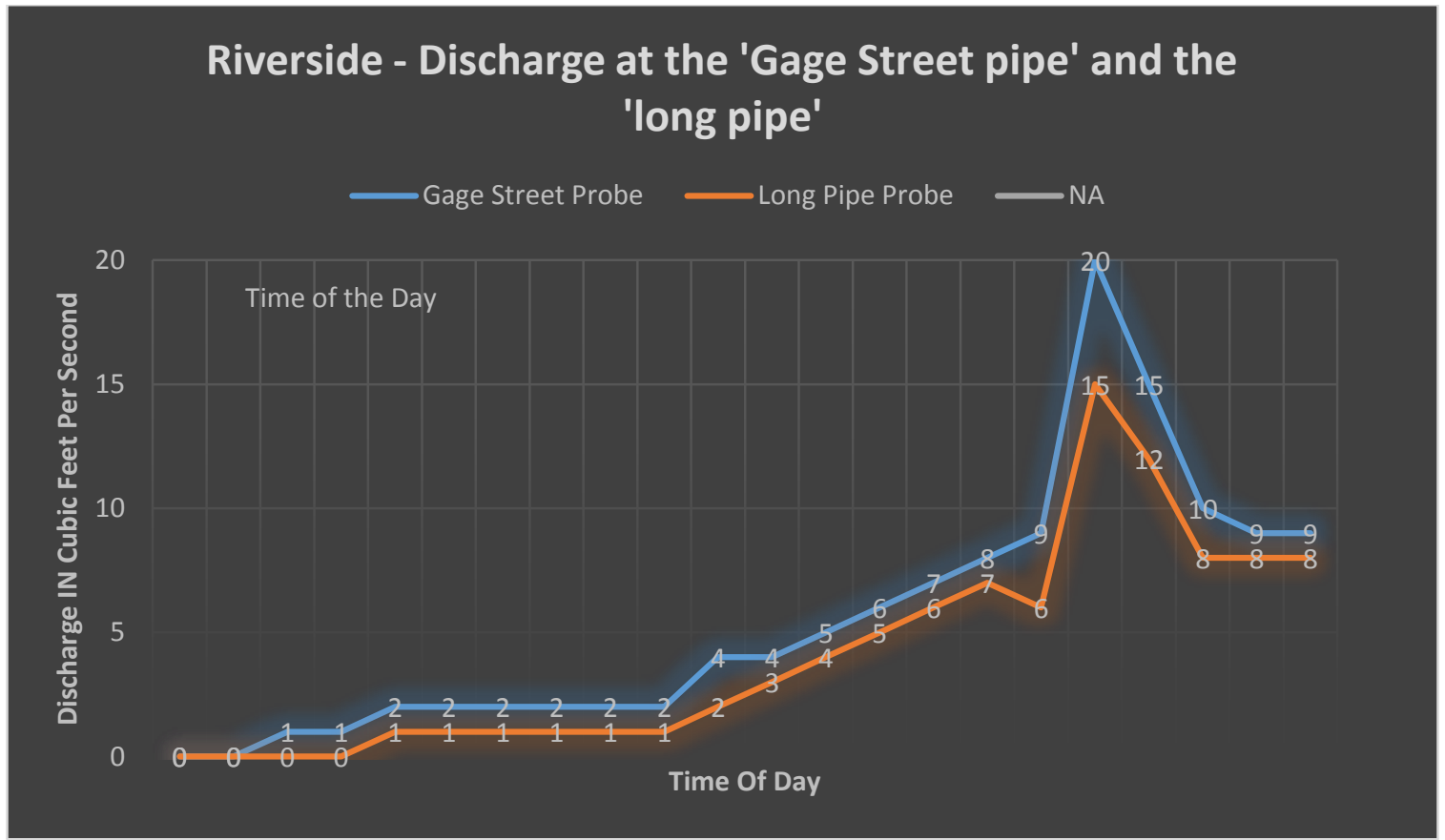

Figure B6: Riverside: Discharge at the 'Gage Street pipe' and the 'long pipe'. Source: Waite, Johnson, \& Hornewer, 2002 


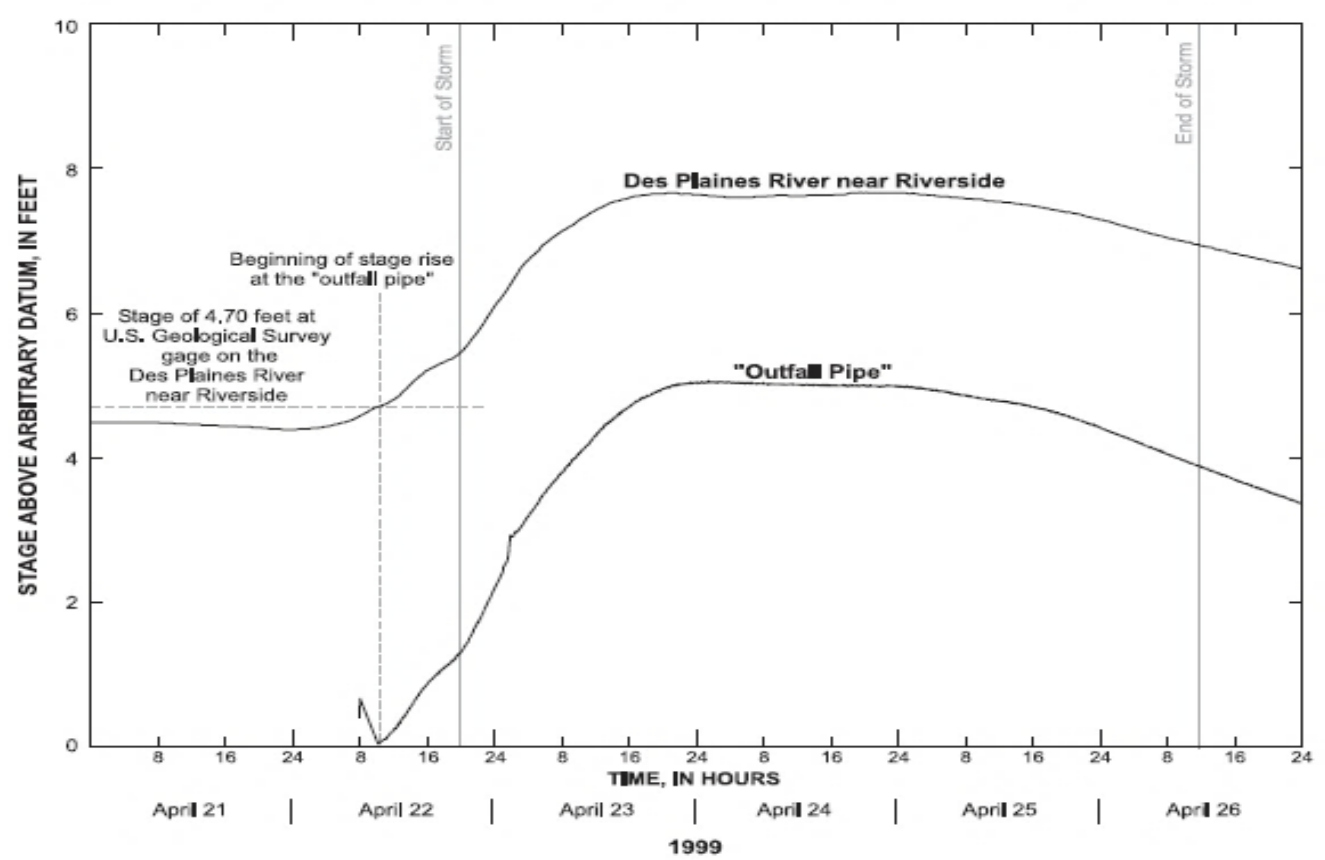

Figure B7: Stage at the "outfall pipe" and the Des Plaines River, Riverside. Source: Waite, Johnson, \& Hornewer, 2002
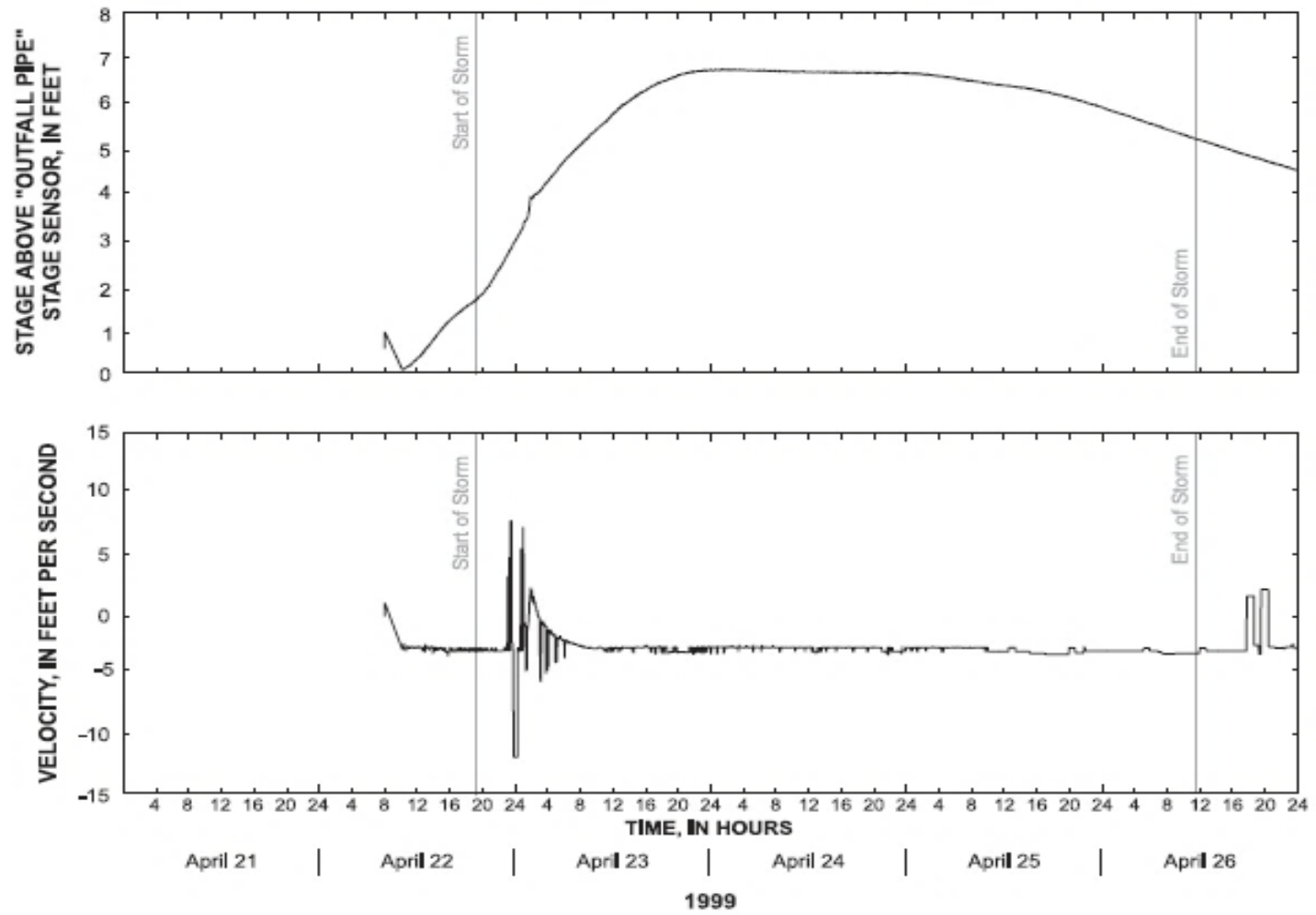

Figure B8: Stage and velocity at the "outfall pipe", Riverside. Source: Waite, Johnson, \& Hornewer, 2002 


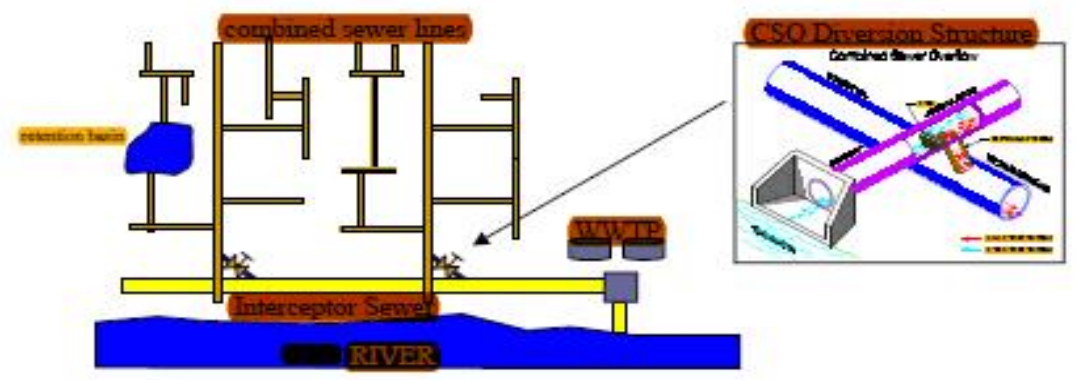

Figure B9: South bends's Interceptor Sewer. Source: Lemmon \& Montestruque, 2008

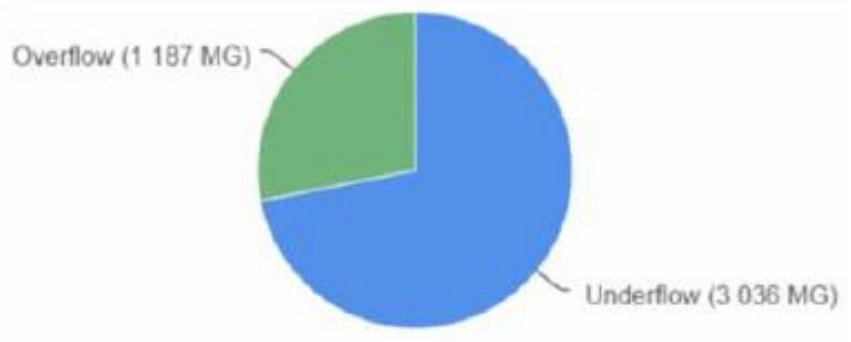

Figure B10: Performance Flow. Source: Montestruque, 2015

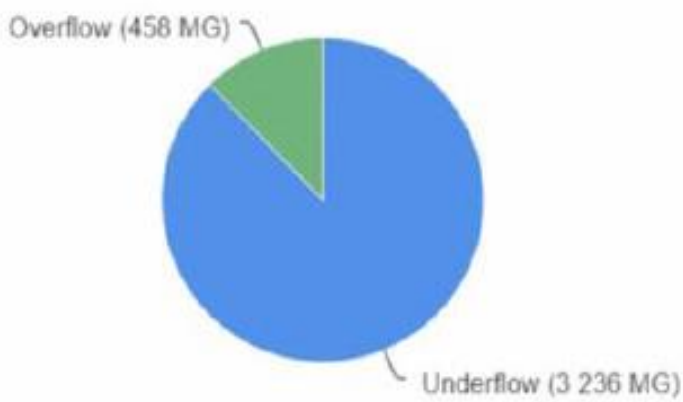

Figure B11: Performance Flow. Source: Montestruque, 2015 


\section{References}

Agbor, E. (2008). Creativity and innovation: The leadership dynamics. Journal of Strategic Leadership, 1 (1), 39-45. Retrieved from

https://www.regent.edu/acad/global/publications/jsl/volliss1/JSL_Volliss1_Agbor.pdf

American Sigma. (1996). American Sigma long term flow monitor: Operating and maintenance manual: Medina, N.Y., American Sigma, Inc.

Chrysostomou, C., Pitsillides, A., \& Sekercioglu, Y. A., (2009). Fuzzy explicit marking: A unified congestion controller for best-effort and diff-serv networks. Computer Networks 53, 650667. doi: 10.1016/j.comnet.2008.11.002

Cisco. (2005). A brief overview of SONET technology. Retrieved June 14, 2017, from https://www.cisco.com/c/en/us/support/docs/optical/synchronous-optical-network-sonet/13567sonet-tech-tips.html

City of Toronto. Engineering and Construction Services. (2012). Basement flooding remediation and water quality improvement master plan: Class environmental assessment (EA) studies. Retrieved from https://wx.toronto.ca/inter/pmmd/callawards.nsf/0/93296260B863E30885257D820068117B/\$fil e/9117-14-7256\%20Viewing\%20Copy.pdf

Ecojustice. (2013). The Great Lake sewage report card. Retrieved from https://www.ecojustice.ca/wp-content/uploads/2014/08/FINAL-The-Great-Lakes-SewageReport-Card-2013.pdf

Fan, C., Cao, W., Li, J., Banting, D., Shamead, S. M., Lei, J., \& Joksimovic, D. (2014). City of Toronto'S approach on implementing the new federal wastewater effluent regulations using a gis-based hydrologic and hydraulic model. CUNY Academic Works. Retrieved from https://academicworks.cuny.edu/cc_conf_hic/359/

Field, R., Villeneuve, E., Stinson, M. K., Jolicoeur, N., Pleau, M., \& Lavallee, P. (2000). Implementing real-time control schemes offers combined sewer flow control for complex urban collection system. Rochester, NY: U.S. Environmental Protection Agency, Office of Research and Development, National Risk Management Research Laboratory.

Foster, I., Zhao, Y., Raicu, I., \&Lu, S. (2008). Cloud computing and grid computing 360-degree compared. IEEE. 1-10. doi: 10.1109/GCE.2008.4738445

Gemma, P., Sang, Z., Mc Intosh, A., \& Ospina, A.V. (2014). ITU-T focus group on smart sustainable cities: Smart Water Management in Cities. Retrieved from https://www.itu.int/en/ITU-T/focusgroups/ssc/Documents/.../TR-SWM-cities.docx

Hamilton, P. (2014). How Lake Ontario Waterkeeper is protecting Toronto's water from sewage pollution - Ecojustice [Web log post]. (2014, September 4). Retrieved from 
http://www.ecojustice.ca/how-lake-ontario-waterkeeper-is-protecting-torontos-water-fromsewage-pollution/

Holmes, M, Wristen, K. G., \& Bonner, M. (1999). The national sewage report card (number two): rating the treatment methods and discharges of 21 Canadian cities. Canada. Canadian Cataloguing in Publishing Data.

IBM. (2012). IBM, Notre Dame, Emnet help South Bend, Indiana protect public health, reduce pollution with smarter cities cloud analytics. Retrieved from https://www03.ibm.com/press/us/en/pressrelease/38153.wss

International Joint Commission. (2003). Status of restoration activities in Great Lakes areas of concern: a special report. Retrieved from http://ijc.org/files/publications/aoc_report-e.pdf International Joint Commission. (2009). The impact of urban areas on Great Lakes water quality. IJC, Windsor, Ontario: Great Lakes Science Advisory Board, Great Lakes Water Quality Board, International Air Quality Advisory Board and Health Professionals Task Force.

Joksimovic, D. (1999). Screening model for advanced real time control (smartc) (master's thesis). Retrieved from http://www.collectionscanada.gc.ca/obj/s4/f2/dsk1/tape8/PQDD_0006/MQ45937.pdf

Keohan, P., Armes, M., \& Stevens, P. (2013). Boston's pilot project to measure cso flows relies on new technology and scattergraphs to detect overflows. Boston, MA: ADS Environment.

Khalil, O.E.M. (1996). Innovative work environments: the role of information technology and systems. SAM Advanced Management Journal, 61(3), 32-6. Retrieved from http://www.freepatentsonline.com/article/SAM-Advanced-Management-Journal/18926780.html

Lake Ontario Waterkeeper. (2015) .Toronto sewage bypass log. Retrieved from http://www.waterkeeper.ca/blog/2015/6/16/toronto-sewage-bypass-log\#comment-2386019495

Lake Ontario Waterkeeper. (n.d). Case Toronto sewage bypass alerts. Retrieved from http://www.waterkeeper.ca/toronto-sewage

Lyandres, O, \& Welch, L. (2012). Reducing combined sewer overflows in the Great Lakes: Why investing in infrastructure is critical to improving water quality. Alliance for the Great Lakes.

Martins, E.C., \& Terblanche, F. (2003). Building organisational culture that stimulates creativity and innovation. European Journal of Innovation Management, 6 (1), 64-

74. https://doi.org/10.1108/14601060310456337

Mattson, M. (2015). City of Toronto withholding information about sewage bypasses [Web log post]. Retrieved December 20, 2015, from http://www.waterkeeper.ca/blog/2015/6/24/city-oftoronto-withholding-information-about-sewage-bypasses 
MCcorvey,J.J. (2013). How South Bend Indiana saved 100 million by tracking its sewers. Retrieved from https://www.fastcompany.com/3014805/how-south-bend-indiana-saved-100million-by-tracking-its-sewers

McIntosh, A. C. (2014). Urban water supply and sanitation in Southeast Asia: A guide to good practice. Mandaluyong City, Philippines: Asian Development Bank (ADB).

MMM Group Limited. (2012). Don River and central waterfront project: municipal class EA environmental studies report. Retrieved from https://www1.toronto.ca/city_of_toronto/toronto_water/files/pdf/don-river-and-cw-class-ea-esrmain-report-august-2012.pdf

Montestruque, L. (2017). Combined sewer problems [PowerPoint slide]. Retrieved from Emnet, LLC:http://www.otcoinc.org/Uploads/downloads/Presentations/Columbus\%20Day/Ed\%20Kelly $\%$ 20CSONETPresentation.pdf

Montestruque, L., \& Lemmon, M. D. (2015). Globally coordinated distributed storm water management system. ACM, (10), 1-6. doi:10.1145/2738935.2738948

Montestruque, L., \& Lemmon, M. D (2008). CSOnet: a metropolitan scale wireless sensoractuator network. Retrieved from https://www3.nd.edu/ lemmon/projects/21CTF260911/Publications/2008/modus08-csonet-revised2.pdf

Mulley, M. (2014). Standing committee on environment and sustainable development. Retrieved from https://openparliament.ca/committees/environment/41-2/14/michael-dandrea-1/only/

OECD (2011). Water Governance in OECD Countries: A Multi-level approach, OECD Publishing, Paris. http://dx.doi.org/10.1787/9789264119284-en

OECD (2012). Policies to support smart water systems. Lessons from countries experience, working party on biodiversity, water and ecosystems. OECD, Paris, France.

Ruggaber, T, Talley, J, \& Montestruque, L. (2007). Using embedded sensor networks to monitor, control, and reduce cso events: A pilot study. Environmental Engineering Science, 24 (2), 172182. https://doi.org/10.1089/ees.2006.0041

Shattow, M. (1996). Out of the blue. Electric Perspectives, 21(3), 44-45. Retrieved from https://www.sciencedirect.com/science/article/pii/S1809203916310749

Sierra Legal Defence Fund Report. (2004). The national sewage report card (Number three): Grading the sewage treatment of 22 Canadian cities. Report prepare for the Labour Environment Alliance Society, T Buck Suzuki Environmental Foundation, and Georgia Strait Alliance, Vancouver, Canada 
Smith, D. (2015). City of Toronto Wet Weather Flow Monitoring Network: Baseline conditions 2008 - 2011 [PDF]. Retrieved from The Ontario Ministry of Environment and Climate Change: http://abca.iwebsmart.net/downloads/Smith-1130.pdf

Stallings, W. \& Brown, L. (2017). Computer Security, Principles and Practice $4^{\text {th }}$ ed., New York, Pearson Publication.

Stoianov, I., Nachman, L., Whittle, A., Madden, S., \& Kling, R. (2008). Sensor networks for monitoring water supply and sewer systems: lessons from Boston. Retrieved from http://wwwf.imperial.ac.uk/infrasense/PDF_Files/WDSA2006_Ivans.pdf

The City of Toronto Sewers Bylaw. (n.d.). Protecting water quality. How can you help to avoid, reduce and eliminate pollution? Retrieved from http://www1.toronto.ca/City Of Toronto/Toronto Water/Files/pdf/protecting-water-quality.

Toronto Water (2006). Wet Weather Flow Master Plan: Implementation report 2004-2005. Toronto, Toronto Water.

Toronto Water. (2014) Update on Toronto water implementation of new federal wastewater

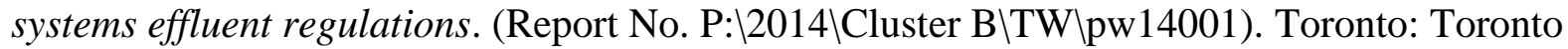
Water.

Toronto Water. (2013). Impact of July 8, 2013 storm on the City's Sewer and Stormwater Systems. (Report No. P:/2012/Cluster B/TW/pw13017). Toronto: Toronto Water.

Toronto Water. (2013). Impact of new federal wastewater systems effluent regulations on Toronto water. (Report No. P:/2012/ClusterB/TW/pw13017). Toronto: Toronto Water.

Tully, K. (2014, July 7). Toronto has a sewage bypass problem - the argument for a sewage alert protocol in Toronto [Web log post]. Retrieved December from

http://www.waterkeeper.ca/blog/2014/7/7/toronto-has-a-sewage-bypass-problem-the-argumentfor-a-sewage-alert-protocol-in-toronto

UNDP (1990). Urbanisation and human development. In $h d r$. Retrieved from http://hdr.undp.org/en/media/hdr_1990_en_chap5.pdf

United Nations Development Programme. (2011). Human development report 2011:

Sustainability and equity: A better future for all. New York: United Nations Development Programme.

U.S. Army Corps of Engineers. (1998). Special re-evaluation report and final environmental impact statement. Chicago, Ill, U.S. Army Corps of Engineers.

U.S. Environmental Protection Agency. (1974). Computer Management of a Combined Sewer System (Report No. EPA-670/2-74-022). Cincinnati, OH: Municipal Environmental Research Laboratory. 
Van Gelder, P.,\& Barlow, D. (1995). City of Poughkeepsie New York, combined sewer overflow monitoring plan. Journal of Water Management Modeling R183-18. 283-302.

doi:10.14796/JWMM.R183-18.

Waite, A. M., Johnson, G. P., Hornewer, N. J., (U.S.), G. S., \& United States. Army. Corps of Engineers. Chicago District. (2002). Monitoring and analysis of combined sewer overflows, riverside and Evanston, Illinois, 1997-99 (Report No. 01-4121). Urbana, Illinois: U.S.

Department of the Interior, U.S. Geological Survey.

Wan, P, \& Lemmon, M. (2007). Distributed flow control using embedded sensor-actuator networks for the reduction of combined sewer overflow (CSO) events. IEEE Conference on Decision and Control, 1529-1534. doi: 10.1109/CDC.2007.4434773

Zhang, F, Wen, Y, \& Guo, X. (2014). CRISPR/Cas9 for genome editing: progress, implications and challenges. Human Molecular Genetics. 23 (1): 40-46. doi:

https://doi.org/10.1093/hmg/ddu12 